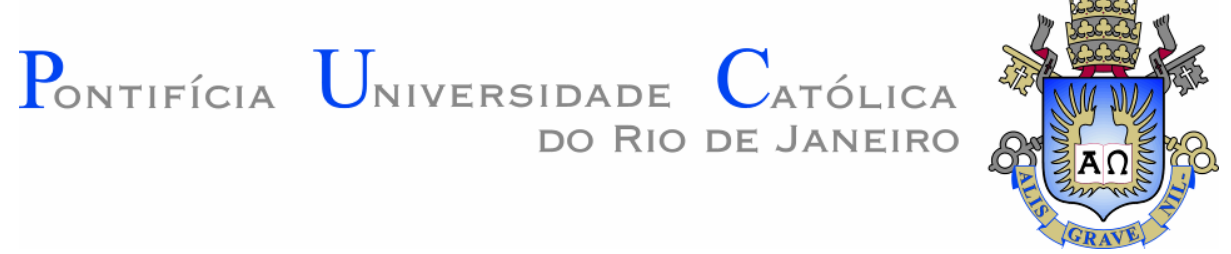

Leonardo Simões de Abreu Carneiro

\title{
Covalent Organic Frameworks
}

baseados em carbazóis: concepção, síntese e caracterização.

\section{Dissertação de Mestrado}

Dissertação apresentada como requisito parcial para obtenção do grau de Mestre pelo Programa de PósGraduação em Química da PUC-Rio.

Orientadora: Prof ${ }^{a}$. Camilla Djenne Buarque Muller Co-orientador: Prof. Pierre Mothé Esteves 


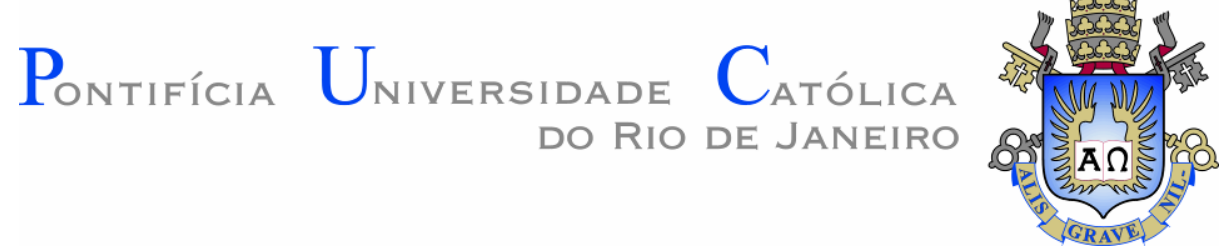

Leonardo Simões de Abreu Carneiro

\begin{abstract}
Covalent Organic Frameworks baseados em carbazóis: concepção, síntese e caracterização.
\end{abstract}

Dissertação apresentada como requisito parcial para obtenção do grau de Mestre pelo Programa de Pós-Graduação em Química do Departamento de Química da PUC-Rio. Aprovada pela Comissão Examinadora abaixo assinada.

Profa. Camilla Djenne Buarque Müller Orientadora Departamento de Química - PUC-Rio

Prof. Pierre Mothé Esteves Co-orientador UFRJ

Prof. Simon John Garden UFRJ

Prof. Rodrigo Barbosa Capaz UFRJ

Prof. Volodymyr N. Zaitsev Departamento de Química - PUC-Rio

Prof. Márcio da Silveira Carvalho

Coordenador Setorial do Centro

Técnico Científico - PUC-Rio

Rio de Janeiro, 29 de março de 2016 
Todos os direitos reservados. É proibida a reprodução total ou parcial do trabalho sem autorização da universidade, do autor e da orientadora.

\section{Leonardo Simões de Abreu Carneiro}

Graduou-se em Química pela PUC-Rio em 2014. Possui experiência em Química Orgânica com ênfase em síntese de materiais nanoporosos orgânicos, métodos de caracterização de materiais e reações de acoplamento cruzado catalisadas por paládio.

Ficha Catalográfica

Carneiro, Leonardo Simões de Abreu

Covalent Organic Frameworks baseados em carbazóis: concepção, síntese e caracterização / Leonardo Simões de Abreu Carneiro; orientadora: Camilla Djenne Buarque Muller; co-orientador: Pierre Mothé Esteves. - 2016.

112 f. : il. color. ; $30 \mathrm{~cm}$

Dissertação (mestrado) - Pontifícia Universidade Católica do Rio de Janeiro, Departamento de Química, 2016.

Inclui bibliografia

1. Química - Teses. 2. Covalent organic frameworks. 3. Carbazol. 4. Tautomeria. 5. Materiais bidimensionais. 6. Porosidade. I. Muller, Camilla Djenne Buarque. II. Esteves, Pierre Mothé. III. Pontifícia Universidade Católica do Rio de Janeiro. Departamento de Química. IV. Título. 


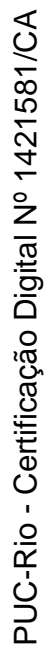

À minha mãe pelos anos de dedicação e amor. 


\section{Agradecimentos}

À minha família, em especial aos meus pais por todo apoio e carinho ao longo dessa jornada.

Aos meus orientadores pelo apoio, amizade e confiança no meu trabalho.

A todos os membros presentes da banca por terem aceito participarem e contribuir com o trabalho.

À família LabSint pelas horas de descontração nos momentos mais tensos desse trabalho. Um agradecimento especial aos meus "filhos científicos" Alessandra, Francisco e Bruno pela ajuda ao longo desse trabalho!

Á todos do Interlab por terem me acolhido da melhor forma possível ao grupo. Agradeço especialmente Geisa e Sunny por terem me ajudado em vários momentos desse trabalho!

Às amigas Vanessa, Anastácia e Leila pela amizade e momentos de alegria.

Ao Prof. Roberto Avillez e a Dr. Sonia Letichevsky, ambos da PUC-Rio, pelo uso do DRX e do SAXS e pelas discussões sobre a estrutura cristalina dos materiais.

Á Prof. Deyse Gomes da Costa, da UFV, e ao Prof. Rodrigo B. Capaz, da UFRJ, pelos cálculos teóricos dos COFs e discussões.

Ao Dr. Braulio Archanjo e Dr. Martin Mendoza, ambos do INMETRO, pelas imagens no microscópio eletrônico de transmissão.

Á Central Analítica do Departamento de Química Inorgânica da UFRJ pelos espectros de infravermelho. 
Ao Instituto de Pesquisas em Produtos Naturais, da UFRJ, pelos espectros de massas de alta resolução.

Ao Prof. Nicolás A. Rey, da PUC-Rio, pelas análises de termogravimetria.

Ao CNPq pela bolsa de mestrado. 


\section{Resumo}

Carneiro, Leonardo Simões de Abreu; Müller, Camilla Djenne Buarque. Covalent organic frameworks baseados em carbazóis: concepção, síntese e caracterização. Rio de Janeiro, 2016. 112p. Dissertação de Mestrado - Departamento de Química, Pontifícia Universidade Católica do Rio de Janeiro.

Materiais bidimensionais apresentam possibilidades de funcionalização que os tornam versáteis para diversas aplicações, tais como em dispositivos eletrônicos. A presença de poros nesses materiais pode trazer novas funções, como adsorção de gases, liberação controlada de fármacos e catálise. Os covalent organic frameworks (COFs) são uma nova classe de materiais orgânicos porosos cristalinos que têm recebido destaque em química reticular. O objetivo dessa dissertação é apresentar a síntese e caracterização de quatro novos COFs baseados em carbazóis, que constitui uma classe de compostos utilizada na obtenção de polímeros condutores. O bloco de montagem principal utilizado foi o 3,6-diamino-9H-carbazol e as fontes de aldeído foram triformilfloroglucinol, triformilfenol, 1,3,5-tri(4-formilfenil)benzeno e triformilbenzeno para a síntese do RIO2, RIO3, RIO5 e RIO6, respectivamente. RIO2 e RIO3 apresentaram-se sob a forma ceto-enamina e imina, respectivamente, além de pouca cristalinidade e baixa área específica. Através de cálculos baseados na Teoria do Funcional da Densidade (DFT), foi verificado que esses COFs apresentam suas folhas deslocadas e rotacionadas devido às interações eletrostáticas e para minimizar os momentos de dipolo das ligações N-H dos carbazóis. RIO5 e RIO6 também se apresentaram pouco cristalinos e com áreas específicas baixas. Apesar desses resultados, esses materiais ainda podem ser aplicados em eletrônica orgânica por apresentarem estrutura química compatível com tal aplicação.

\section{Palavras-chave}

Covalent organic frameworks; carbazol; tautomeria; materiais bidimensionais; porosidade. 


\section{Abstract}

Carneiro, Leonardo Simões de Abreu; Müller, Camilla Djenne Buarque (Advisor). Carbazole-based covalent organic frameworks: conception, synthesis and characterization. Rio de Janeiro, 2016. 112p. MSc. Dissertation - Departamento de Química, Pontifícia Universidade Católica do Rio de Janeiro.

Two-dimensional materials have functionalization possibilities that make them versatile for various applications such as in electronic devices. The presence of pores in these materials can give new features to them, such as gas adsorption, drug delivery and catalysis. The covalent organic frameworks (COFs) are a new class of crystalline porous organic materials that have been prominent in reticular chemistry. The purpose of this work is to present the synthesis and characterization of four new COFs based on carbazoles, which are a class of compounds used to obtain conductive polymers. The main building block used was 3,6-diamine- $9 \mathrm{H}$ carbazole with the aldehyde sources were triformylphloroglucinol, triformylphenol, 1,3,5-tri(4-formylphenyl)benzene and triformylbenzene to obtain RIO2, RIO3, RIO5 and RIO6, respectively. RIO2 and RIO3 are in keto-enamine and imine form, respectively, as well as have low crystallinity and low specific area. Calculus based on Density Functional Theory (DFT) found that these COFs present their sheets displaced and rotated due to electrostatic interactions and to minimize the dipole moments of the $\mathrm{N}-\mathrm{H}$ bonds of carbazoles. In an attempt to avoid the absence of pores, RIO5 and RIO6 materials were synthesized, however these COFs also performed poorly crystalline and with low specific areas. Despite these results, these materials can also be applied in organic electronics by presenting chemical structure compatible with such application.

\section{Keywords}

Covalent organic frameworks; carbazole; tautomerism; two-dimensional materials, porous materials. 


\section{Sumário}

1 Introdução 18

1.1. Materiais 2D e a química reticular 19

1.2. Covalent Organic Frameworks (COFs) 21

1.3. Carbazol 34

$\begin{array}{ll}2 \text { Objetivos } & 37\end{array}$

3 Resultados e discussão 38

3.1. Síntese dos blocos de montagem dos COFs 38

3.2. Síntese e caracterização dos COFs 48

\. 3. Estrutura lamelar do RIO3. 77

4 Conclusão $\quad 87$

5 Perspectivas futuras $\quad 88$

6 Procedimento experimental $\quad 89$

6.1. Materiais e métodos $\quad 89$

6.2. Obtenção dos blocos de montagem e compostos modelo 91

6.3. Obtenção dos COFs 99

7 Referências bibliográficas 101 


\section{Lista de figuras}

Figura 1: Alguns exemplos de SBUs para construção de MOFs bidimensionais. Adaptado de Tranchemontagne et al. (2009).

Figura 2: Blocos de montagem usados na síntese do NUS-1 e sua visão ao longo do eixo cristalográfico [010]. Adaptado de Zhang, M. et al. (2014).

Figura 3: COF-1 e COF-5, os primeiros sintetizados por Yaghi e colaboradores (Cote et al., 2005).

Figura 4: Diferentes COFs formados a partir de um bloco de montagem em comum, o HHTP.

Figura 5: Principais tipos de COFs separados por grupos funcionais: (a) e (b) contendo boro, (c) contendo imina, (d) contendo ceto-enamina, (e) contendo hidrazona, (f) contendo polimida.

Figura 6: Síntese do COF-5-x usando modulador, sendo x a concentração de modulador (Calik et al., 2015).

Figura 7: Origem do fenômeno da difração de raios-X a partir da interferência construtiva de dois feixes refletidos (Barnes et al., 1999).

Figura 8: Aplicação da difração de raios-X na solução da estrutura cristalina e conformação de um COF feito de porfirina. Adaptado de Chen et al. (2015).

Figura 9: Formação de canais unidimensionais no COF-5 após empilhamento das nanofolhas (Spitler et al., 2011).

Figura 10: Formato do poro dependente da geometria dos blocos de montagem: (a) alguns blocos de montagem e seus formatos de acordo com os grupos funcionais, (b) tipos de poros que podem ser formados usando os blocos de montagem escolhidos.

Figura 11: Tipos de isotermas de adsorção de um gás em um sólido (Sing et al., 1985). 
Figura 12: Algumas aplicações de derivados do carbazol: a) 3,6dicarboxicarbazol (Xie et al., 2015); b) 2,7-dicarboxicarbazol (Yi et al., 2014).

Figura 13: Cz-1 na síntese de um POF: a) síntese do Cz-POF-1; b) dehalogenação redutiva fotocatalítica de brometos de fenacila e derivados; c) hidroxilação oxidativa fotocatalítica de ácidos arilborônicos;

d) a-alquilação fotocatalítica de aldeídos.

Figura 14: Espectro de ESI-MS de 2.

Figura 15: Espectro de IV de 2.

Figura 16: Espectro de RMN- ${ }^{1} \mathrm{H}(400 \mathrm{MHz})$ em acetona- $d_{6}$ de 2.

Figura 17: Espectro de massas de 3.

Figura 18: Espectro de IV de 3. 41

Figura 19: Espectro de RMN- ${ }^{1} \mathrm{H}(400 \mathrm{MHz})$ em DMSO- $d_{6}$ de 3.

Figura 20: Espectro de IV de 4.

Figura 21: Espectro de $\mathrm{RMN}^{-1} \mathrm{H}(400 \mathrm{MHz})$ em $\mathrm{CDCl}_{3}$ de 4.

Figura 22: Espectro de $\mathrm{RMN}-{ }^{1} \mathrm{H}(400 \mathrm{MHz})$ em $\mathrm{CDCl}_{3}$ de 5.

Figura 23: Espectro de $\mathrm{RMN}^{-1} \mathrm{H}(400 \mathrm{MHz})$ em $\mathrm{CDCl}_{3}$ de 6.

Figura 24: Espectro de $\mathrm{RMN}^{-1} \mathrm{H}(400 \mathrm{MHz})$ em $\mathrm{CDCl}_{3}$ de 8.

Figura 25: Espectros de IV do RIO2: 4 (amarelo), 3 (azul), RIO2 (vermelho), 9 (verde).

Figura 26: Espectros de (a) RMN $-{ }^{13} \mathrm{C}$ calculado e (b) CP/MAS RMN- ${ }^{13} \mathrm{C}$ para 9.

Figura 27: Espectro de CP/MAS RMN-13C do RIO2 (vermelho) e espectro de $\mathrm{RMN}-{ }^{13} \mathrm{C}$ calculado por DFT (azul).

Figura 28: Espectro de IV do RIO3: triformilfenol (amarelo), 3,6-diamino9H-carbazol (azul), RIO3 (vermelho) e composto modelo do RIO3 (verde).

Figura 29: Espectros de CP/MAS RMN-13C do RIO3 (vermelho) e do composto modelo (azul).

Figura 30: Duas possíveis estruturas modeladas para o RIO2: (a) estrutura plana com visão ao longo do eixo c (esquerda) e do eixo b 
(direita); (b) estrutura enrugada com visão ao longo do eixo c (esquerda) e do eixo $b$ (direita).

Figura 31: Diagrama de energia em função do espaçamento entre folhas de RIO2: o COF plano foi chamado de f-RIO2 e o COF enrugado de c$\mathrm{RIO} 2$.

Figura 32: Função de localização eletrônica para o RIO2: a) forma plana;

b) forma enrugada.

Figura 33: Distância entre os átomos de nitrogênio dos carbazóis para a estrutura (a) plana e (b) enrugada.

Figura 34: RIO2 em conformação AA. 60

Figura 35: RIO2 em conformação AA'. 60

Figura 36: RIO2 em conformação AB.

Figura 37: RIO2 em conformação AB'.

Figura 38: RIO2 em conformação serrada. $\quad 61$

Figura 39: RIO2 em conformação inclinada.

Figura 40: Difratogramas de raios-X obtido para o RIO2 e suas conformações.

Figura 41: Função de localização eletrônica para o RIO3: a) forma plana;

b) forma enrugada.

Figura 42: Diagrama de energia em função do espaçamento entre folhas de RIO3: o COF plano foi chamado de f-RIO3 e o COF enrugado de cRIO3.

Figura 43: Conformação AA do RIO3. 65

Figura 44: Conformação AA' do RIO3. 65

Figura 45: Conformação AB do RIO3. 66

Figura 46: Conformação AB' do RIO3. 66

Figura 47: Conformação serrada do RIO3. 66

Figura 48: Conformação inclinada do RIO3. 67

Figura 49: Difratogramas de raios-X do RIO3 comparado com seus modelos. 
Figura 50: Isoterma de adsorção/dessorção de $\mathrm{N}_{2}$ do RIO2.

Figura 51: Gráfico multi-point BET para o RIO2.

Figura 52: Distribuição de tamanho de poros do RIO2 obtida por NLDFT.

Figura 53: Isoterma de adsorção/dessorção de $\mathrm{N}_{2}$ do RIO3.

Figura 54: Gráfico multi-point BET para o RIO3.

Figura 55: Distribuição de tamanho de poros do RIO3 obtida por NLDFT. 72

Figura 56: Isotermas de adsorção/dessorção de Ar para RIO2 e RIO3. 72

Figura 57: Perfil de SAXS do RIO2 e RIO3. 73

Figura 58: Gráfico $\ln \left[\ln \left(\mathrm{P}_{0} / \mathrm{P}\right)\right]$ x $\ln \left(\mathrm{V} / \mathrm{V}_{\text {mono }}\right)$ para o $\mathrm{RIO} 2$ (azul) e RIO3 (vermelho).

Figura 59: Distribuição P(r) para o RIO2 e RIO3. 75

$\begin{array}{ll}\text { Figura 60: Termograma do RIO2. } & 76\end{array}$

Figura 61: Termograma do RIO3. 76

Figura 62: Comparação dos padrões de difração de raios-X entre grafite (azul) e RIO3 (vermelho).

Figura 63: Imagens de HRTEM do RIO3: a) imagem em campo claro de nanofolhas empilhadas; b) padrão de difração de elétrons da região da foto (a); c) imagem em campo escuro de um spot da imagem (b).

Figura 64: Imagens em TEM do RIO3: (a) nova região da amostra em campo claro; (b) padrão de difração de elétrons dessa região; (c) imagem de um dos spots internos em campo escuro; (d) imagem do primeiro círculo de difração em campo escuro.

Figura 65: Nano-cebolas formadas a partir do RIO3. 80

Figura 66: Espectros de IV do RIO5 (azul) e RIO6 (vermelho). 81

Figura 67: Difratogramas de raios-X do RIO5 e RIO6. 82

Figura 68: Estrutura do AB-RIO6. 83

Figura 69: Grupos imina alinhados para cancelar os momentos de dipolo na conformação AB-RIO6. 
Figura 70: Isoterma de adsorção/dessorção de $\mathrm{N}_{2}$ do RIO5.

Figura 71: Isoterma de adsorção/dessorção de $\mathrm{N}_{2}$ do RIO6.

Figura 72: Gráfico multi-point BET para o RIO5.

Figura 73: Gráfico multi-point BET para o RIO6.

Figura 74: Distribuição de tamanho de poros do RIO5 por NLDFT.

86

Figura 75: Distribuição de tamanho de poros do RIO6 por NLDFT. 


\section{Lista de tabelas}

Tabela 1: Propriedades termodinâmicas (em Hartree) calculadas para compostos modelo com e sem carbazol do RIO2 (compostos 11 e 12) e RIO3 (compostos 13 e 14) à $298 \mathrm{~K}$.

Tabela 2: Energias de empilhamento para as conformações do RIO2.

60

Tabela 3: Energias de empilhamento para as conformações do RIO3.

65

Tabela 4: Energias de empilhamento para as conformações do RIO6.

82 


\section{Lista de abreviaturas}

2D

AFM

BET

BJH

BN

CG-MS

COF

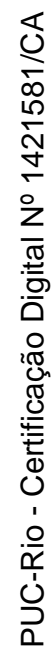
${ }^{13} \mathrm{C}$

DRX

FWHM

hBN

HHTP

HK

HMTA

Bidimensional

Microscopia de força atômica

Método de Brunauer, Emmett e Teller

Método de Barrett, Joyner e Halenda

Nitreto de boro

Cromatografia gasosa acoplada ao espectrômetro de massas

Covalent organic framework

CP/MAS RMN- Ressonância magnética nuclear de carbono $13 \mathrm{com}$ polarização cruzada com rotação em torno do ângulo mágico

DPEP 4,4'-(2,2-diphenylethene-1,1-diyl)dibenzoic acid

Difração de raios- $X$

Largura de pico à meia altura

Nitreto de boro hexagonal

Hexahidróxi trifenileno

Método de Horvath-Kawazoi

Hexametilenotetramino

HOMO

Orbital molecular ocupado de maior energia

HRTEM

Microscopia eletrônica de transmissão de alta resolução

IV

Infravermelho

LUMO

Orbital molecular desocupado de menor energia

MOF

Metal-organic framework

MOP

Metal-organic polyhedra

MS

Espectrometria de massas

NLDFT

Teoria do funcional da densidade não local

POF

Porous organic framework 
RMN-13 C Ressonância magnética nuclear de carbono 13

RMN-1H Ressonância magnética nuclear de hidrogênio 1

SBU

Secondary building units

T.a.

Temperatura ambiente

TMDC

Transition metal dichalcogenide

TMDC

Dicalcogenetos lamelares de metais de transição

ZIF

Zeolitic imidazolate framework 


\section{1}

\section{Introdução}

Materiais bidimensionais (2D) têm recebido atenção dos pesquisadores desde o isolamento do grafeno (Bhimanapati et al., 2015; Morpurgo, 2015), que consiste numa monocamada de átomos de carbono $\mathrm{sp}^{2}$ (Novoselov et al., 2004). Suas propriedades, tais como condutividade elétrica térmica e resistência mecânica, despertaram o interesse dos pesquisadores nesse tipo de material (Ornes, 2015).

A estrutura lamelar do grafite o torna passível de sofrer esfoliação, isto é, sofrer processo químico ou físico para a quebra das ligações ou interações que unem as folhas e, assim, separá-las. Novoselov et al. (2004) conseguiram a obtenção do grafeno esfoliando sucessivamente grafite em flocos usando uma fita adesiva. No ano seguinte, Novoselov et al. (2005) seguiram a mesma ideia para materiais lamelares inorgânicos (nitreto de boro (BN), $\mathrm{MoS}_{2}, \mathrm{NbSe}_{2}$ e $\mathrm{Bi}_{2} \mathrm{Sr}_{2} \mathrm{CaCu}_{2} \mathrm{O}_{x}$ ) cujas camadas são fortemente ligadas. Ao friccionar esses materiais sobre uma superfície sólida, eles obtiveram pequenos flocos observáveis a olho nu, mas formados por poucas camadas de material 2D, como comprovado por microscopia óptica, microscopia de força atômica (AFM) e microscopia eletrônica de transmissão de alta resolução (HRTEM). O resultado mais importante desse estudo foi verificar que as propriedades elétricas dos mesmos foram mantidas e que esses materiais se apresentaram estáveis à temperatura ambiente, permanecendo monocristalinos.

Em um trabalho mais recente, Withers et al. (2015) conseguiram obter heteroestruturas 2D que consistiam de folhas intercaladas de grafeno, nitreto de boro hexagonal ( $\mathrm{hBN}$ ) e dicalcogenetos lamelares de metais de transição (TMDC) para fabricação de dispositivos emissores de luz. Esse exemplo mostra a versatilidade: novos materiais $2 \mathrm{D}$ podem ser obtidos ou otimizados para que determinada propriedade seja aperfeiçoada (Roth et al., 2016). 


\section{1. \\ Materiais 2D e a química reticular}

Materiais porosos como as zeólitas e sílicas porosas são comumente utilizados como trocadores iônicos (Kodaira e lkeda, 2010; Ates e Akgul, 2016), membranas (Mühlmann et al., 2012) e catalisadores (Frindy et al., 2015; Antunes et al., 2016), além de promover separações (Kosinov et al., 2016; Liu et al., 2016) e liberação controlada de fármacos (Yang et al., 2015; Pena et al., 2016).

Aliar a presença de poros aos materiais 2D gerou novas possibilidades de materiais a serem explorados. A química reticular é uma nova área da química que estuda materiais formados por blocos de montagem moleculares (compostos orgânicos ou inorgânicos) em estruturas pré-determinadas chamadas de blocos de montagem secundários (do inglês secondary building blocks, SBUs) que se repetem e são ligadas entre si por ligações fortes (Yaghi e Li, 2009). Ao se utilizar moléculas rígidas e de estrutura bem definida, os processos de síntese desses materiais mantém a integridade estrutural delas (Yaghi et al., 2003), o que provoca a formação de redes porosas estendidas em duas ou três dimensões.

Os principais exemplos de materiais que compõem essa nova área da química são os metal-organic frameworks (MOFs), covalent organic frameworks (COFs), metal-organic polyhedra (MOP), zeolitic imidazolate frameworks (ZIFs) e porous organic frameworks (POFs), dentre outros. O primeiro deles, o MOF, é um material formado por centros metálicos, podendo ser íons ou clusters metálicos (natureza catiônica), ligados entre si por moléculas orgânicas (natureza aniônica) e que apresenta topologia bem definida e com elevada simetria (Rowsell e Yaghi, 2004). Quando os blocos de montagem são submetidos a processos solvotérmicos, a temperaturas abaixo de $300{ }^{\circ} \mathrm{C}$, geram macromoléculas de estrutura ordenada, o que confere alta área específica (Kuppler et al., 2009; Zhoua e Kitagawa, 2014).

Para se obter um MOF bidimensional é necessário que o centro tenha os pontos de extensão (ou sítios de coordenação, se usar a nomenclatura usual de química de coordenação) formando uma figura plana. Tranchemontagne et al. (2009) resumiram em seu trabalho todos os tipos de SBUs (Figura 1). 


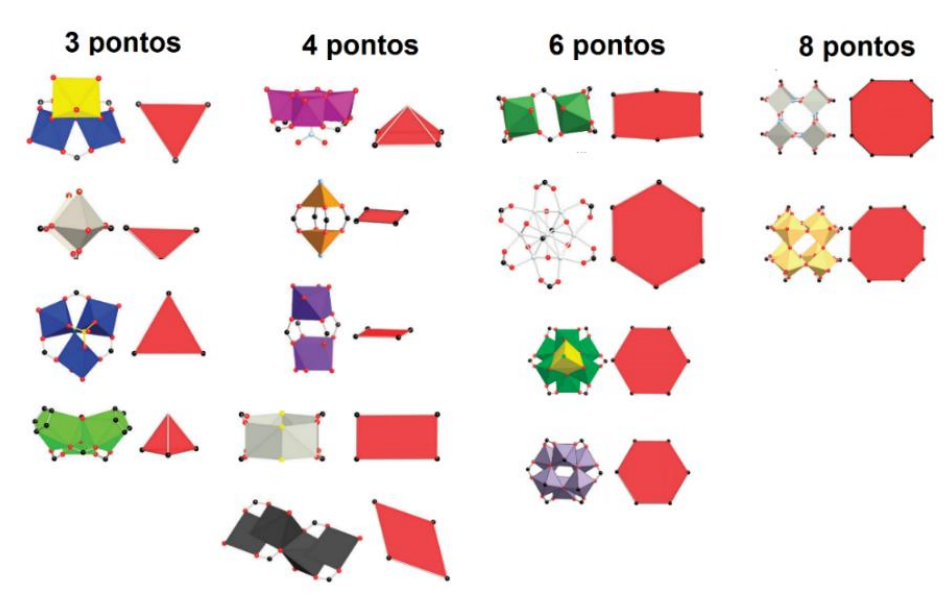

Figura 1: Alguns exemplos de SBUs para construção de MOFs bidimensionais. Adaptado de Tranchemontagne et al. (2009).

Diversos artigos de revisão já foram publicados discutindo desde questões relacionadas à química e estrutura dos MOFs (O'keeffe e Yaghi, 2012; Devic e Serre, 2014; Schneemann et al., 2014) como também para aplicações específicas, como adsorção de gases (Getman et al., 2012; Barea et al., 2014; He et al., 2014; Langmi et al., 2014) e catálise (Yoon et al., 2012; Liu, J. et al., 2014; Zhang e Lin, 2014; Jiang e Yaghi, 2015). Para ilustrar a estrutura bidimensional de alguns desses materiais é apresentado o NUS-1 (Figura 2) (Zhang, M. et al., 2014), obtido a partir da reação entre $\mathrm{Zn}\left(\mathrm{NO}_{3}\right)_{2} \cdot 4 \mathrm{H}_{2} \mathrm{O}$ com o ligante DPEB (Figura 2). O cristal obtido apresenta unidade de montagem secundária de quatro pontos que consiste de íons $\mathrm{O}^{2-}$ envolvidos por quatro íons $\mathrm{Zn}^{2+}$ e as folhas de MOF empilhadas formaram canais unidimensionais a partir dos poros hexagonais. Após remoção das moléculas de solventes presas na estrutura cristalina, o material, então denominado NUS-1a, apresentou transição de fase semelhante à transição vítrea sob condições criogênicas e excelente capacidade de adsorção de gases.

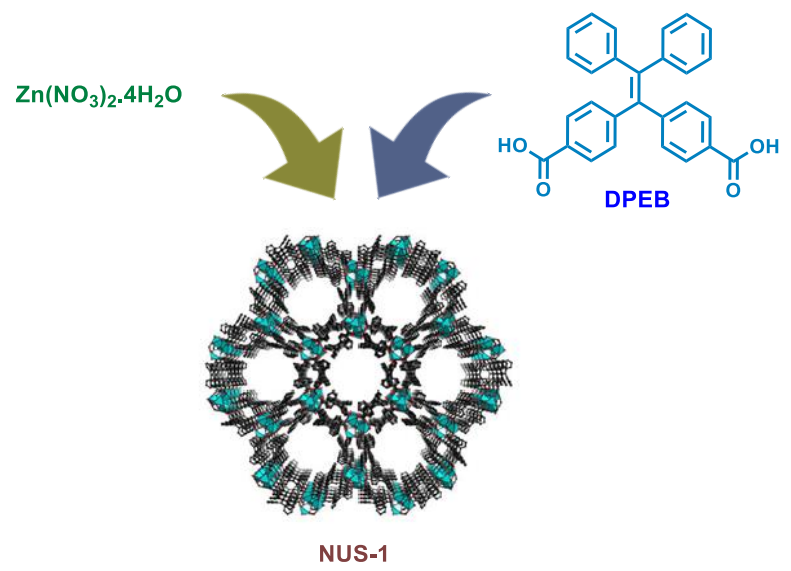

Figura 2: Blocos de montagem usados na síntese do NUS-1 e sua visão ao longo do eixo cristalográfico [010]. Adaptado de Zhang, M. et al. (2014). 


\section{2.}

\section{Covalent Organic Frameworks (COFs)}

Em 2005, Yaghi e colaboradores publicaram dois materiais bidimensionais formados por blocos de montagem orgânicos ligados entre si por ligações covalentes fortes (Cote et al., 2005). Eles foram chamados de COF-1 e COF-5 (Figura 3) e serviram como ponto de partida para uma nova classe de materiais. As características de um COF compreendem o fato de serem cristalinos e possuírem ligações covalentes fortes do tipo C-C, C-O, C-N e C-B, apresentarem alta área específica e baixa densidade, e procedimentos de síntese one-pot com elevados rendimentos. Outra característica é sua baixa solubilidade, o que é característico de estruturas estendidas ligadas covalentemente (Hunt, 2009).
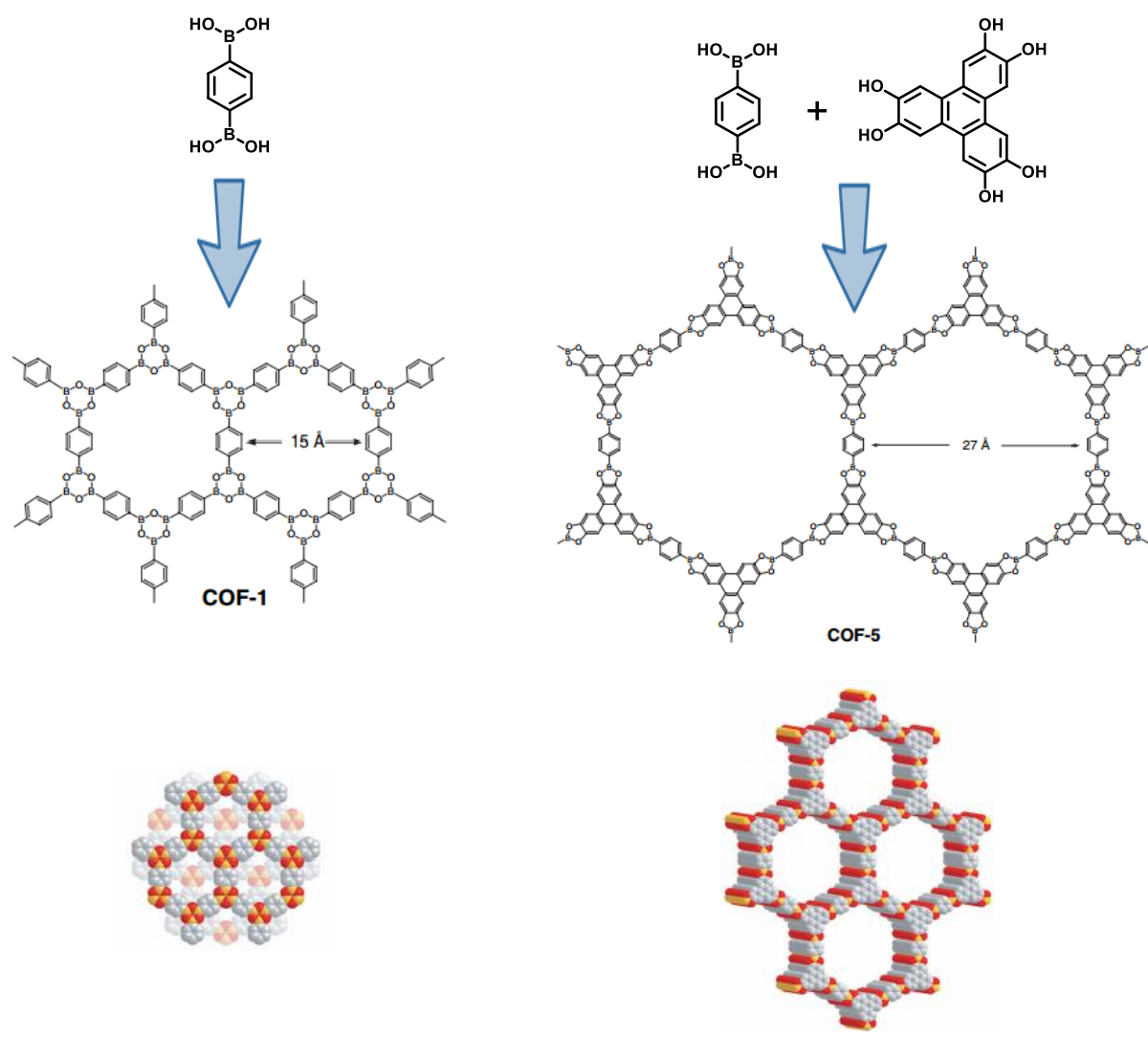

Figura 3: COF-1 e COF-5, os primeiros sintetizados por Yaghi e colaboradores (Cote et al., 2005).

A grande variedade de moléculas orgânicas que podem ser usadas como blocos de montagem garante um grande número de possibilidades que podem ser 
exploradas para novos tipos de COFs. Com um mesmo bloco, é possível sintetizar diferentes materiais (Figura 4).
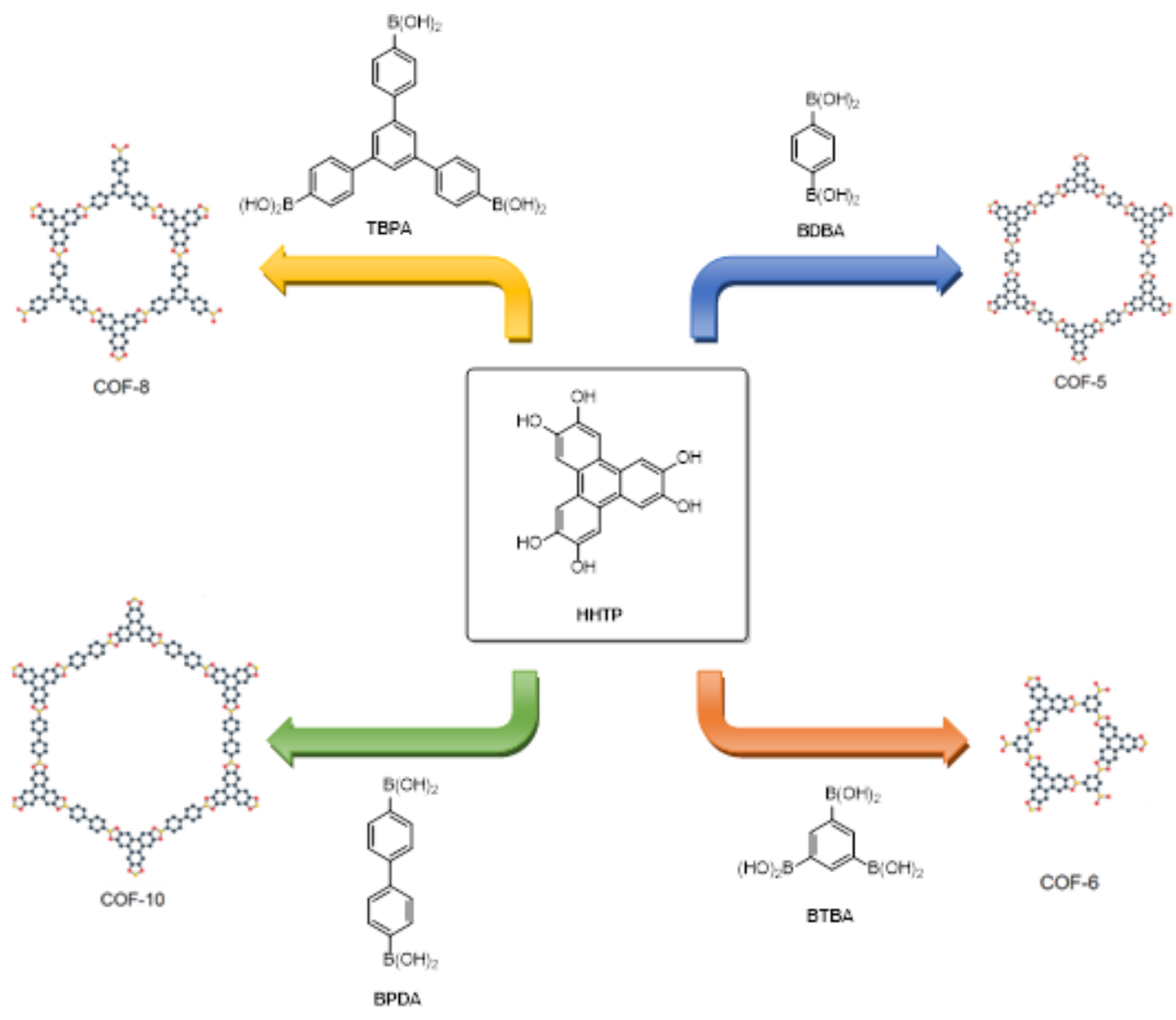

Figura 4: Diferentes COFs formados a partir de um bloco de montagem em comum, o HHTP.

É possível dividir os COFs em categorias de acordo com os grupos funcionais presentes no material. As classificações apresentadas a seguir foram adaptadas e atualizadas de Ding, S.-Y. e Wang, W. (2013).

- Contendo boro: podem ser obtidos por condensação de ácido borônico com dióis (Figura 5a) (Cote et al., 2007) ou autocondensação de grupos ácidos borônicos (Figura 5b) (Cote et al., 2005).

- Contendo iminas ou enaminas: obtidos pela reação em meio ácido de aminas com aldeídos (Figura 5c) (Rabbani et al., 2013). Se ocorrer tautomeria irreversível, o COF passa a ter grupos cetoenamínas (Figura 5d) (Kandambeth et al., 2012). 
- Contendo hidrazonas: gerados a partir da reação entre hidrazinas e aldeídos (Figura 5e) (Uribe-Romo et al., 2011).

- Contendo imidas: a partir da reação entre polianidridos aromáticos cíclicos e aminas (Figura 5f) (Fang et al., 2014).
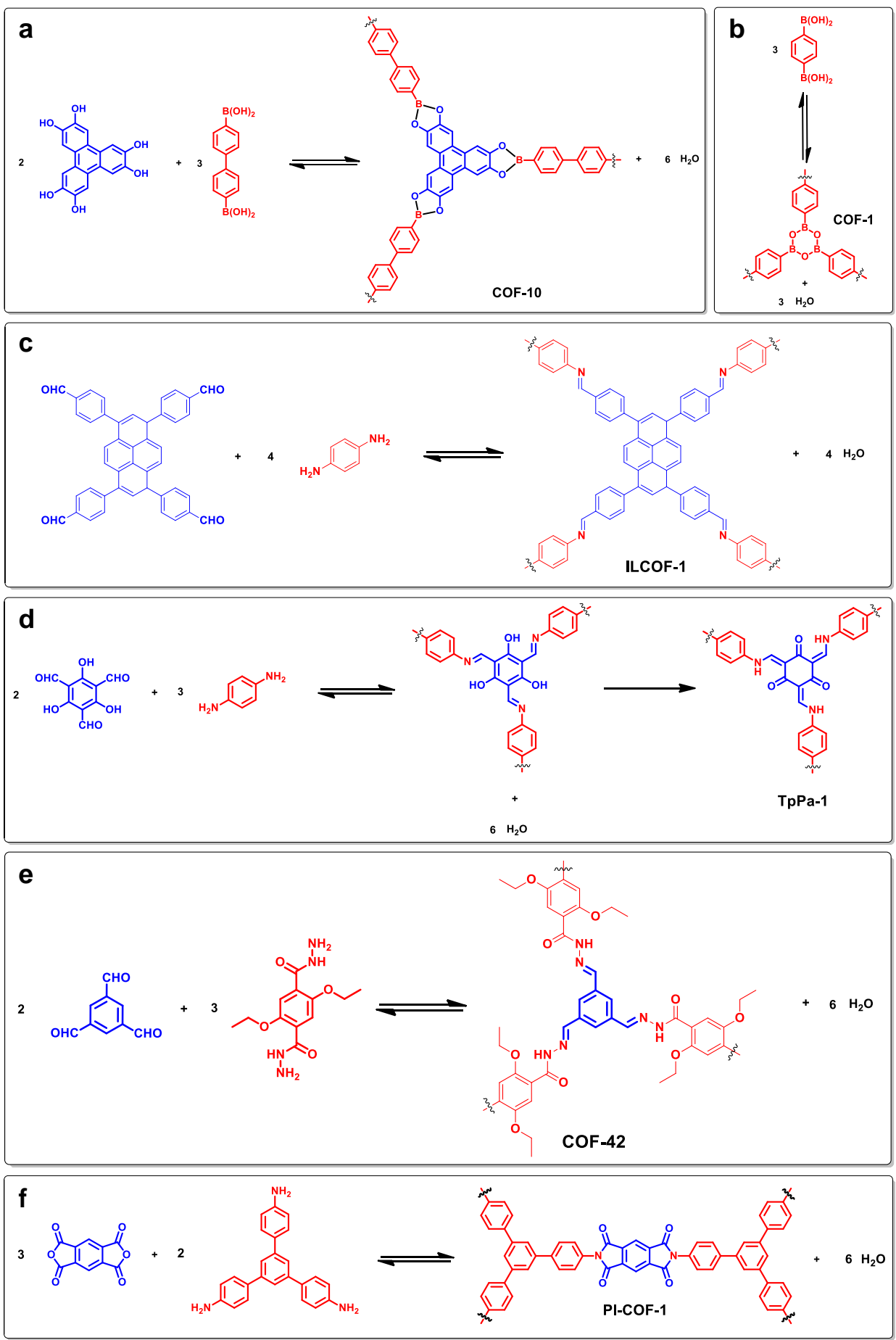

Figura 5: Principais tipos de COFs separados por grupos funcionais: (a) e (b) contendo boro, (c) contendo imina, (d) contendo ceto-enamina, (e) contendo hidrazona, (f) contendo polimida. 


\subsection{1. \\ Estrutura cristalina dos COFs}

Uma das principais características dos COFs é a cristalinidade, segundo a definição dada por Yaghi (Cote et al., 2005). A estratégia empregada na síntese de moléculas de longa extensão e complexas como essas baseia-se na química covalente dinâmica (Feng et al., 2012), um processo dinâmico que tem como objetivo a formação da espécie de menor energia através da reversibilidade das reações usadas na síntese do material (Ding, S. Y. e Wang, W., 2013; Jin et al., 2013; Ciesielski et al., 2014). Isso difere, então, os COFs de materiais supramoleculares, que se baseiam na auto-organização dos blocos de montagem por interações intermoleculares não-covalentes (Jin et al., 2013). A vantagem de se desenvolver um material baseado em reações reversíveis é a possibilidade da estrutura se "autocorrigir" até obter ordenação característica de material cristalino (Mastalerz, 2013).

Apesar de se utilizar reações sob controle termodinâmico, outros fatores também afetam a cristalinidade do produto obtido. Duncan et al. (2012) mostraram que o solvente influencia na posição do equilíbrio da reação de formação de iminas. A partir de uma reação modelo entre um tetra-aldeído com uma amina primária, foi possível observar que quando 1,4-dioxana foi usada como solvente da reação, a constante de equilíbrio obtida foi de 26,7, um valor intermediário entre o solvente que gerou a menor (0,07 em clorofórmio) e a maior constante (247,9 em DMSO). Esse valor indica que a reação produz menos imina quando comparada com DMSO, sendo necessário maior tempo de reação para a obtenção do produto cristalino, devido à reversibilidade do processo. Usualmente os primeiros produtos sólidos formados são oligômeros e o material apresenta baixa cristalinidade/vítreo. A reversibilidade do processo faz com que esse material amorfo vá formando lentamente o produto desejado, com cristalinidade. Ao utilizar o DMSO, há pouca reversibilidade (equilíbrio muito deslocado no sentido dos produtos) o que faz com que seja obtido o material amorfo, que poderia ser considerado um produto cinético. Esse produto amorfo do e baixa cristalinidade ainda pode ser poroso, devido à disposição não ordenada da rede formadora dos poros, como é o caso dos POFs (Zhu e Ren, 2015).

Calik et al. (2015) destacam que a cristalinidade de COFs 2D podem ser aprimoradas a partir do conceito de modularização, que já foi aplicada à esses materiais 3D. O modulador é uma molécula similar a um dos reagentes polipodais mas com menos grupos funcionais reativos (solubilidade parecida, dentre outras 
características) que compete com esse reagente na reação de formação de COF. Assim, ele compete com o reagente "original" na incorporação ao cristal de COF. Essa competição é na prática ganha pelo reagente original, pois ele fornece o sólido mais estável (COF). Entretanto, o modulador acaba por forçar que o núcleo crítico de cristalização seja maior e mais puro. Isso leva a uma maior cristalinidade dos materiais. Na síntese do COF-5 utilizando-se 10\% de modulador observou-se o afinamento dos picos das reflexões, indicativo de que o tamanho do cristalito aumentou. Segundo a equação de Scherrer, equação 1, o tamanho do cristalito ( $\beta$ ) é inversamente proporcional a largura do pico de difração à meia altura (FWHM) (Patterson, 1939). Como consequência observou-se aumento da área do COF de $1200 \mathrm{~m}^{2} \mathrm{~g}^{-1}$ para $2100 \mathrm{~m}^{2} \mathrm{~g}^{-1}$ e do volume de poro de $0,64 \mathrm{~cm}^{3} \mathrm{~g}^{-1}$ para $1,14 \mathrm{~cm}^{3} \mathrm{~g}^{-1}$. O mecanismo proposto pelos pesquisadores se baseia no equilíbrio termodinâmico. Quando o modulador se liga à rede do COF, este faz parar o crescimento ao longo de sua direção. Isso provoca aumento na quantidade de etapas de precipitações e dissoluções, o que corrige defeitos na rede cristalina e permite obter cristalitos maiores.

$$
\mathrm{FWHM}=\frac{\mathrm{K} \lambda}{\beta \cos \theta}
$$

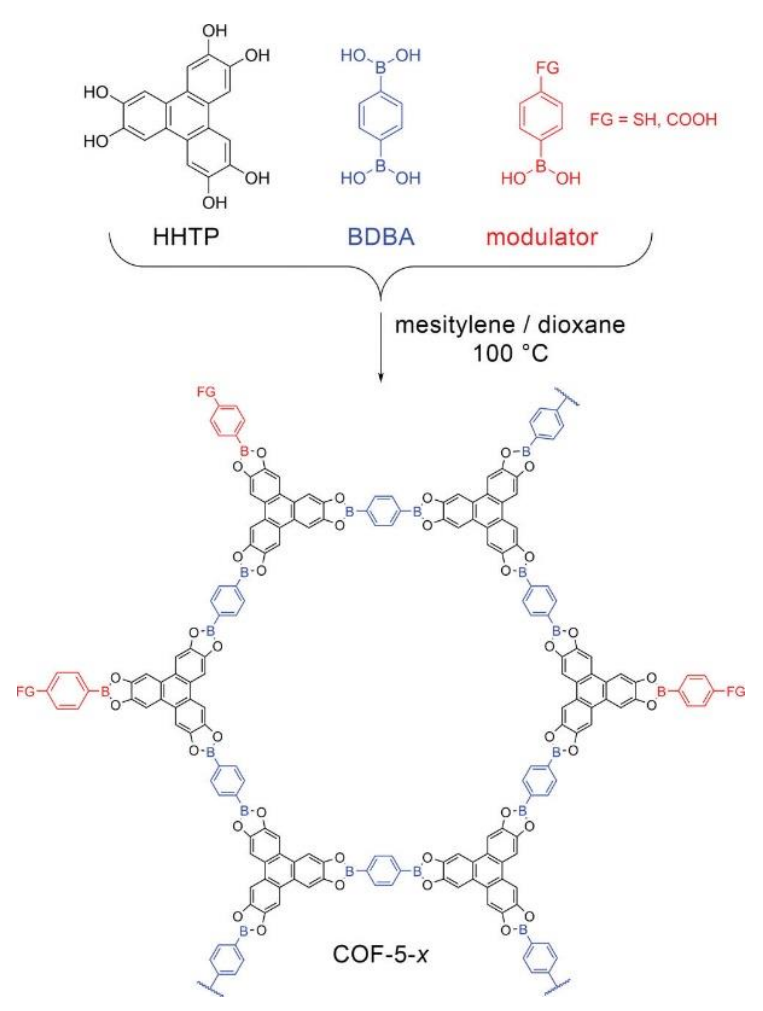

Figura 6: Síntese do COF-5-x usando modulador, sendo x a concentração de modulador (Calik et al., 2015). 
A estrutura dos COFs é definida como cristalina ou amorfa a partir da difração de raios- $X$ usando o método do pó. Essa técnica se baseia em incidir raios- $X$, de comprimentos de onda conhecidos, sobre uma amostra na forma de um pó, em diferentes ângulos. Ao se considerar dois ou mais planos atômicos adjacentes com raios- $X$ sendo incididos num determinado ângulo, se ocorrer interferência construtiva entre as radiações refletidas, então é dito que aquela família de planos é capaz de difratar naquele determinado ângulo, conhecido como ângulo de Bragg (Figura 7) (Cullity e Stock, 2001). A Lei de Bragg, equação 2 , é a relação matemática que explica esse fenômeno, onde $\lambda$ é o comprimento de onda da radiação usada, d é a distância entre os planos cristalográficos, $2 \theta$ é o ângulo de Bragg e $n$ é uma constante tal que $n \in \mathbb{N}$ e está relacionada com a ordem de difração.

$$
\mathrm{n} \lambda=2 \mathrm{~d} \sin 2 \theta
$$

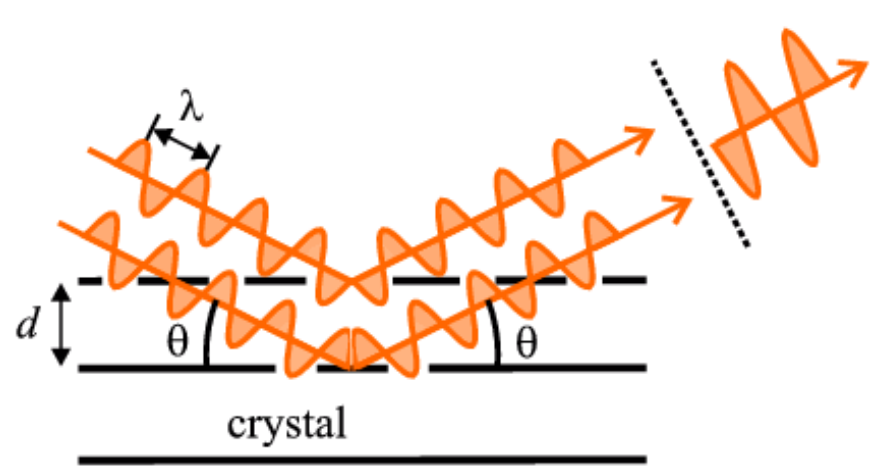

Figura 7: Origem do fenômeno da difração de raios-X a partir da interferência construtiva de dois feixes refletidos (Barnes et al., 1999).

Para cada ângulo de Bragg onde ocorre difração, um pico é gerado com uma determinada intensidade. A posição do pico se refere exclusivamente ao plano cristalográfico que difrata. A intensidade está relacionada com outros fatores, como fator de espalhamento atômico, fator de estrutura e formato do cristal, dentre outros (Tilley, 2014).

Uma vez que o padrão de difração do monocristal do material tenha sido obtido experimentalmente, a próxima etapa consiste na análise cristalográfica, que permite elucidar a estrutura cristalina do mesmo. O método mais utilizado para esse fim é o de Rietveld (Rietveld, 1967; 1969), que também permite análise quantitativa de diferentes fases presentes no mesmo material. Esse método 
consiste no uso do método dos mínimos quadrados e leva em consideração fatores instrumentais e de estrutura para ajustar um padrão de difração experimental em um calculado (Will, 2006). Entretanto, o que se observa na análise de COFs é o uso do método de Pawley devido à baixa resolução dos padrões de difração obtidos (Ding, S. Y. e Wang, W., 2013).

Para efeito de comparação e ajuste da melhor conformação, utiliza-se softwares para simulação das estruturas dos COFs. O mais utilizado para esse fim é o MaterialStudio ${ }^{\circledR}$. Após a simulação da estrutura cristalina, compara-se a mesma com o padrão de difração de pó experimental. Quando mais de uma conformação é possível, utiliza-se os padrões de cada conformação para se determinar qual é a presente, de fato, no material.

Para exemplificar o uso da DRX, na Figura 8 é mostrado o difratograma de raios-X (em vermelho) obtido para o CuP-DHPh COF (Chen et al., 2015). O ajuste feito pelo método de Pawley é mostrado pelos pontos verdes sobre o difratograma experimental. A linha preta mostra a diferença entre os dois. Duas conformações seriam possíveis para esse COF: $A A$, onde os poros são alinhados, e $A B$, onde o centro porfirínico encontra-se no centro do poro da folha de cima. Após simulação dos padrões de difração de cada conformação, é possível observar por simples comparação que a conformação AA é a adotada pelo material.
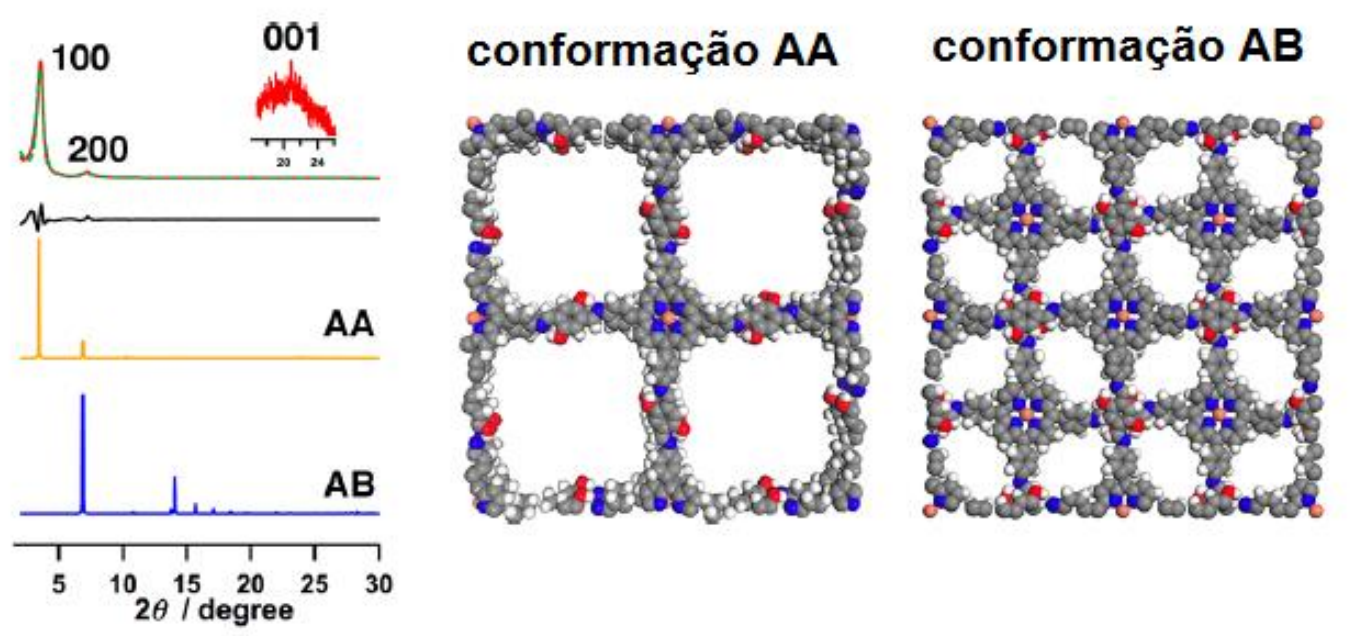

Figura 8: Aplicação da difração de raios-X na solução da estrutura cristalina e conformação de um COF feito de porfirina. Adaptado de Chen et al. (2015). 


\subsection{2.}

\section{Estrutura hierárquica de poros e topologia}

Um material poroso pode ser classificado de acordo com o tamanho dos seus poros. Essa classificação segue recomendação da IUPAC. Materiais macroporosos apresentam poros com diâmetro maior que $50 \mathrm{~nm}$. Materiais mesoporosos apresentam diâmetro entre 2 e $50 \mathrm{~nm}$. Já os materiais microporosos tem diâmetro de poro menor que $2 \mathrm{~nm}$, podendo ainda receber subclassificações, como supermicroporoso (entre 0,7 e $2 \mathrm{~nm}$ ), ultramicroporoso $(<0,7 \mathrm{~nm}$ ) e submicroporoso (<0,4 nm). Outras escalas de diâmetros de poro também existem, como apresentada por Dubinin (1979) e Zdravkov et al. (2007), entretanto a classificação IUPAC é a mais usual e recomendada.

A formação de poros na estrutura dos COFs está diretamente relacionada com a retenção da geometria dos blocos de montagem. Para formação de materiais $2 \mathrm{D}$, esses blocos devem ser rígidos e planos. Como consequência, o COF cresce como nanofolhas que se empilham formando estruturas lamelares com seus poros alinhados (Figura 9) (Zhuang et al., 2015). Ao se combinar os blocos de montagem é possível obter diferentes topologias para o material; no caso dos COFs bidimensionais, o formato dos poros pode ser triangular, quadrado e hexagonal, dentre outros (Figura 10).

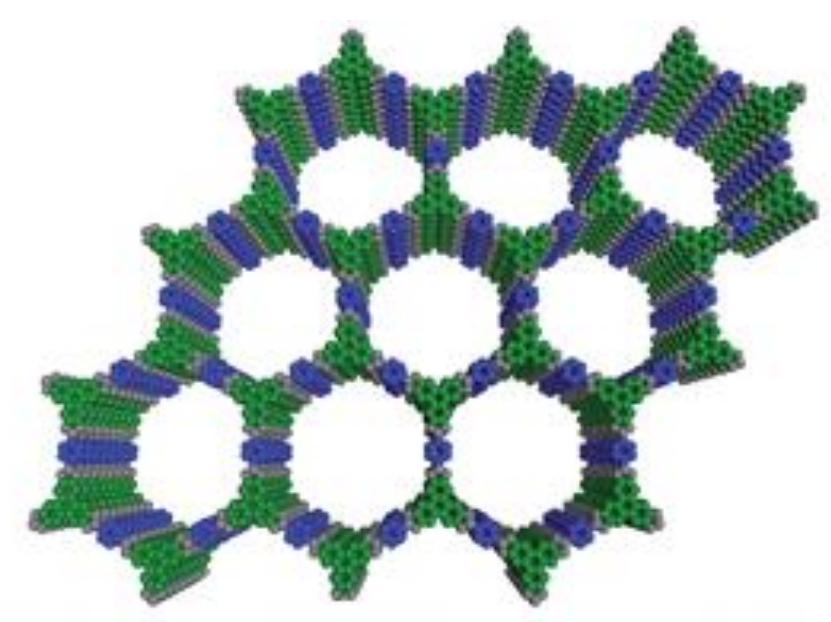

Figura 9: Formação de canais unidimensionais no COF-5 após empilhamento das nanofolhas (Spitler et al., 2011).

As principais propriedades avaliadas em materiais porosos são a área específica e a distribuição de tamanho de poro. O método mais comum para se obter esses dados é a isoterma de adsorção/dessorção de gás. A técnica se 
baseia na adsorção de gás nitrogênio na superfície do sólido (adsorvato) cujas propriedades serão analisadas. O modelo mais utilizado na análise de COF é o de BET, que é válido de acordo com algumas premissas (Brunauer et al., 1938): o gás adsorvido é considerado ideal, mais de uma molécula pode ser adsorvida num mesmo sítio, cada molécula adsorvida gera um novo sítio numa camada acima, todos os sítios de adsorção são equivalentes, não há interação gás-sólido, as moléculas adsorvidas ficam imóveis e o gás adsorvido a partir da segunda camada se comporta como líquido.
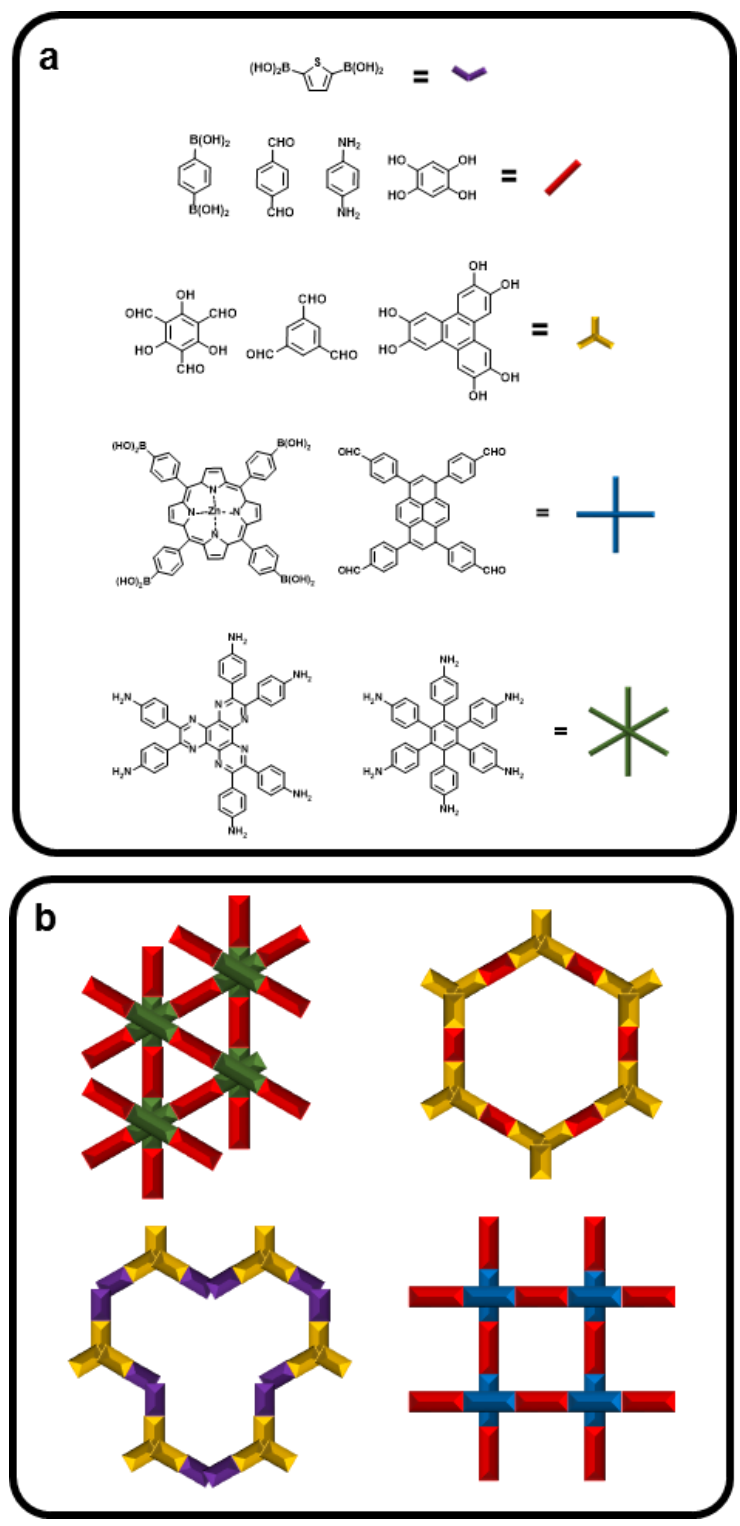

Figura 10: Formato do poro dependente da geometria dos blocos de montagem: (a) alguns blocos de montagem e seus formatos de acordo com os grupos funcionais, (b) tipos de poros que podem ser formados usando os blocos de montagem escolhidos. 
Existem seis modelos de isotermas (Figura 11), sendo que cada tipo corresponde a uma classe de materiais (Sing et al., 1985):

- Tipo I: materiais microporosos, com formação de monocamada de gás adsorvido. Também conhecida como isoterma de Langmuir.

- Tipo II: materiais não-porosos ou macroporosos.

- Tipo III e V: materiais com interação adsorvente-adsorbato fraca.

- Tipo IV: materiais mesoporosos com presença de histerese na isoterma devido ao fenômeno da condensação capilar.

- Tipo VI: quando um gás é adsorvido na superfície de um material não-poroso.

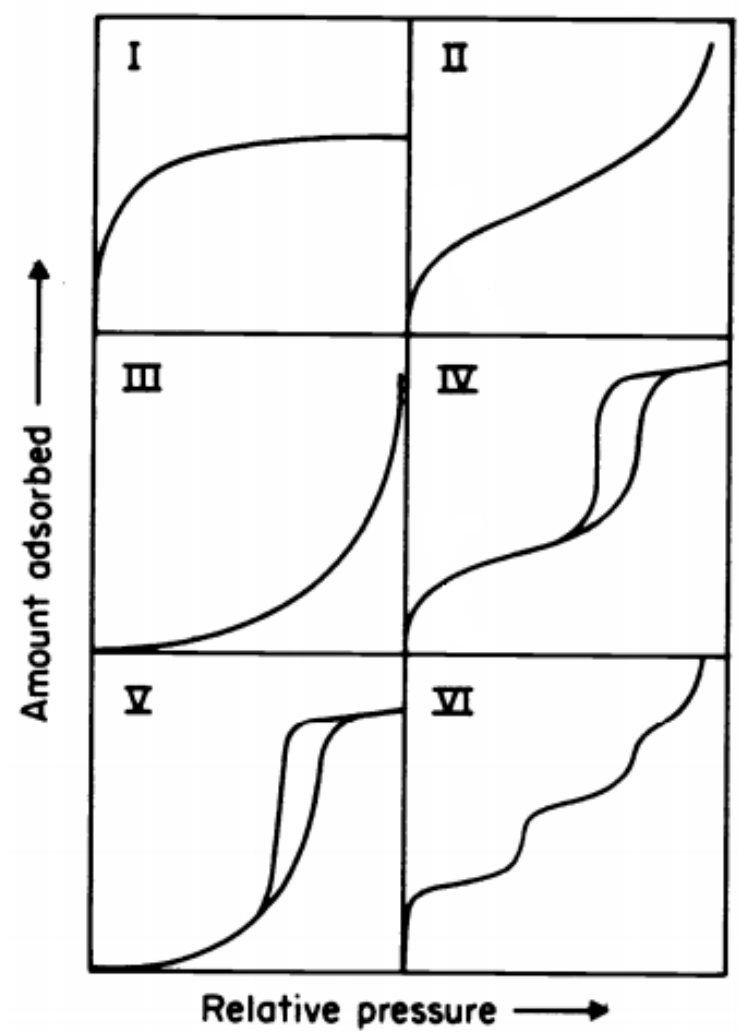

Figura 11: Tipos de isotermas de adsorção de um gás em um sólido (Sing et al., 1985).

\subsubsection{1.}

\section{Cálculo da área específica}

Diferentes regiões da isoterma são usadas para calcular as propriedades do material poroso. A região entre $0,05<\mathrm{P} / \mathrm{P}_{0}<0,3$ é usada para o cálculo da área específica utilizando o método multi-point BET. Essa região é escolhida devido 
representar a formação de monocamada de gás adsorvido. A equação do modelo de BET pode ser arrumada como a equação de uma reta, onde c é a constante $\mathrm{BET}, \mathrm{W}_{\mathrm{m}}$ é a massa de gás adsorvida por uma monocamada, $\mathrm{W}$ é a massa total de gás adsorvida e $P$ e $P_{0}$ são as pressões de equilíbrio e saturação, respectivamente.

$$
\frac{1}{W\left(P_{0} / P-1\right)}=\frac{1}{W_{m} c}+\frac{c-1}{W_{m} c}\left(\frac{P}{P_{0}}\right)
$$

A partir de um gráfico $\frac{1}{W\left(P_{0} / P^{-1}\right)} \times \frac{P}{P_{0}}$ obtém-se o valor de $W_{m}$ a partir dos coeficientes angular (a) e linear (b) da reta obtida por regressão linear.

$$
\mathrm{W}_{\mathrm{m}}=\frac{1}{a+b}
$$

Por fim, a área do material (em $\mathrm{m}^{2}$ ) é obtida através da equação 5 , onde $\mathrm{N}$ é o número de Avogadro, $A_{\mathrm{sc}}$ é a seção de choque do gás e $M$ é sua massa molar. Ao dividir a área obtida pela massa de amostra utilizada é obtido o valor da área específica em $\mathrm{m}^{2} \mathrm{~g}^{-1}$.

$$
S=\frac{W_{m} N A_{s c}}{M}
$$

\subsubsection{2.}

\section{Cálculo da distribuição de tamanho de poros}

Existem várias metodologias para o cálculo do tamanho do poro de um material, como BJH (Barrett, Joyner e Halenda) e HK (Horvath-Kawazoe). Entretanto, os COFs têm suas distribuições de tamanho de poros calculados a partir da aplicação da Teoria do Funcional da Densidade não local. O uso da NLDFT apresenta resultados mais realísticos que os métodos baseados na equação de Kelvin, como o BJH (Landers et al., 2013).

Segundo Jessop et al. (1991), a isoterma obtida experimentalmente resulta na soma de isotermas individuais provenientes de cada poro individual do material. Pode-se determinar o número de mol adsorvido de gás a uma dada pressão $P, N(P)$, através da equação 6 . 


$$
N(P)=\int_{0}^{\infty} \rho(P, H) f(H) d H
$$

Nessa equação, $\rho(P, H)$ é a densidade molar do gás adsorvido a uma dada pressão em um determinado poro de tamanho $\mathrm{H}$ e $\mathrm{f}(\mathrm{H})$ é a função de distribuição de tamanho de poro. No caso dessa equação não apresentar solução analítica ela pode ser resolvida na forma discreta a partir de um somatório (Olivier et al., 1994).

$$
N(P)=\sum_{i} \rho\left(P, H_{i}\right) f\left(H_{i}\right)
$$

Nesse caso, dado um conjunto de isotermas modelo, $\rho\left(P, H_{i}\right)$, e a isoterma experimental, $N(P)$, um programa computacional pode ser usado para determinar um conjunto de valores, $f\left(H_{i}\right)$, positivos ou nulos, que satisfazem a equação 7 (Olivier et al., 1994).

Essa teoria é fundamentada na Mecânica Estatística e pode ser determinada de forma particular para cada tipo de material, como grafite (Lastoskie et al., 1993) e a sílica mesoporosa MCM-41 (Ravikovitch et al., 1995). O equipamento utilizado nas análises apresenta um banco de dados contendo alguns modelos onde é possível escolher aquele que melhor se adapta ao material analisado e esses cálculos são feitos.

\subsubsection{3.}

\section{Aplicação da técnica de espalhamento de raios-X em baixo ângulo (SAXS) no estudo de materiais porosos}

De acordo com a Lei de Bragg, quanto maior for a distância entre os planos cristalográficos, menor será o ângulo de difração. Estruturas estendidas como polímeros e proteínas tendem, então, a apresentar planos com distâncias grandes o suficiente para que os ângulos de difração sejam pequenos. Para contornar esse problema, as técnicas de espalhamento a baixos ângulos são adotadas.

O SAXS se baseia no fenômeno do espalhamento da radiação. A intensidade do espalhamento dos raios- $X$ provocado ao se colidir um feixe com uma amostra é função do chamado vetor de espalhamento q. Ele pode ser expresso como função do ângulo de espalhamento $\theta$ (Schnablegger e Singh, 2011). 


$$
q(\theta)=\frac{4 \pi \sin \theta}{\lambda}
$$

A variação angular do espalhamento é um dado importante nesse tipo de análise pois está diretamente relacionado com a densidade eletrônica, $\rho(\mathbf{r})$, do material. A amplitude do espalhamento, $A(\mathbf{q})$, é dada pela transformada de Fourier da densidade eletrônica num ponto de coordenada $\mathbf{r}$ qualquer no espaço recíproco (Guinier e Fournet, 1955). Sendo A(q) uma função complexa, ela pode ser definida como o produto do módulo pela fase.

$$
A(\mathbf{q})=\iiint \rho(\mathbf{r}) e^{-i \mathbf{q} \cdot r} \mathrm{~d}^{3} \mathbf{r}=|A(\mathbf{q})| e^{i \boldsymbol{\varphi}}
$$

A intensidade do espalhamento de raios-X é a grandeza que de fato é medida no SAXS e pode ser definida como sendo o produto da amplitude $A(\mathbf{q})$ pelo seu conjugado $A^{*}(\mathbf{q})$. Essa abordagem é necessária pois o fenômeno de interferência somente é aplicável a pares de elétrons e matematicamente isso é descrito como o quadrado da amplitude (Goesten et al., 2013).

$$
\mathrm{I}(\mathbf{q})=\mathrm{A}(\mathbf{q}) \cdot \mathrm{A}^{*}(\mathbf{q})=|\mathrm{A}(\mathbf{q})|^{2}=\iiint \iiint \rho(\mathbf{r}) \rho^{*}(\mathbf{r}) \mathrm{e}^{-\mathrm{iq} \cdot\left[\mathrm{r}-\mathbf{r}^{*}\right]} \mathrm{d}^{3} \mathbf{r} \mathrm{d}^{3} \mathbf{r}^{*}
$$

Uma vez obtida a intensidade e, por sua vez, a amplitude, poderia ser feita uma transformada de Fourier inversa para obter a densidade eletrônica. Se esse cálculo fosse possível, poder-se-ia determinar a estrutura do material, entretanto não é possível obter a amplitude diretamente a partir da intensidade devido ao problema de fase. A partir da raiz quadrada de $\mathbf{I}(\mathbf{q})$ obtém-se o módulo da amplitude, entretanto experimentalmente não é possível obter a fase (Da Róz et al., 2015).

Em particular, o SAXS pode ser usado como técnica complementar para o estudo de materiais porosos, conferindo informações além das cristalográficas (Stribeck e Smarsly, 2005). Algumas zeólitas (Greaves et al., 2003; Du e Wu, 2007; Aerts et al., 2011) e MOFs (Tsao et al., 2007; Goesten et al., 2013) já foram estudados utilizando SAXS, entretanto a técnica ainda não foi explorada na análise de COFs. Reich et al. (1990) destacam vantagens para essa aplicação do SAXS: é uma técnica não destrutiva, não há necessidade de realizar prétratamento da amostra e é sensível à porosidade total, ou seja, tanto a poros abertos quanto aos fechados. Entretanto, também destacam suas desvantagens: 
a porosidade proveniente de poros fechados pode não ser importante para as aplicações do material, apenas uma pequena escala de $\mathbf{q}$ pode ser avaliada e a medida de I(q) é indireta.

O cálculo da área específica via SAXS vem da Lei de Porod. Porod (1951) estudou o perfil de $\mathbf{I}(\mathbf{q})$ quando q tende ao infinito. Ele observou que para sistemas onde a superfície de um sólido apresenta interface bem definida com um fluido (gás ou solvente), isto é, um material poroso, I(q) tende ao infinito num fator proporcional a $\mathrm{q}^{-4}$. Após algumas derivações matemáticas, é possível obter uma equação para se determinar a área específica (S) de um material poroso (Kohlbrecher, 2009).

$$
S=\frac{\pi \lim _{q \rightarrow \infty} q^{4} I(q)}{\int_{0}^{\infty} q^{2} I(q) d q}
$$

\section{3. \\ Carbazol}

O carbazol é um composto heterocíclico formado por um anel benzênico fundido em um indol. A síntese de materiais baseados nesse composto tem recebido destaque, principalmente na área de dispositivos com propriedades elétricas, devido ao seu sistema $\pi$ que confere emissão de luz e condutividade elétrica, além de ser quimicamente estável e passível de catálises por metais de transição (Masuda e Maeda, 2013). Grigalevicius (2006) ainda destaca em seu artigo de revisão a fácil oxidabilidade do nitrogênio e o transporte de centros de carga positivas por radicais cátions como propriedades do carbazol que o torna aplicável na obtenção de dispositivos fotocondutores, materiais fotorrefrativos e transistores de efeito de campo. O fato do carbazol ser um grupo doador de elétrons mais fraco que outros grupos amina leva ao aumento do gap entre os níveis HOMO e LUMO, tornando os polímeros desse composto emissores de luz azul (Legaspi et al., 2015).

Devido a essas propriedades, pesquisadores têm explorado a síntese de polímeros baseados em carbazóis, sendo obtidos materiais amorfos (Grigalevicius, 2006; Promarak et al., 2008; Souharce et al., 2009) ou cristalinos (Manickam et al., 2001; Camerel et al., 2011; Shi et al., 2012). Alguns copolímeros com outros compostos também são usados para esses fins, como tiofeno (Hsu et al., 2011; Zhang et al., 2011), fluoreno (Brunner et al., 2004; Chen et al., 2011; Lemasson et al., 2012) e combinando os três (Kuznetsov et al., 2015). 
Para a obtenção de materiais porosos, destaca-se a aplicação do carbazol em materiais 3D: o 3,6-dicarboxicarbazol (Figura 12a) foi usado como ligante na síntese de alguns MOFs para encapsular íons $\mathrm{Eu}^{3+}$ e $\mathrm{Tb}^{3+}$ na fabricação de dispositivos emissores de luz branca (Xie et al., 2015), enquanto que o 2,7dicarboxicarbazol para emissão de fluorescência na região azul do espectro de luz visível e atividade catalítica para condensação de Knoevenagel (Yi et al., 2014). Outros MOFs tridimensionais também foram propostos por Li et al. (2009) e Stoeck et al. (2012).

a)<smiles>O=C(O)c1ccc2[nH]c3ccc(C(=O)O)cc3c2c1</smiles>

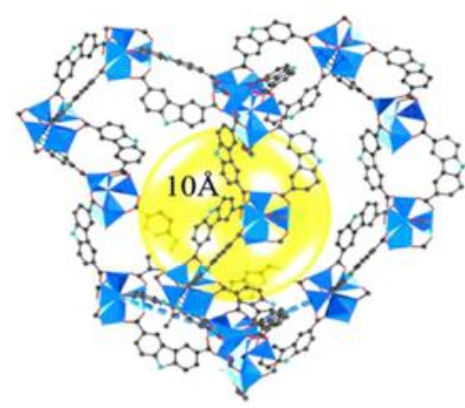

b)
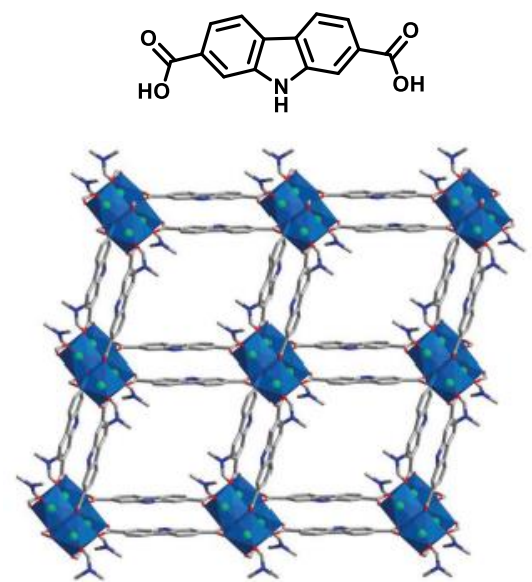

Figura 12: Algumas aplicações de derivados do carbazol: a) 3,6dicarboxicarbazol (Xie et al., 2015); b) 2,7-dicarboxicarbazol (Yi et al., 2014).

Materiais porosos 2D com carbazóis ainda são um campo de estudo pouco explorado. Luo et al. (2015) obtiveram um POF chamado de Cz-POF-1 (Figura 13a) com área específica de $2065 \mathrm{~m}^{2} \mathrm{~g}^{-1}$ utilizando-se o $\mathbf{C z}-1$ como bloco de montagem. Ele apresentou emissão máxima de fluorescência em 464 nm e poder oxidante comparável com $\left[\mathrm{Ru}(\mathrm{bpy})_{3}\right]^{3+}$. Tendo em vista essas propriedades, o material foi testado como catalisador para dehalogenação redutiva de brometos de fenacila (Figura 13b), hidroxilação oxidativa de ácidos arilborônicos (Figura 13c) e a-alquilação de aldeídos fotocatalítica (Figura 13d), com mecanismos propostos. As reações apresentaram rendimentos acima de $71 \%$ e o material se apresentou como boa alternativa para aplicação em sínteses na ausência de metais como catalisadores. Além de aplicações eletrônicas e catalíticas, materiais porosos 2D a partir de carbazóis também se destacam em adsorção de gases (Chen, Q. et al., 2012; Qiao et al., 2014; Yang et al., 2014; Zhang, X. et al., 2014). 
a)<smiles>Ic1ccc2c(c1)c1ccccc1n2-c1cc(-c2cc(-n3c4ccccc4c4ccccc43)cc(-n3c4ccccc4c4cc(I)ccc43)c2)cc(-n2c3ccccc3c3ccccc32)c1</smiles>

Cz-POF-1

b)

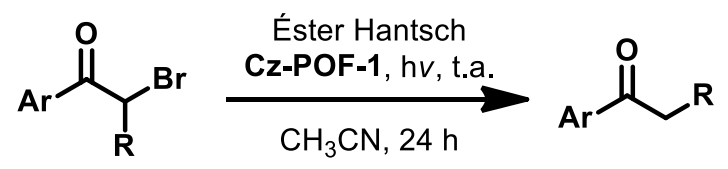

c)

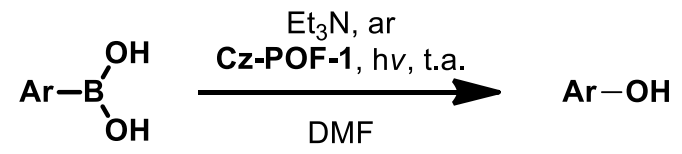

d)

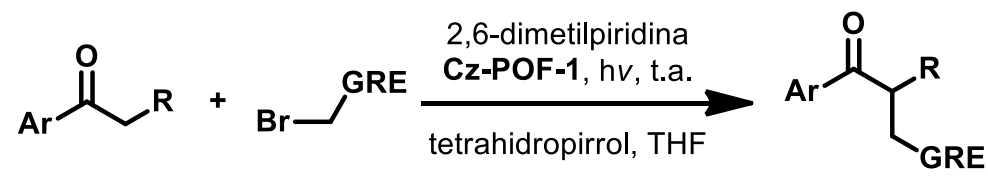

Figura 13: Cz-1 na síntese de um POF: a) síntese do Cz-POF-1; b) dehalogenação redutiva fotocatalítica de brometos de fenacila e derivados;

c) hidroxilação oxidativa fotocatalítica de ácidos arilborônicos; d) $\alpha$ alquilação fotocatalítica de aldeídos.

Apesar dos resultados apresentados por esses materiais, uma característica em comum deles é a ausência da caracterização da estrutura cristalina, provavelmente por eles terem sido amorfos. Isso pode ter ocorrido devido às reações empregadas na síntese dos materiais serem consideradas irreversíveis, obtendo-se, assim, produtos cinéticos. Por esse motivo, esses materiais não podem ser considerados como COFs e o que se vê até o presente momento é que nenhum COF baseado em carbazol foi sintetizado. 


\section{2 \\ Objetivos}

Tendo em vista as aplicações de compostos derivados de carbazol em eletrônica orgânica e catálise e o advento da química reticular, o objetivo geral desse trabalho foi obter novos materiais orgânicos porosos do tipo covalent organic frameworks baseados nesse composto. Para que esse objetivo fosse alcançado, alguns objetivos específicos foram traçados:

- Síntese e caracterização do 3,6-diamino-9H-carbazol.

- Síntese e caracterização de blocos de montagem baseados em aldeídos: triformilfloroglucinol e 1,3,5-tri(4-formilfenil)benzeno.

- Síntese de quatro novos COFs baseados em iminas usando o 3,6diamino-9H-carbazol e variando as fontes de aldeído.

- Caracterização dos COFs denominados RIO2 e RIO3 por espectroscopia de IV, CP/MAS $R M N-{ }^{13} \mathrm{C}$, difração de raios-X, isotermas de adsorção/dessorção de nitrogênio e argônio e SAXS.

- Caracterização dos COFs denominados RIO5 e RIO6 por espectroscopia de IV, difração de raios-X e isoterma de adsorção/dessorção de nitrogênio.

- Comparação dos resultados obtidos para os materiais com cálculos por DFT para estudo da estrutura dos mesmos. 


\section{3 \\ Resultados e discussão}

\section{1.}

\section{Síntese dos blocos de montagem dos COFs}

Inicialmente foram sintetizados os compostos precursores dos materiais RIO2 e RIO3. Para a síntese do 3,6-diamino-9H-carbazol, primeiro realizou-se a nitração do $9 H$-carbazol (1) gerando o 3,6-dinitro-9H-carbazol (2) através das condições de Menke (Esquema 1) (Chen e Natansohn, 1999), que gera acetato de nitrônio como agente de nitração.

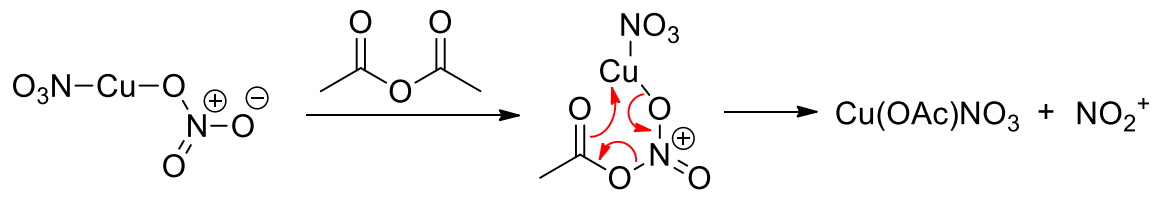

\section{Esquema 1}

O mecanismo da reação de nitração de 1 baseia-se na substituição eletrofílica aromática, tendo como posições preferenciais os carbonos 3 e 6 (Esquema 2) (Katritzky e Taylor, 1990). A formação do isômero 1,6-dinitro-9Hcarbazol também ocorre, mas este é separado na etapa de dissolução em potassa alcoólica, uma vez que ele não é solúvel nesse meio.

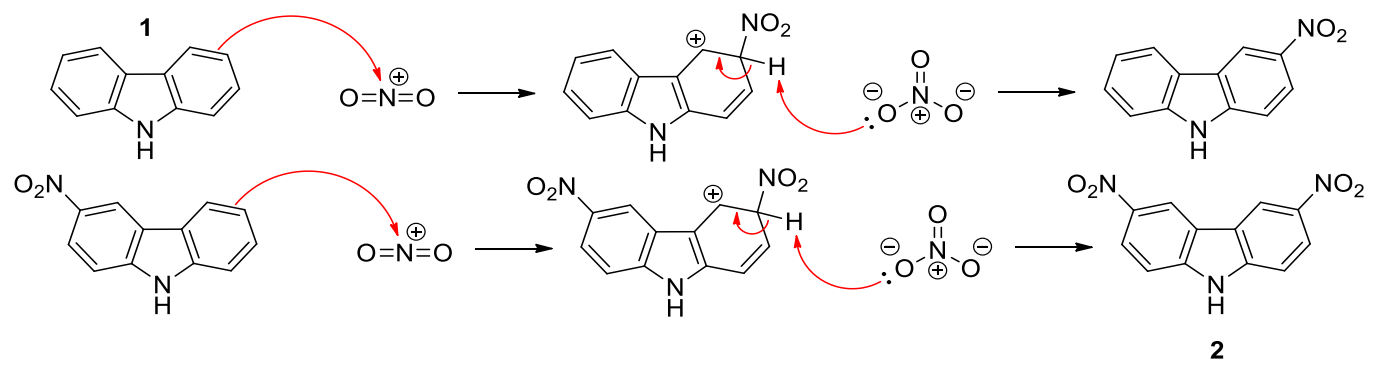

\section{Esquema 2}

O produto obtido apresentou ponto de fusão de $385^{\circ} \mathrm{C}$, compatível com o resultado descrito na literatura (Chen, W.-J. et al., 2012). Devido à sua baixa 
solubilidade nos principais solventes utilizados em CG-MS, o espectro de massas foi obtido utilizando a inserção direta do produto sólido em espectrômetro de massas de alta resolução. O espectro obtido (Figura 14) mostrou a presença de íon molecular de $\mathrm{m} / \mathrm{z}=280,0326$, indicativo da formação de [M+Na], sendo o valor teórico para esta espécie 280,032876.

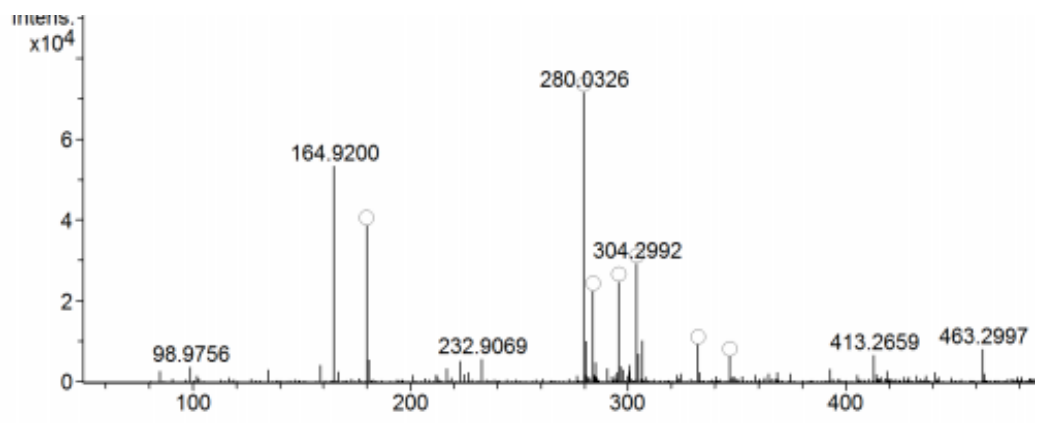

Figura 14: Espectro de ESI-MS de 2.

O espectro de IV (Figura 15) indicou a presença das bandas, em $\mathrm{cm}^{-1}$, em: 3399, deformação axial de N-H; 3090, deformação axial de C-H aromático; 1637, 1582 e 1518, deformação axial de $\mathrm{C}=\mathrm{C}$ aromático; 1612, deformação axial assimétrica de $\mathrm{NO}_{2} ; 1307$ : deformação axial simétrica de $\mathrm{NO}_{2} ; 752$, deformação axial de $\mathrm{C}-\mathrm{NO}_{2} ; 719$, deformação angular $\mathrm{C}-\mathrm{C}=\mathrm{C}$ para fora do plano.

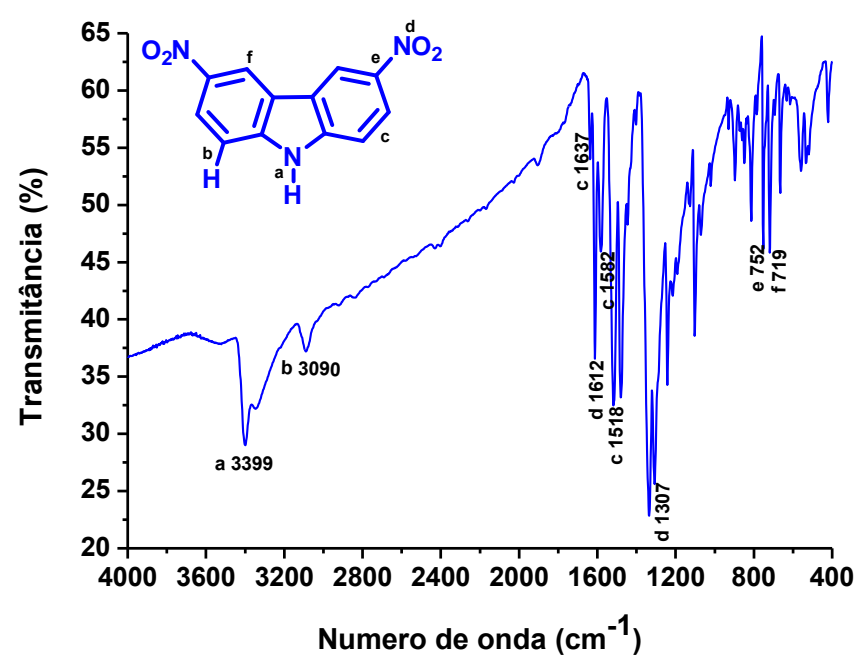

Figura 15: Espectro de IV de 2.

O espectro de $\mathrm{RMN}-{ }^{1} \mathrm{H}$ foi obtido (Figura 16 ) e confirmou a formação do produto de interesse. O composto 2 apresenta apenas quatro grupos homotópicos 
devido ao plano de simetria $\sigma_{v}$ da molécula. O primeiro sinal, em 12,08 ppm, foi um simpleto atribuído ao hidrogênio ligado ao $\mathrm{N}$ do indol. O dubleto em 9,46 ppm corresponde aos hidrogênios 4 e 5 e apresentam $J=2,2 \mathrm{~Hz}$. Os hidrogênios 2 e 7 apresentaram sinal em 8,49 ppm como um dubleto de dubleto com constantes $J=2,3$ e $9,0 \mathrm{~Hz}$. Por fim, o sinal em 7,88 ppm, um dubleto, corresponde aos hidrogênios 1 e 8 . A purificação do material não foi necessária, uma vez que 2 não reage na etapa de redução e é facilmente separado.
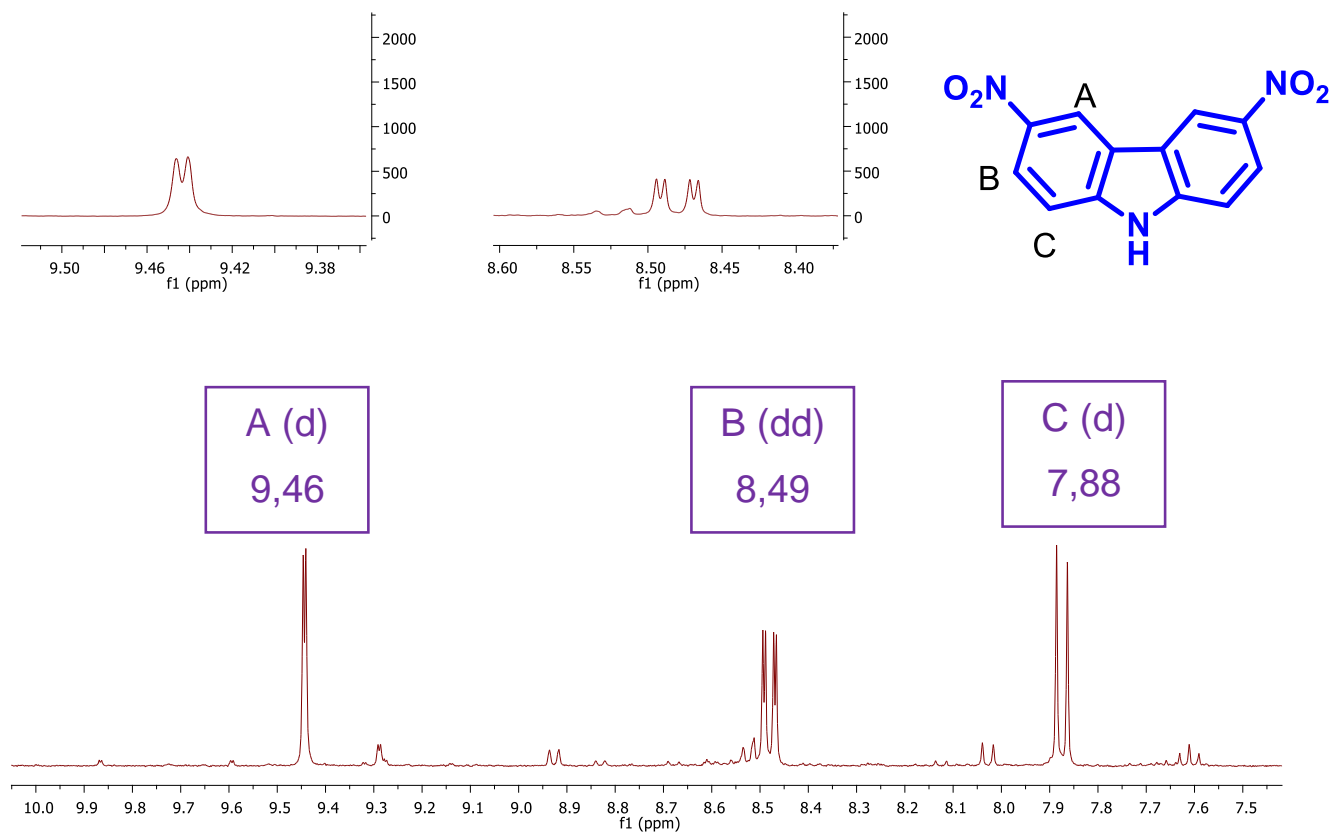

Figura 16: Espectro de $\mathrm{RMN}^{-1} \mathrm{H}(400 \mathrm{MHz})$ em acetona- $d_{6}$ de 2.

Em seguida procedeu-se com a redução dos grupos nitro com $\mathrm{SnCl}_{2}$ em $\mathrm{HCl}$ para síntese do 3,6-diamino-9H-carbazol (3). Não foi possível obter o ponto de fusão da substância, uma vez que ela degradava antes de fundir. O espectro de massas (Figura 17), obtido pela inserção direta do produto sólido no espectrômetro de massas de alta resolução, mostrou a presença de pico em $\mathrm{m} / \mathrm{z}$ de 198,1026, característico do íon molecular $\left[\mathrm{M}^{+}\right]$, cujo valor calculado foi 198,102574, indicando a formação da substância de interesse. 


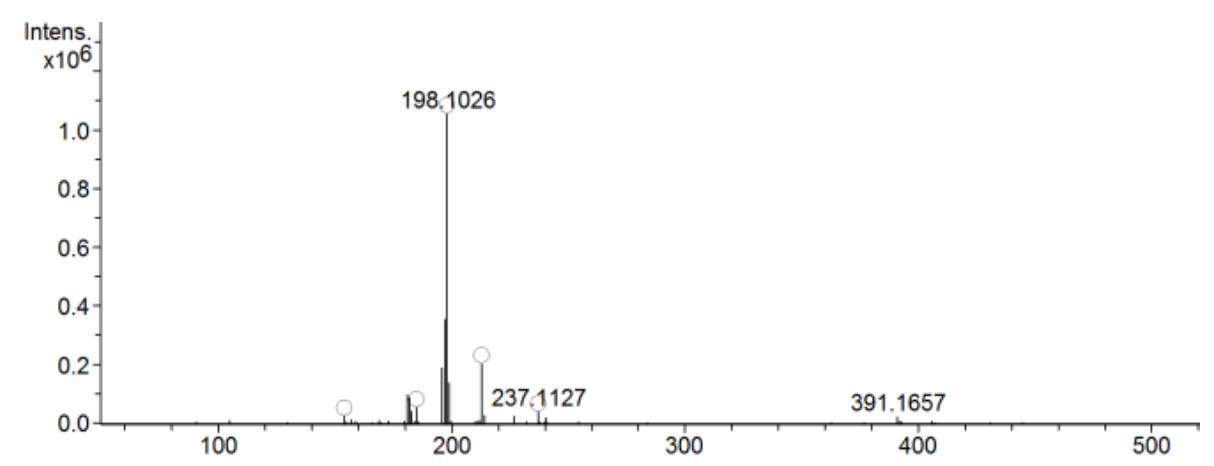

Figura 17: Espectro de massas de 3.

O espectro de IV (Figura 18) mostrou a ausência das bandas características do grupo nitro e a presença das indicativas de grupos amino. A atribuição das bandas pode ser realizada da seguinte forma $\left(\mathrm{em} \mathrm{cm}^{-1}\right)$ : 3395, deformação axial de $\mathrm{N}-\mathrm{H}$; 3283, deformação axial assimétrica do $\mathrm{NH}_{2} ; 3183$, deformação axial simétrica do $\mathrm{NH}_{2} ; 1633$, deformação angular simétrica do $\mathrm{NH}_{2} ; 1578$, 1504 e 1466, deformação axial de $\mathrm{C}=\mathrm{C}$ aromático; 1335, deformação axial de $\mathrm{C}-\mathrm{N}$ pirrólico; 1222, deformação axial de C-NH 806, deformação no plano e fora do plano de $\mathrm{C}-\mathrm{H}$ aromático; 704, vibração balanço (wag) do $\mathrm{NH}_{2}$.

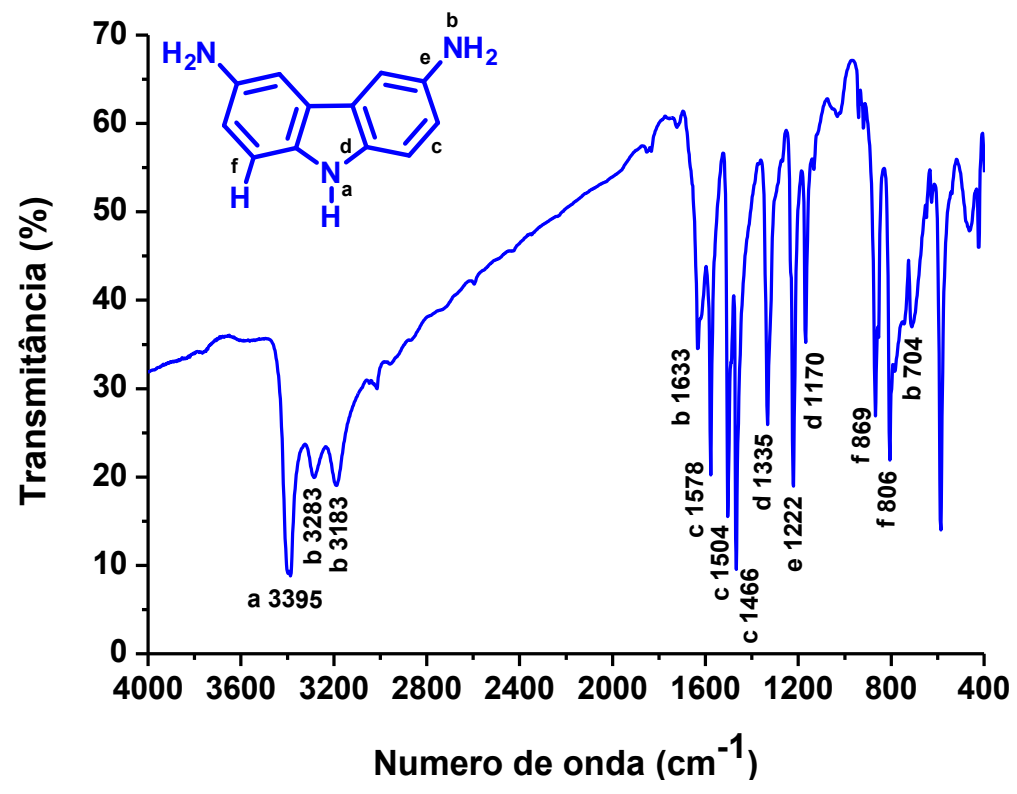

Figura 18: Espectro de IV de 3.

O espectro de RMN- ${ }^{1} \mathrm{H}$ confirmou a formação de 3 (Figura 19). O sinal em 10,11 ppm, um simpleto, corresponde ao $\mathrm{H}$ ligado ao $\mathrm{N}$ do carbazol. Em 7,07 ppm, 
há um simpleto que corresponde ao $\mathrm{H}_{\mathrm{B}}$ e em 7,04 ppm ao $\mathrm{H}_{\mathrm{E}}$. Em 6,66 ppm, o dubleto de dubleto representa o $\mathrm{H}_{\mathrm{c}}$, com constantes $\mathcal{\beta}^{\beta}=9,0 \mathrm{~Hz}$ e $\mathcal{J}^{4}=2,3 \mathrm{~Hz}$. Por fim, o sinal em 4,57 ppm, um simpleto, corresponde aos $H_{D}$ dos grupos amina que, devido à troca rápida dos prótons com solvente, apresenta-se na forma de um pico alargado. Entretanto, foi possível observar a presença de sinais que não são atribuídos à molécula de interesse.
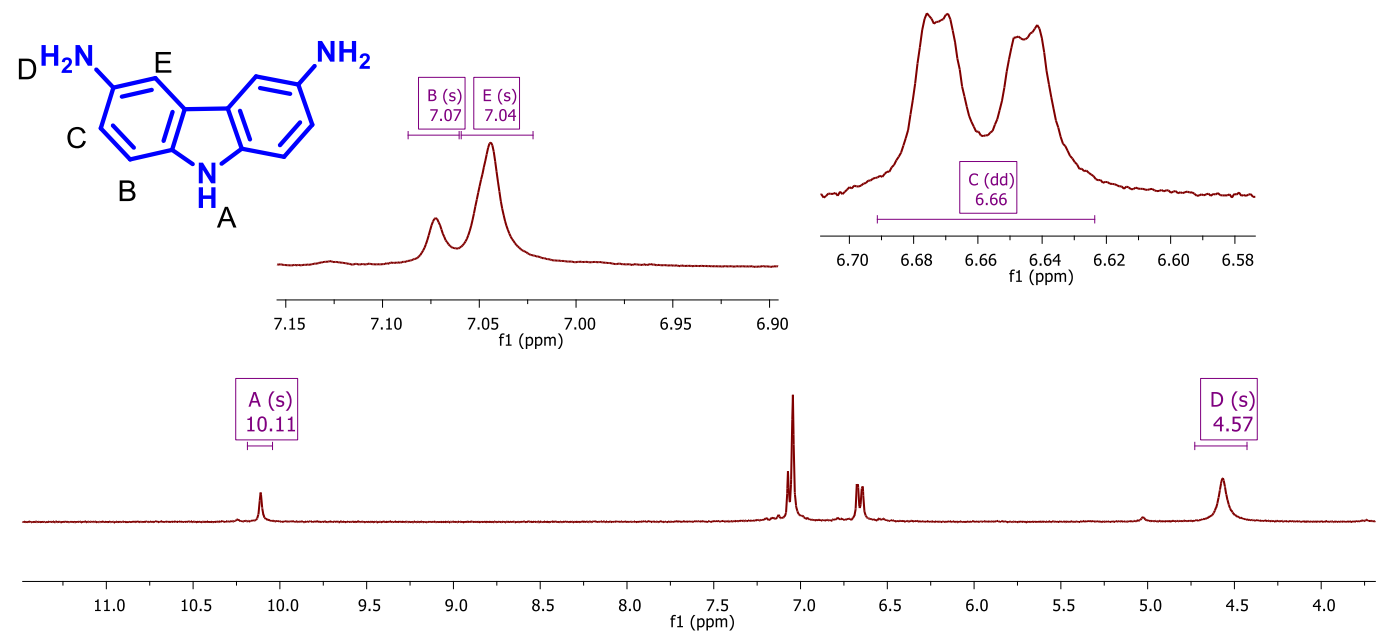

Figura 19: Espectro de RMN-1 $\mathrm{H}(400 \mathrm{MHz})$ em DMSO- $d_{6}$ de 3.

O triformilfloroglucinol (4) foi sintetizado a partir da reação de Duff, cujo mecanismo baseia-se na doação de um grupo metínico ao anel aromático pelo HMTA através de uma série de reações em equilíbrio termodinâmico com intermediários imínicos (Esquema 3). 

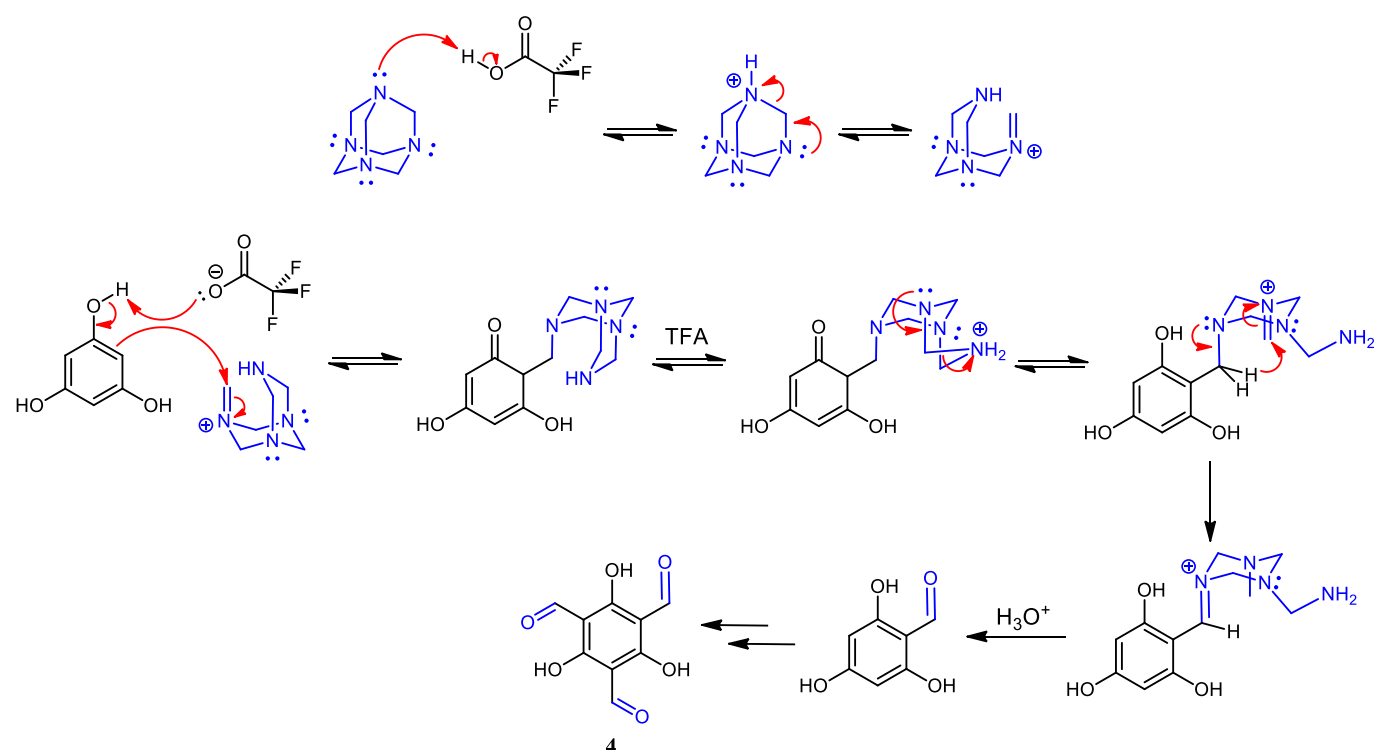

Esquema 3

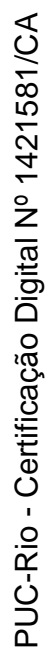

O espectro de IV (Figura 20) apresentou quatro bandas características para esse composto $\left(\mathrm{em} \mathrm{cm}^{-1}\right)$ : 2950, deformação axial de $\mathrm{OH} ; 1642$, deformação axial de $\mathrm{C}=\mathrm{O}$; 1252, deformação axial de $\mathrm{C}-\mathrm{O} ; 606$, deformação angular para fora do plano de $\mathrm{OH}$.

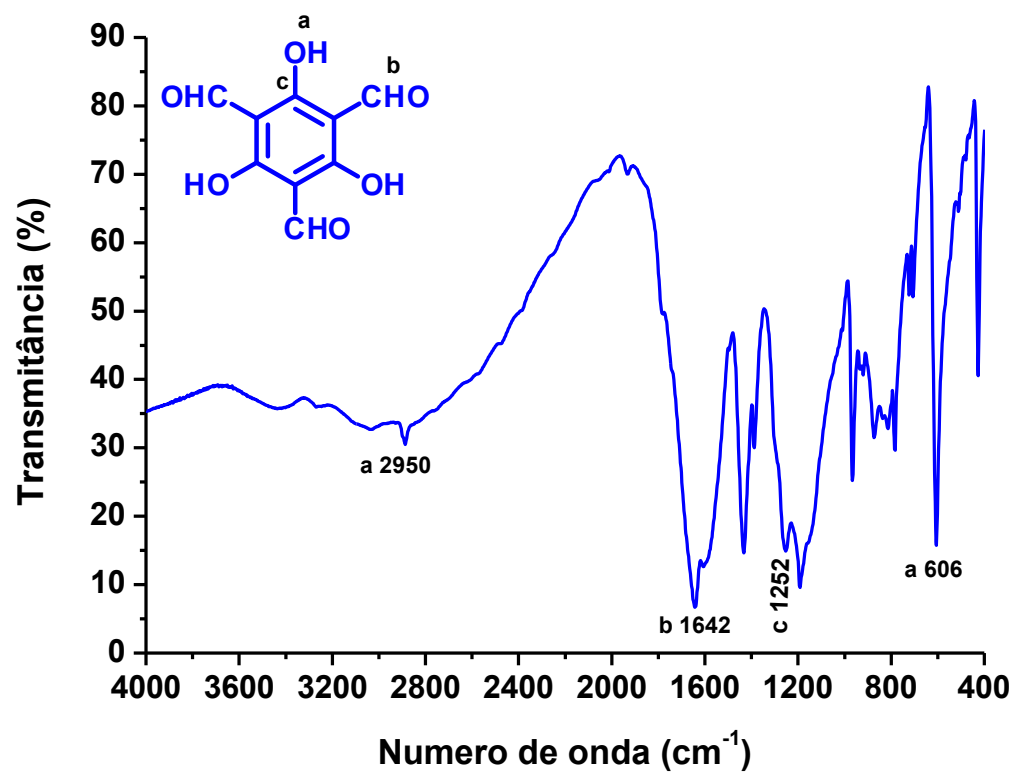

Figura 20: Espectro de IV de 4. 
Por fim, o espectro de $\mathrm{RMN}-{ }^{1} \mathrm{H}$ confirmou a formação da espécie de interesse com a presença dos dois sinais esperados: o simpleto em 14,14 ppm referente aos grupos $\mathrm{OH}$ e outro simpleto em 10,18 ppm que corresponde aos hidrogênios do grupo formila.

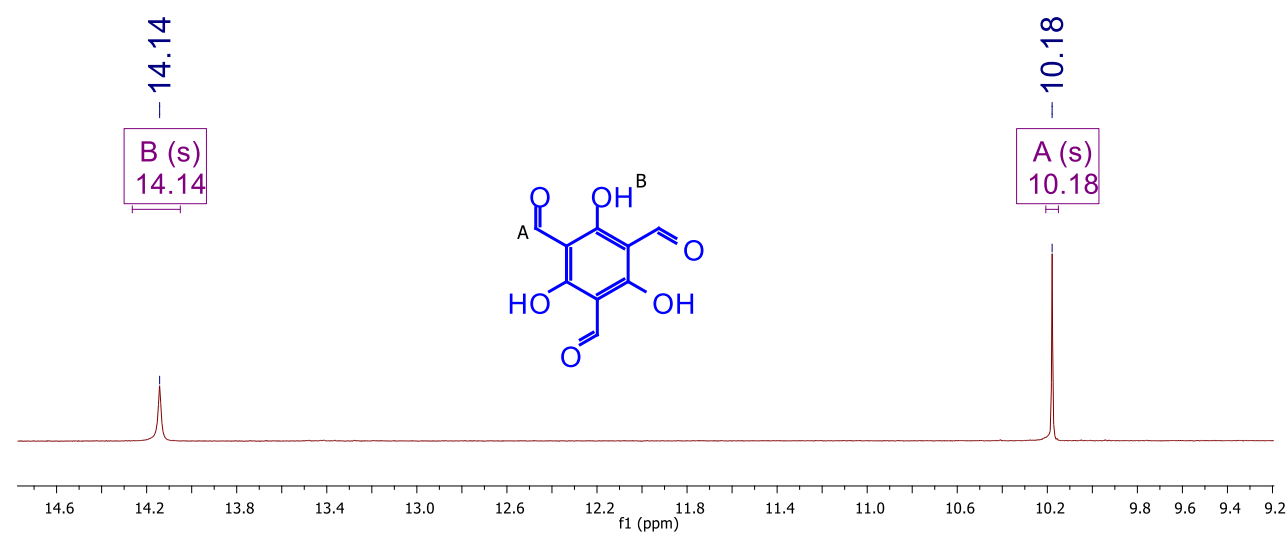

Figura 21: Espectro de $\mathrm{RMN}^{-1} \mathrm{H}(400 \mathrm{MHz})$ em $\mathrm{CDCl}_{3}$ de 4.

O último bloco de montagem obtido foi o 1,3,5-tri(4-formilfenil)benzeno (8) a partir da anilina (4) (Esquema 4).

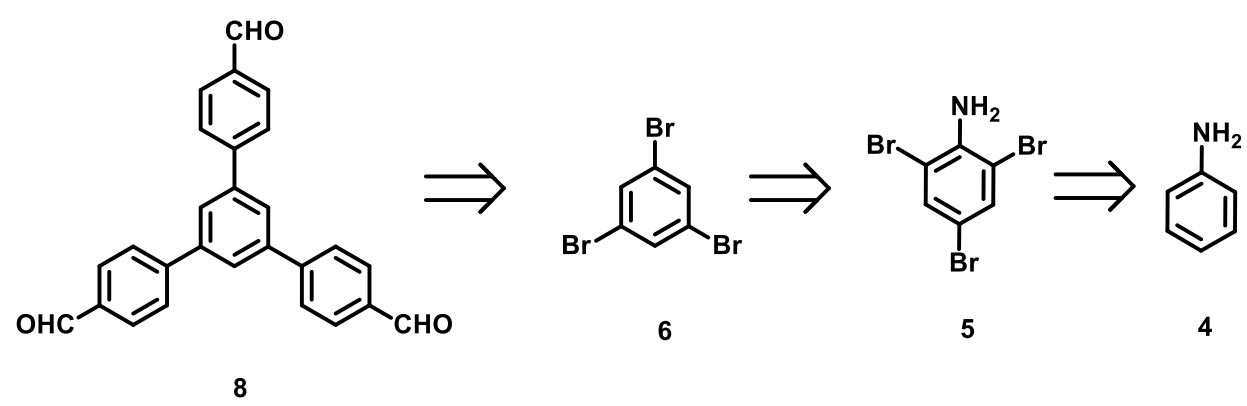

\section{Esquema 4}

A primeira etapa dessa rota foi a bromação oxidativa de 4 usando $\mathrm{KBr}$ (Esquema 5) (Zhang et al.; Salakhov et al., 2008). Foi obtido um sólido branco com rendimento de $62 \%$. 


$$
\mathrm{Br}^{-} \stackrel{\mathrm{H}_{2} \mathrm{O}_{2}}{\longrightarrow} \mathrm{HOBr}
$$

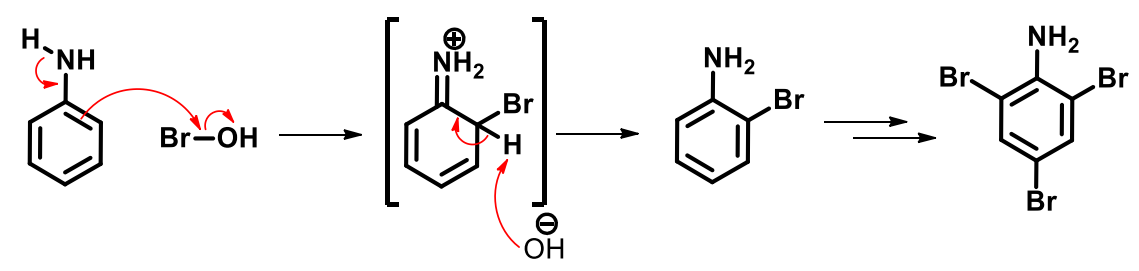

\section{Esquema 5}

O espectro de $\mathrm{RMN}^{-1} \mathrm{H}$ (Figura 22) mostrou um simpleto em 4,57 ppm, característico dos hidrogênios da amina, e outro simpleto em 7,51 ppm, característico dos hidrogênios do anel aromático, confirmando a formação do 2,4,6-tribromoanilina (5). O simpleto em 7,26 ppm é atribuído ao clorofórmio e em $5,30 \mathrm{ppm}$ ao diclorometano.

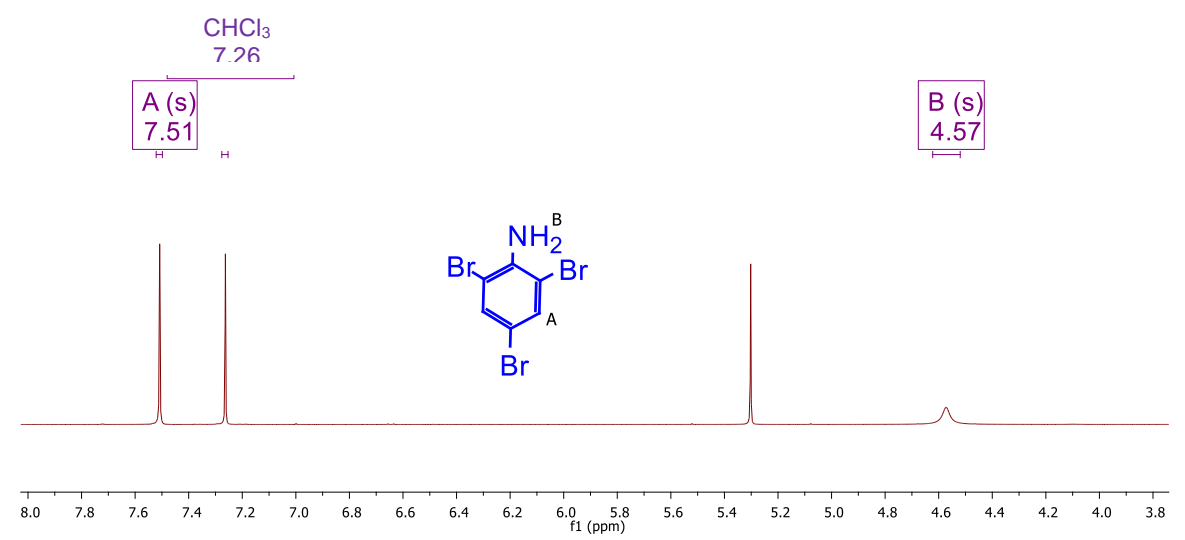

Figura 22: Espectro de $\mathrm{RMN}^{-1} \mathrm{H}(400 \mathrm{MHz})$ em $\mathrm{CDCl}_{3}$ de 5 .

Em seguida foi realizada a desaminação de 5 para gerar 0 1,3,5tribromobenzeno (6) (Esquema 6). Foi obtido um sólido vermelho em rendimento de $82 \%$. O espectro de $\mathrm{RMN}^{-1} \mathrm{H}$ (Figura 23 ) do composto apresentou apenas 0 simpleto em 7,62 ppm relativo aos únicos três hidrogênios do anel aromático. $O$ simpleto em 7,26 ppm corresponde ao hidrogênio de clorofórmio. 


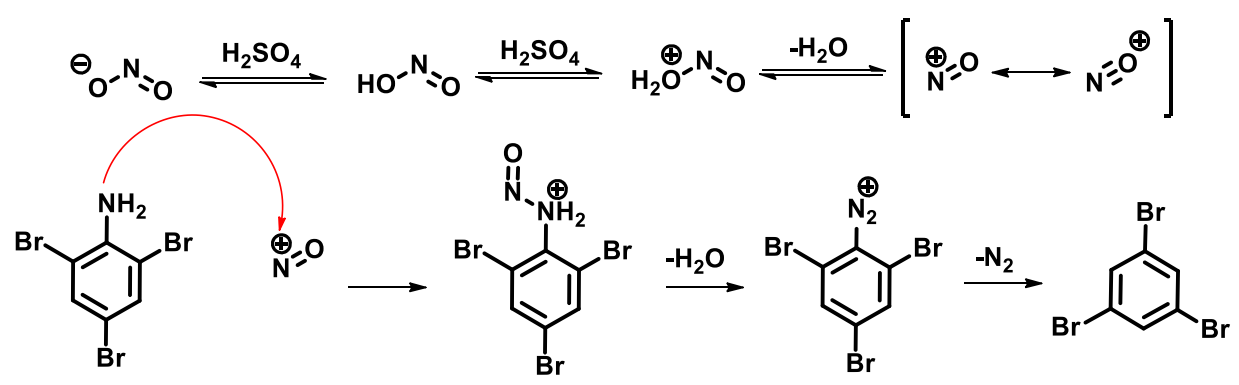

Esquema 6

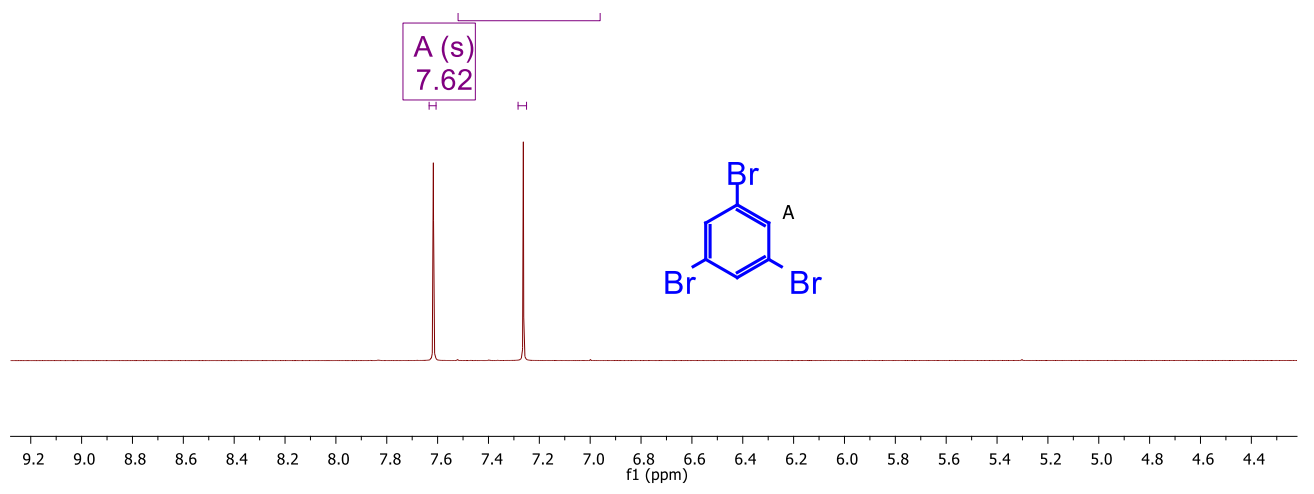

Figura 23: Espectro de $\mathrm{RMN}^{-1} \mathrm{H}(400 \mathrm{MHz})$ em $\mathrm{CDCl}_{3}$ de 6.

Por fim, foi sintetizado o bloco de montagem de interesse através da reação de Suzuki entre 6 e o ácido 4-formilfenilborônico (7). O ciclo catalítico (Esquema 7) apresenta a primeira etapa do mecanismo, que consiste no acoplamento de um grupo 4-formila ao composto 6. O mecanismo não é simultâneo, então dois novos ciclos semelhantes são necessários para a obtenção do bloco de montagem. Foi obtido um sólido amarelo claro em rendimento de $89 \%$. O espectro de $\mathrm{RMN}-{ }^{1} \mathrm{H}$ do produto obtido (Figura 24) indicou a presença de um simpleto em 10,11 ppm correspondente ao hidrogênio da carbonila, um dubleto em 8,02 ppm com $J=8,02$ $\mathrm{Hz}$ relativo aos hidrogênios dos grupos 4-formil próximos à carbonila, um simpleto em 7,91 ppm que corresponde aos três hidrogênios do anel aromático central da molécula e um dubleto em 7,87 ppm com $J=8,02 \mathrm{~Hz}$ que corresponde aos seis hidrogênios restantes do grupo 4-formila. 


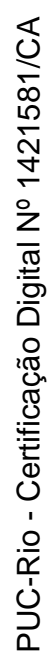

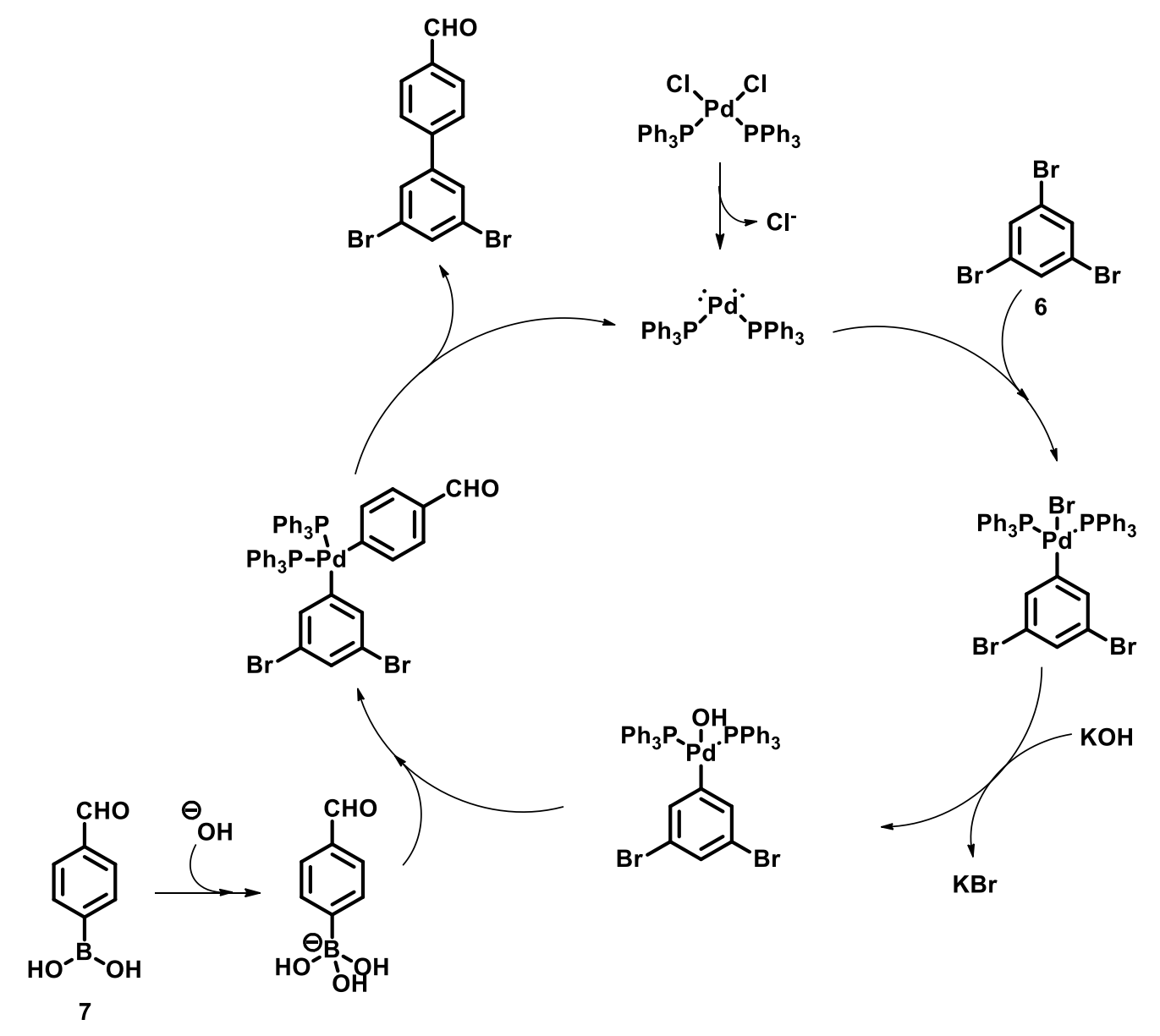

Esquema 7

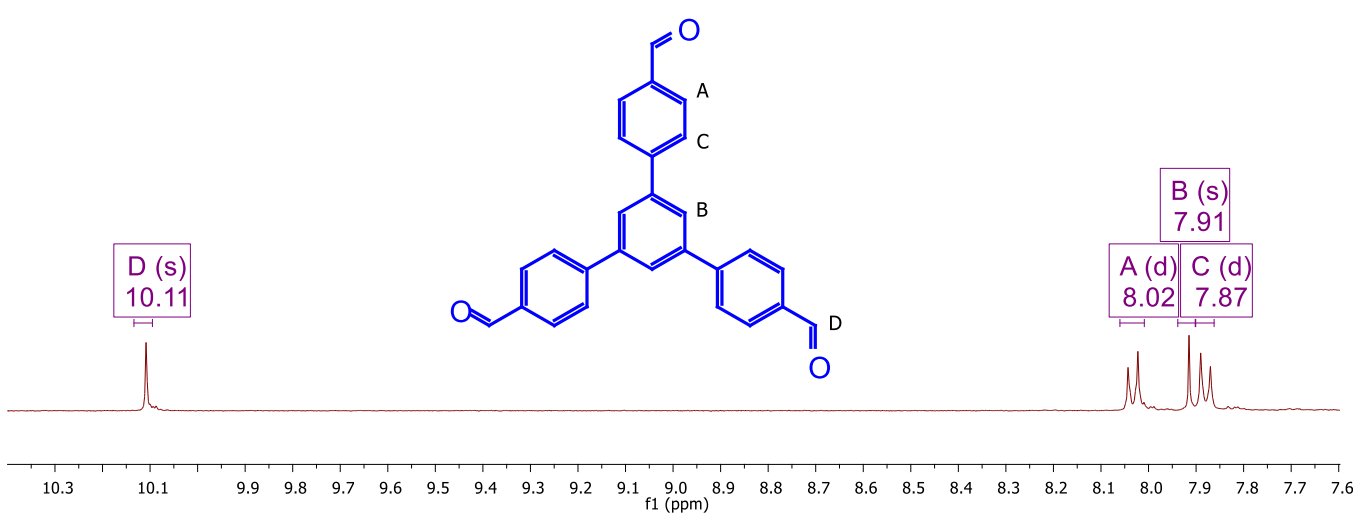

Figura 24: Espectro de $\mathrm{RMN}^{-1} \mathrm{H}(400 \mathrm{MHz})$ em $\mathrm{CDCl}_{3}$ de 8. 


\section{2.}

\section{Síntese e caracterização dos COFs}

Ao longo desse trabalho foram sintetizados quatro COFs baseados em carbazol que foram intitulados RIO2, RIO3, RIO5 e RIO6. Eles apresentam como bloco de montagem em comum o composto 3 e o que os diferenciou foi o aldeído utilizado.

\subsection{1.}

\section{Síntese e caracterização do RIO2 e RIO3}

\subsubsection{1.}

\section{Estrutura química dos materiais}

O RIO2 foi o primeiro COF de carbazol sintetizado. Ele foi obtido a partir da reação entre 3 e 4 em meio de ácido acético $3 \mathrm{~mol} \mathrm{~L}^{-1}$. O mecanismo dessa reação baseia-se na formação de grupos imina em meio ácido por adição nucleofílica do grupo $\mathrm{NH}_{2}$ à carbonila seguida da eliminação de $\mathrm{H}_{2} \mathrm{O}$ num equilíbrio termodinâmico (Esquema 8).

A estrutura química do material foi confirmada por espectroscopia de IV e CP/MAS RMN- ${ }^{1} \mathrm{H}$. Os COFs obtidos por Lohse et al. (2016), Chandra et al. (2016) e Kandambeth et al. (2012) foram apresentados na literatura utilizando 4 como bloco de montagem, observando-se a ocorrência de tautomeria irreversível, priorizando a forma $\beta$-cetoenamina. Segundo Chong et al. (2003), o produto gerado pela reação de anilina com 4 sofre tautomeria irreversível e o mesmo fica sob a forma $\beta$-cetoenamina (Esquema 9). Essa irreversibilidade é causada por pela maior basicidade do hidrogênio enamínico em relação ao fenólico. 


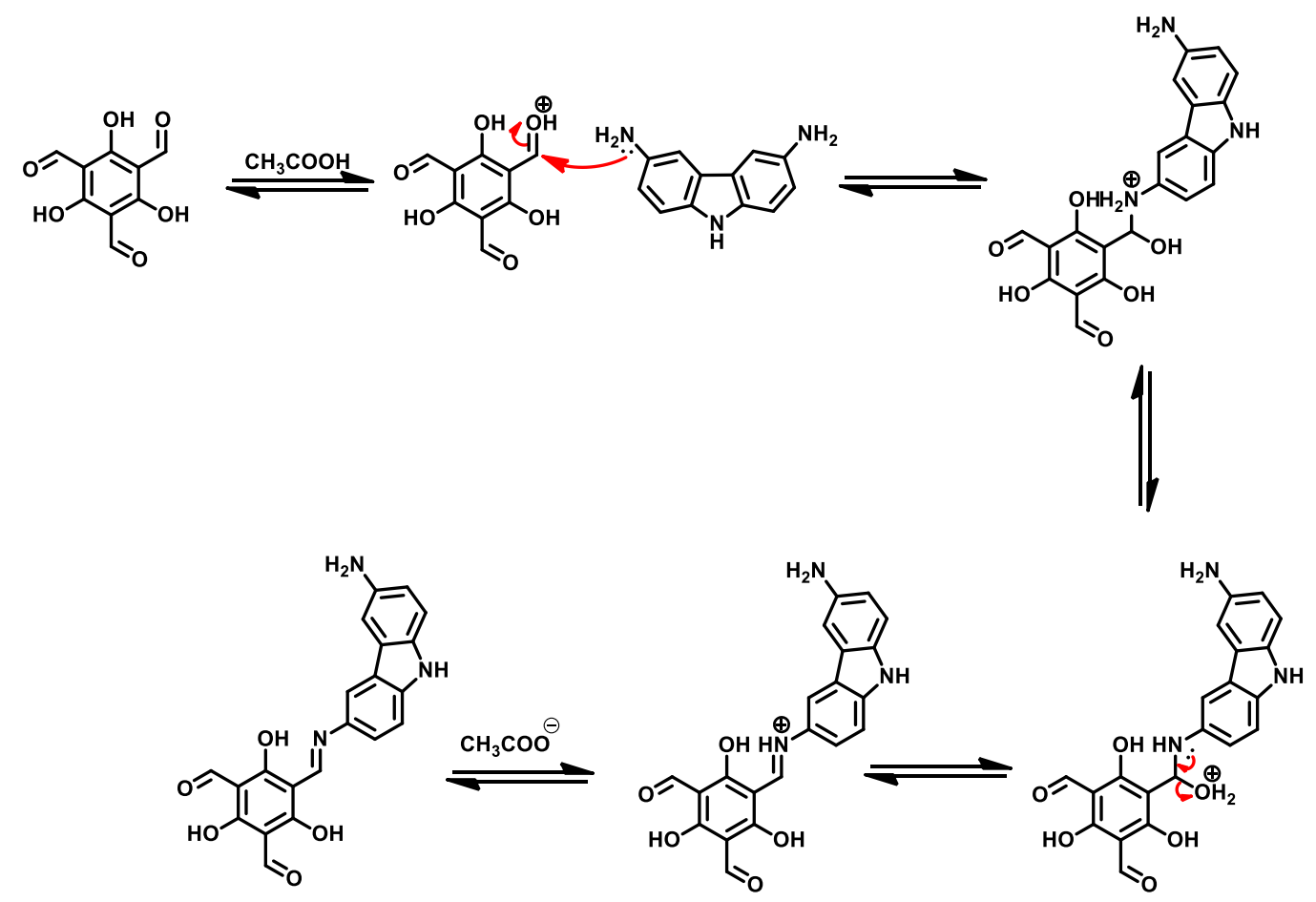

Esquema 8

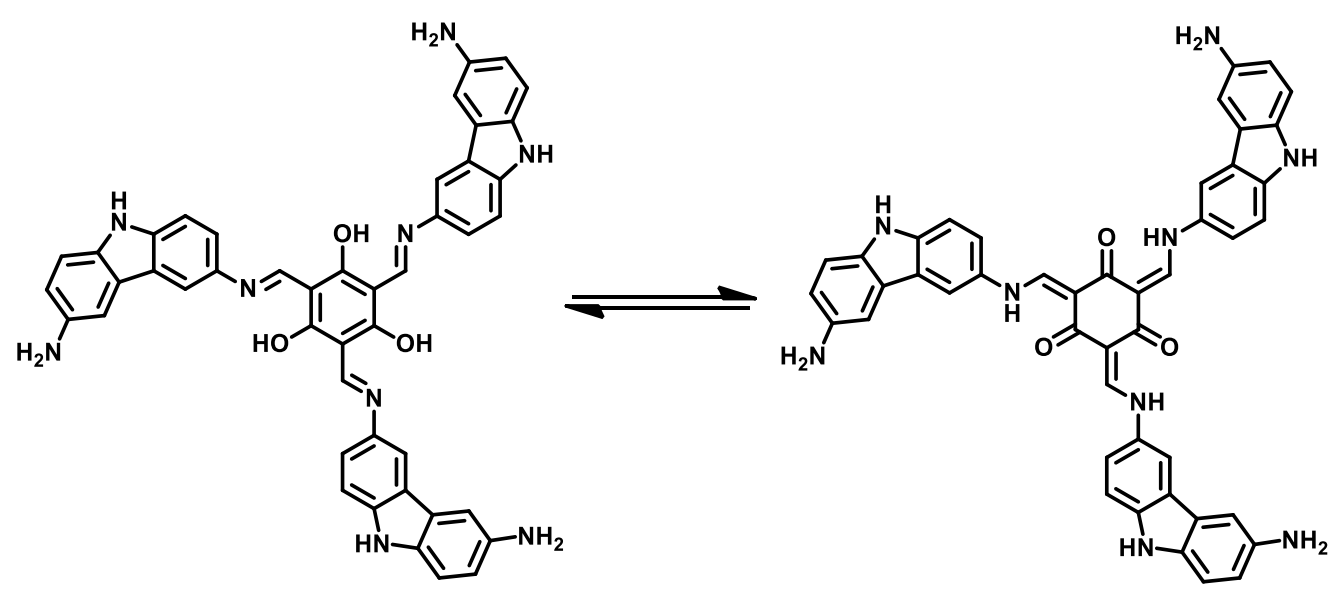

\section{Esquema 9}

Inicialmente obteve-se o espectro de IV do RIO2 (Figura 25). Comparandose com os blocos de montagem, foi possível observar a ausência de bandas de amina primária e carbonila de aldeído, indicativo de que a reação foi realizada por completo. Para facilitar a interpretação de para qual das formas o equilíbrio está deslocado, foi sintetizado o composto modelo 9, que se assemelha com as unidades formadoras do RIO2, sendo que ele já foi descrito na literatura como um composto preferencialmente sob a forma ceto-enamina (Chong et al., 2003). 

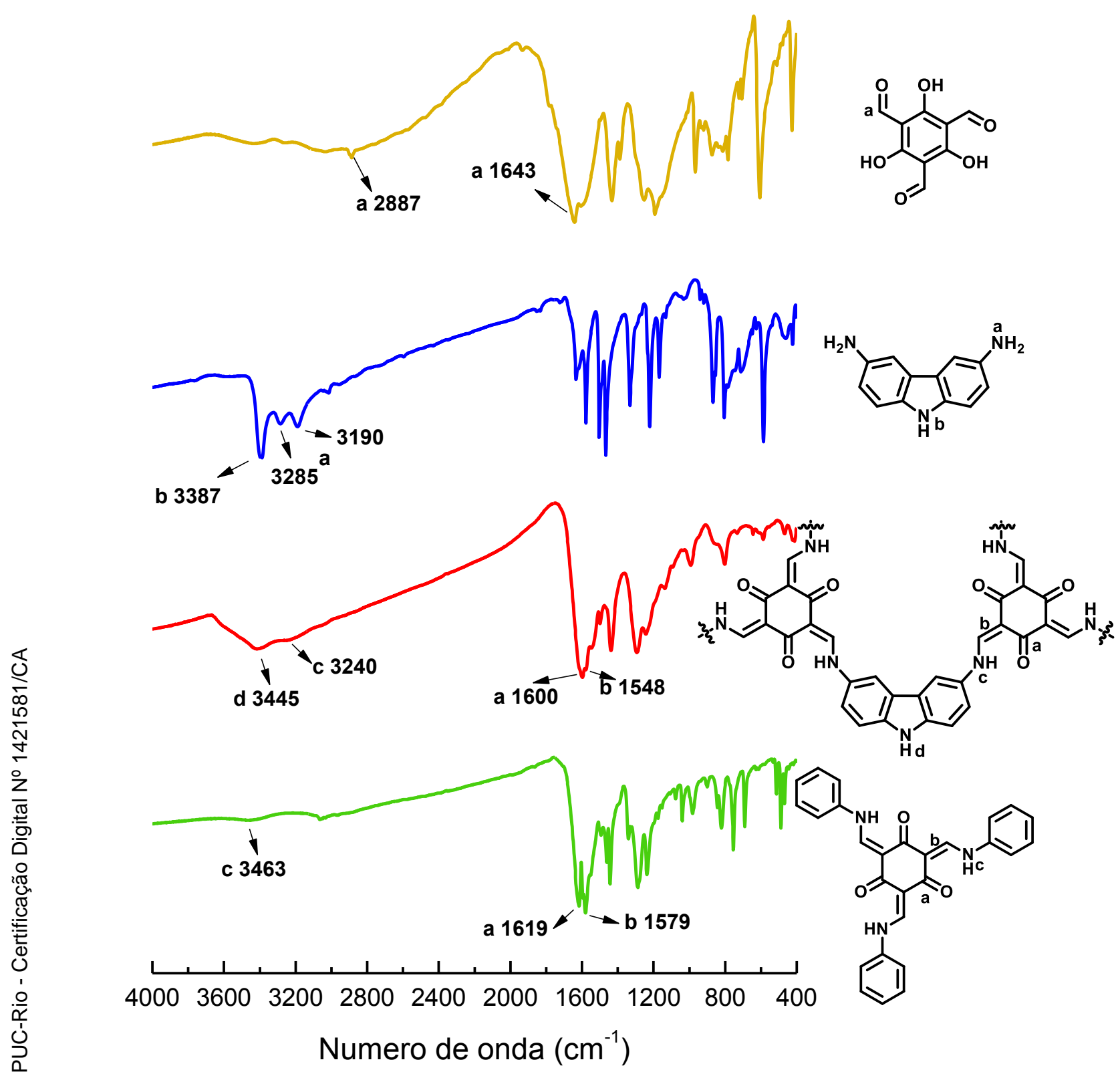

Figura 25: Espectros de IV do RIO2: 4 (amarelo), 3 (azul), RIO2 (vermelho), 9 (verde).

A banda em $3445 \mathrm{~cm}^{-1}$ é característica de estiramento axial do $\mathrm{N}-\mathrm{H}$ do carbazol. Em $3240 \mathrm{~cm}^{-1}$ tem-se a banda de estiramento axial do N-H enamínico, um primeiro indicativo de que o RIO2 tem seu equilíbrio deslocado para a forma ceto-enamina. Em 9, essa banda aparece em $3463 \mathrm{~cm}^{-1}$. A banda em $1600 \mathrm{~cm}^{-1}$ é de estiramento axial de $\mathrm{C}=\mathrm{O}$ de cetona cíclica, que também aparece no modelo em $1619 \mathrm{~cm}^{-1}$. Por fim, a banda em $1548 \mathrm{~cm}^{-1}$ é característica de estiramento de $\mathrm{C}=\mathrm{C}$, que em 9 ocorre em $1579 \mathrm{~cm}^{-1}$. 
Para confirmar essa forma, realizou-se o CP/MAS RMN $-{ }^{13} \mathrm{C} .9$ teve sua estrutura otimizada a nível B3LYP/6-311++G(d,p) com o software Gaussian09 ${ }^{\circledR}$. Seu espectro de RMN calculado (GIAO/B3LYP/6-311++G(d,p)//B3LYP/6$311++G(d, p))$ foi comparado com o obtido experimentalmente (Figura 26).
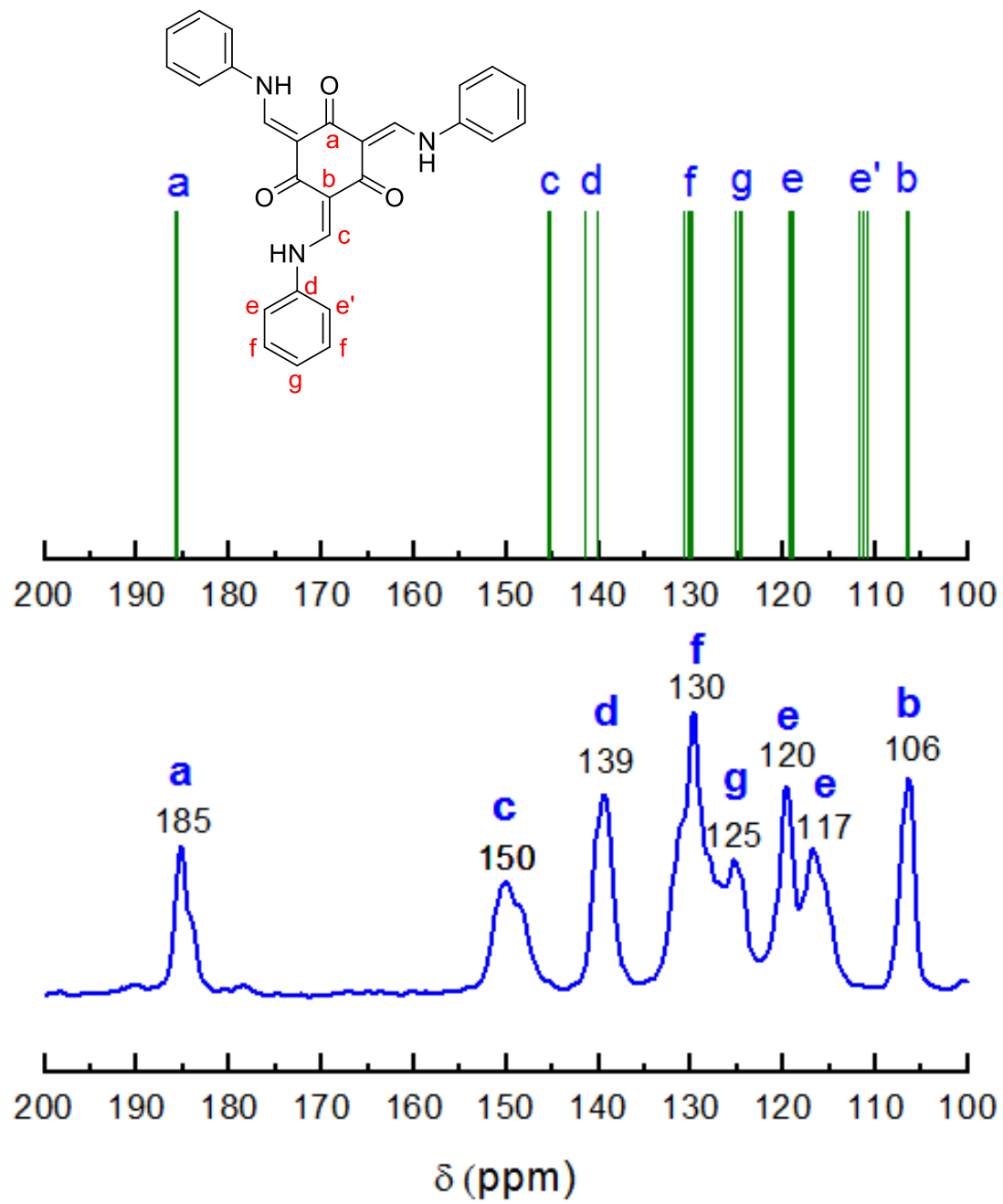

Figura 26: Espectros de (a) RMN- ${ }^{13} \mathrm{C}$ calculado e (b) CP/MAS RMN- ${ }^{13} \mathrm{C}$ para 9.

Através desse espectro foi possível confirmar que o modelo se apresentava sob a forma ceto-enamina. O sinal em 185 ppm corresponde ao carbono da cetona, enquanto que os sinais em 150 e 106 ppm correspondem aos carbonos da ligação $\mathrm{C}=\mathrm{C}$ da enamina. Ao usar como base esse modelo, procedeu-se com a interpretação do espectro de CP/MAS RMN $-{ }^{13} \mathrm{C}$ do RIO2. Ele foi comparado com o RMN- ${ }^{13} \mathrm{C}$ calculado por Teoria do Funcional da Densidade, pela professora Deyse Gomes da Costa, da Universidade Federal de Viçosa (UFV). 


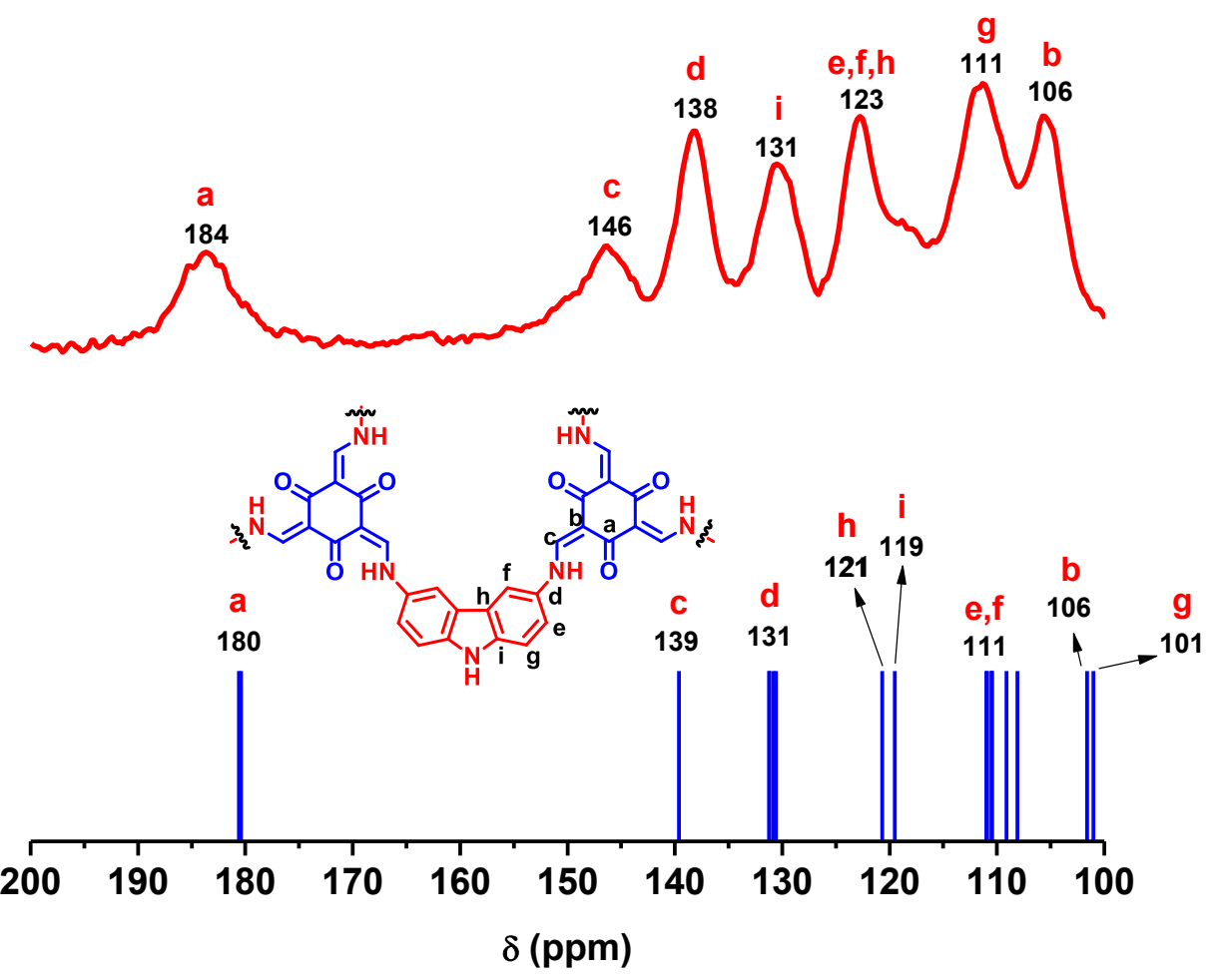

Figura 27: Espectro de CP/MAS RMN-13C do RIO2 (vermelho) e espectro de RMN $-{ }^{13} \mathrm{C}$ calculado por DFT (azul).

Numa tentativa de evitar a tautomeria do RIO2 foi sintetizado o RIO3 a partir do triformilfenol. Foi obtido um sólido preto em $65 \%$ de rendimento. O mecanismo de reação de formação desse COF é semelhante ao do RIO2 (Esquema 8).

O espectro de IV obtido para o RIO3 (Figura 28) foi comparado com os blocos de montagem e com um composto modelo (10) obtido da reação da anilina com o triformilfenol. Por não haver bandas relativas a aldeído e amina primária, pode-se concluir que a reação foi realizada por completo, não sobrando material de partida sem reagir.

A banda em $3405 \mathrm{~cm}^{-1}$ é característica de estiramento axial do $\mathrm{N}-\mathrm{H}$ do carbazol. Em $3210 \mathrm{~cm}^{-1}$ tem-se a banda de estiramento axial do O-H fenólico, o que indica que o RIO3 tem seu equilíbrio deslocado para a forma de imina. Em 10, essa banda aparece em $3409 \mathrm{~cm}^{-1}$. A banda em $1676 \mathrm{~cm}^{-1}$ é de estiramento de $\mathrm{C}=\mathrm{N}$ de imina, que também aparece no modelo em $1625 \mathrm{~cm}^{-1}$. Por fim, as bandas em 1598, 1521 e $1489 \mathrm{~cm}^{-1}$ são características de deformação axial de $\mathrm{C}=\mathrm{C}$ de anel aromático, que em 10 ocorre em 1582 e $1484 \mathrm{~cm}^{-1}$. 

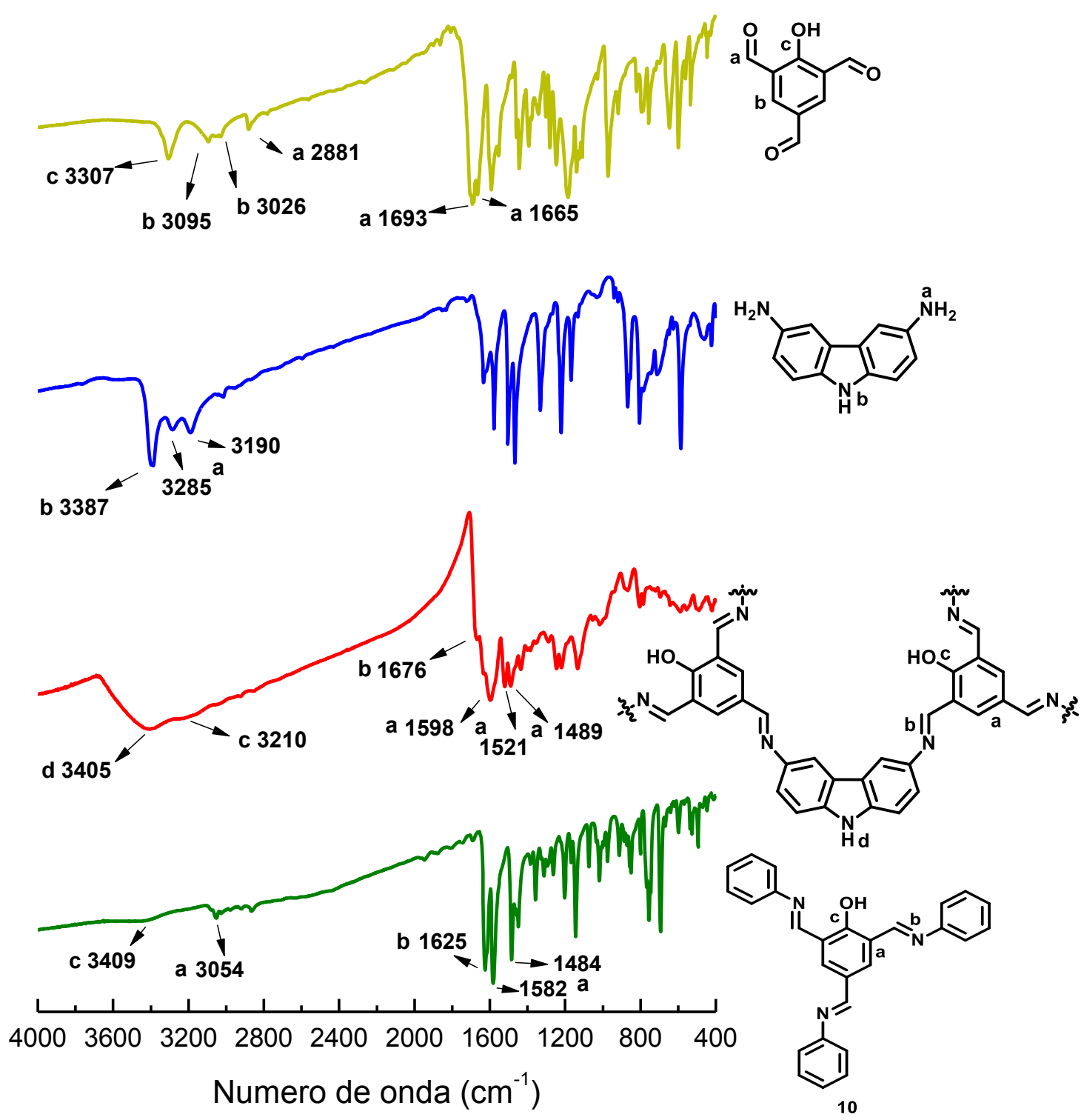

Figura 28: Espectro de IV do RIO3: triformilfenol (amarelo), 3,6-diamino-9Hcarbazol (azul), RIO3 (vermelho) e composto modelo do RIO3 (verde).

Para confirmar que o equilíbrio está deslocado para a forma de imina, foi feito o CP/MAS RMN $-{ }^{13} \mathrm{C}$ do RIO3 que foi comparado com seu modelo (Figura 29). Nesse composto, o sinal em 162 ppm corresponde ao carbono fenólico. Os carbonos e e $\mathbf{f}$ de $\mathrm{C}=\mathrm{N}$ das iminas apresentam dois sinais diferentes, em 160 e 156 ppm, respectivamente, devido à simetria do composto. Esses três sinais são suficientes para provar a forma imina do modelo. Ao analisar o espectro do COF observa-se que o sinal referente ao carbono fenólico apresenta deslocamento para campo baixo em relação ao composto modelo, em 176 ppm, devido à influência dos carbazóis. Os carbonos da ligação $\mathrm{C}=\mathrm{N}$ apresentam o mesmo sinal em 153 ppm. As demais indexações são mostradas no espectro. 


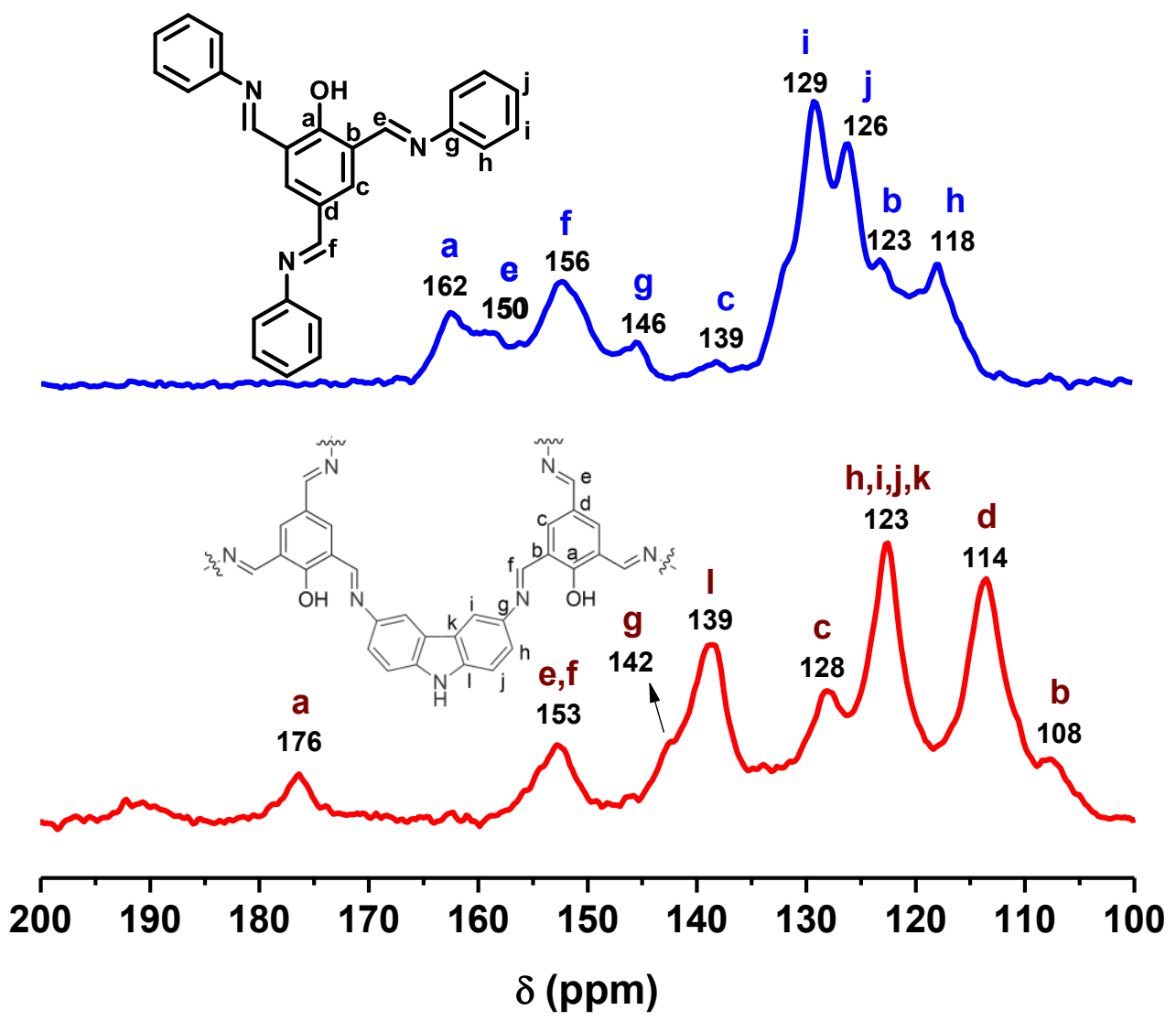

Figura 29: Espectros de CP/MAS RMN-13C do RIO3 (vermelho) e do composto modelo (azul).

Através de cálculos a nível B3LYP/6-31G pôde-se calcular a entalpia, a entropia e a energia livre de Gibbs de formação (Tabela 1) para quatro espécies modelo contendo carbazol a fim de se verificar o deslocamento do equilíbrio das tautomerias para RIO2 e RIO3 (Esquema 10).

Tabela 1: Propriedades termodinâmicas (em Hartree) calculadas para compostos modelo com e sem carbazol do RIO2 (compostos 11 e 12) e RIO3 (compostos 13 e 14) à $298 \mathrm{~K}$.

\begin{tabular}{cccc}
\hline Composto & $\boldsymbol{\Delta H}$ & $\mathbf{T} \boldsymbol{\Delta} \mathbf{S}$ & $\boldsymbol{\Delta G}$ \\
12 & $-2286,463412$ & 0,111920 & $-2286,575332$ \\
11 & $-2286,404641$ & 0,122888 & $-2286,527529$ \\
14 & $-2135,945725$ & 0,121267 & $-2136,066992$ \\
13 & $-2135,947678$ & 0,119973 & $-2136,067651$ \\
\hline
\end{tabular}



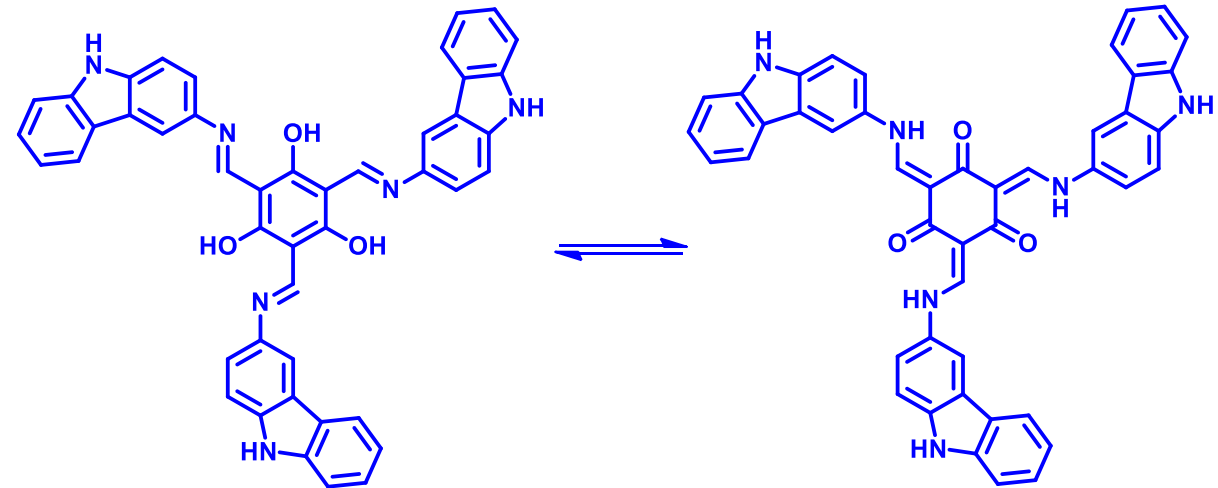

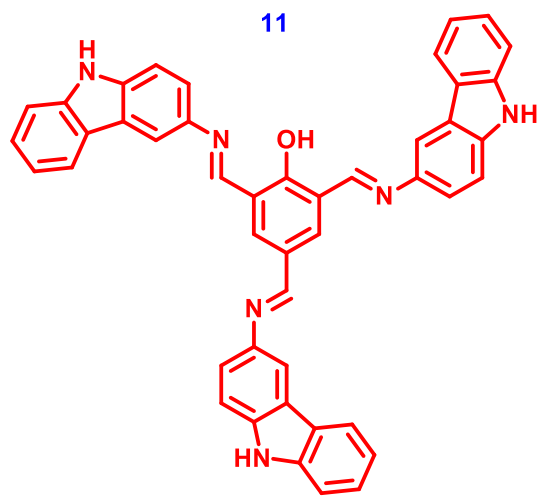

13

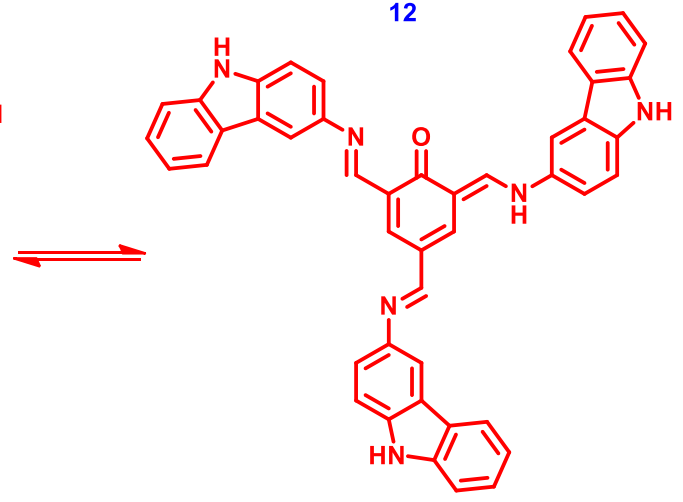

14

Esquema 10

A reação considerada foi a forma de imina sendo convertida em forma cetoenamina. $O$ valor de $\Delta G$ da reação em questão para o RIO2, 11 sendo convertido em 12, é $-30,2 \mathrm{kcal} \mathrm{mol}^{-1}$ e para o RIO3, 13 sendo convertido em 14, é 0,4 kcal $\mathrm{mol}^{-1}$. Esses resultados mostram que a formação da forma ceto-enamina é espontânea para o RIO2, porém não para o RIO3, apesar de o valor de $\Delta \mathrm{G}$ nesse caso ser próximo de zero, o que poderia indicar a presença também da forma ceto-enamina. Com esses valores pôde-se calcular as constantes de equilíbrio da tautomeria a partir da equação 12.

$$
K_{e q}=e^{-\Delta G / R T}
$$

Para o modelo do RIO2 a constante de equilíbrio à $298 \mathrm{~K}$ calculada vale $1,03 \times 10^{22}$, ou seja, isso indica que o equilíbrio é deslocado para a formação da forma ceto-enamina, corroborando com o valor determinado para $\Delta \mathrm{G}$. Entretanto para o modelo do RIO3 a constante, na mesma temperatura, vale 0,497, evidenciando que para esse COF o equilíbrio é deslocado para a forma imina. Ao assumir a temperatura da reação da síntese dos COFs, $393 \mathrm{~K}$, as constantes para 
RIO2 e RIO3 valem, respectivamente, $4,89 \times 10^{16}$ e 0,589 , isto é, a mesma tendência no deslocamento do equilíbrio como à temperatura ambiente. Esses resultados estão de acordo com os obtidos experimentalmente.

\subsubsection{2.}

\section{Estrutura cristalina dos materiais}

Para elucidar a estrutura cristalina dos COFs obtidos, foram modelados inicialmente para o RIO2 dois tipos de estruturas por Teoria do Funcional da Densidade utilizando o software QuantumEspresso ${ }^{\circledR}$. Esses cálculos foram realizados pela Professora Deyse Gomes da Costa, da Universidade Federal de Viçosa (UFV). O primeiro modelo gerado (Figura 30a) apresentou estrutura plana, com célula unitária hexagonal de parâmetros de rede $\mathrm{a}=\mathrm{b}=23.468 \AA$ e $\mathrm{c}=5.160$ $\AA ̊$ e grupo espacial $\mathrm{P} \overline{3}$. O segundo modelo (Figura 30b) apresentou estrutura enrugada, onde cada carbono do anel de seis membros do triformilfloroglucinol apresentou ângulo diferente de $180^{\circ}$, mesmo tendo hibridização $\mathrm{sp}^{2}$. A célula hexagonal apresentou $\mathrm{a}=\mathrm{b}=17.287 \AA$ e $\mathrm{c}=4.494 \AA$ com grupo espacial $\mathrm{P} \overline{3}$. Devido à estrutura enrugada, a célula unitária se mostrou mais compacta.
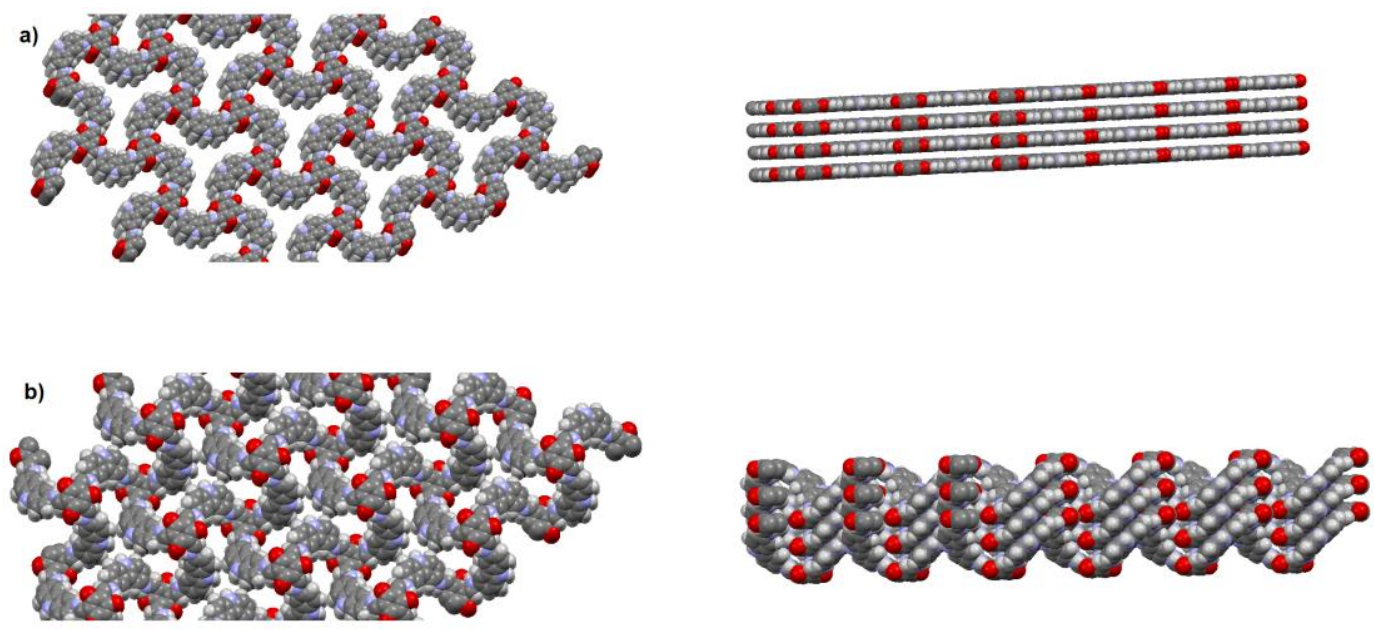

Figura 30: Duas possíveis estruturas modeladas para o RIO2: (a) estrutura plana com visão ao longo do eixo c (esquerda) e do eixo b (direita); (b) estrutura enrugada com visão ao longo do eixo c (esquerda) e do eixo b (direita).

O diagrama de energia (Figura 31) mostrou que a forma termodinamicamente mais estável seria a enrugada. Ao observar a Figura 30b é possível notar que o hidrogênio ligado ao nitrogênio enamínico está fora do plano 
da ligação $\mathrm{C}-\mathrm{N}$ e faz ligação de hidrogênio intramolecular com o oxigênio da carbonila, sendo assim necessária a distorção da ligação. A função de localização eletrônica (Figura 32) revelou a presença de interações inter e intramoleculares mais efetivas na estrutura enrugada, o que corrobora com a maior estabilidade termodinâmica mostrada nos cálculos. No centro de cada poro existem três grupos $\mathrm{NH}$ do carbazol apontados para dentro do mesmo. Para que o momento de dipolo desses grupos se cancelem, também é possível que a estrutura se distorça. $\mathrm{Na}$ estrutura enrugada, mais estável, esses grupos estão distantes 5,454 $\AA$ (Figura 33b), enquanto que na estrutura plana estão a 9,213 $\AA$ (Figura 33a). Essa diferença provavelmente está relacionada com a minimização desses efeitos.

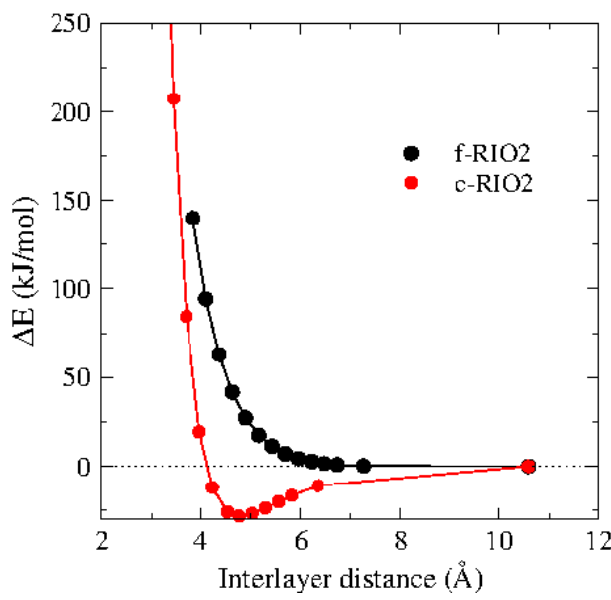

Figura 31: Diagrama de energia em função do espaçamento entre folhas de RIO2: o COF plano foi chamado de f-RIO2 e o COF enrugado de c-RIO2.
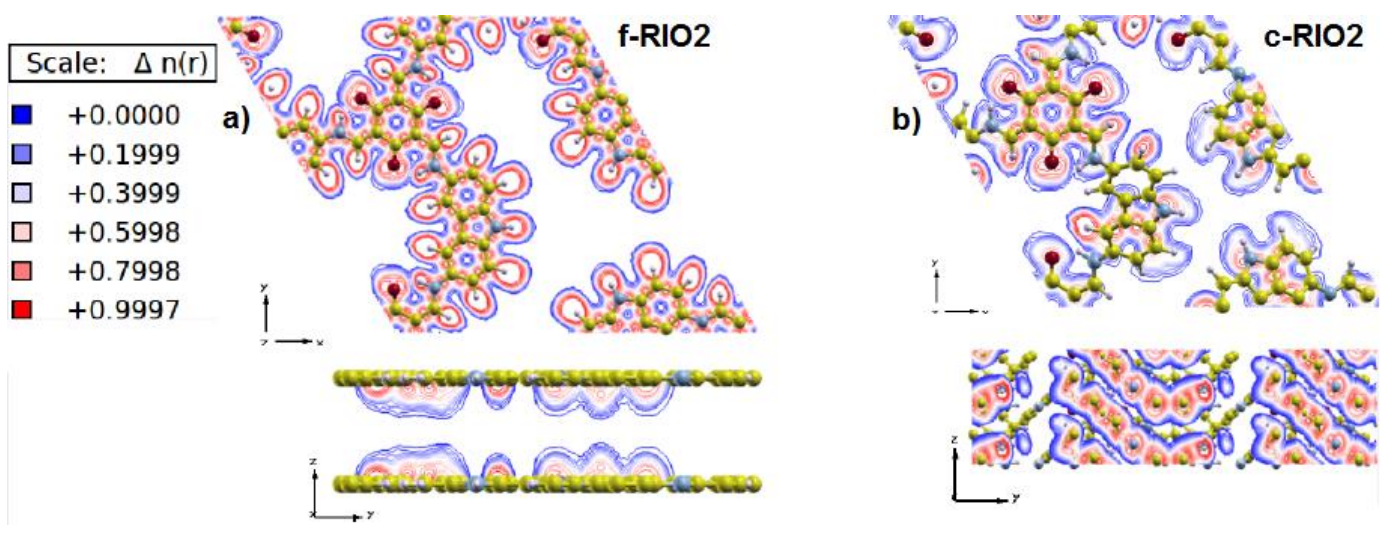

Figura 32: Função de localização eletrônica para o RIO2: a) forma plana; b) forma enrugada. 
a)

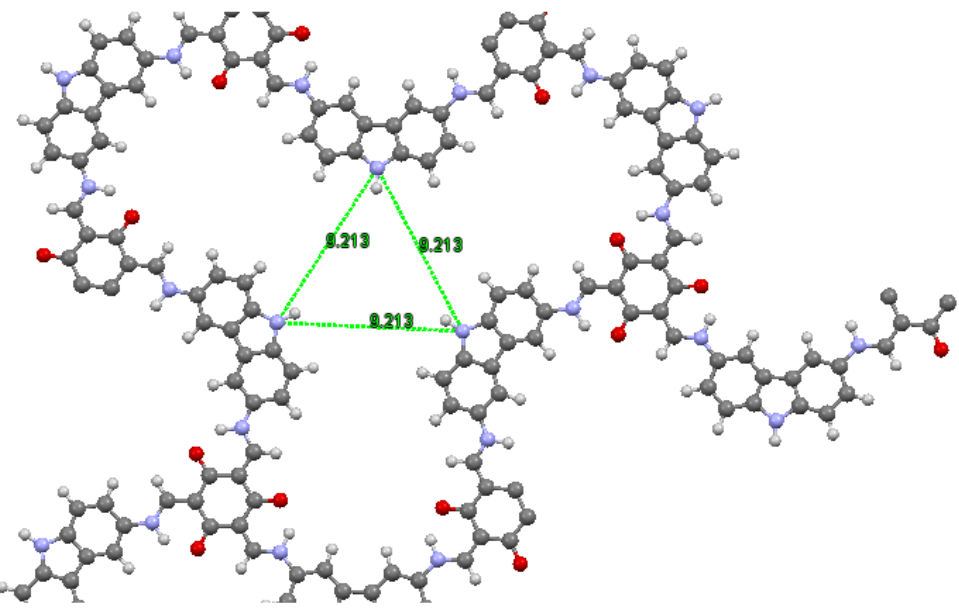

b)

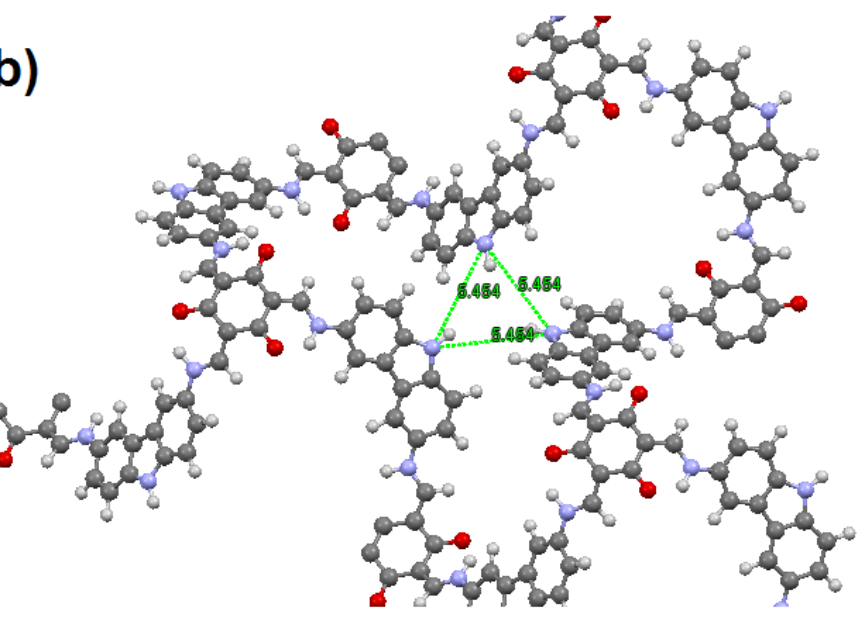

Figura 33: Distância entre os átomos de nitrogênio dos carbazóis para a estrutura (a) plana e (b) enrugada.

Segundo Lukose et al. (2011), COFs com átomos de boro e oxigênio podem apresentar deslocamento entre as folhas, causando não mais um empilhamento perfeito entre os poros, devido às interações coulombianas entre as folhas pelos átomos iguais. Através de seus cálculos, eles mostraram que as folhas na verdade estão deslocadas e rodadas uma em relação às outras. Para o RIO2, esse fenômeno também poderia acontecer devido à presença de átomos de oxigênio e nitrogênio, muito eletronegativos. Esse efeito foi verificado simulando quatro estruturas para o RIO2, fixando a distância entre as folhas em 3,4 $\AA$ e considerando as posições relativas de duas folhas de COF entre si, que foram denominadas da seguinte forma:

- AA-RIO2 (Figura 34): duas folhas empilhadas com grupos ceto em conformação eclipsada sem deslocamento e/ou rotação. Apresenta 
célula unitária hexagonal com $\mathrm{a}=\mathrm{b}=23,5180 \AA$ e $\mathrm{c}=3,4 \AA$ e grupo espacial $\mathrm{P} \overline{6} 2 \mathrm{~m}$.

- AA'-RIO2 (Figura 35): duas folhas empilhadas com grupos ceto em conformação eclipsada e rotacionadas $180^{\circ}$ em relação à outra. Apresenta célula unitária hexagonal com $\mathrm{a}=\mathrm{b}=23,5180 \AA$ e $\mathrm{c}=6,8$ $\AA ̊$ e grupo espacial $\mathrm{P} \overline{6_{3}} \mathrm{mcm}$.

- AB-RIO2 (Figura 36): duas folhas empilhadas com grupos ceto em conformação estrelada com ângulo de $60^{\circ}$ entre os grupos carbonila. Apresenta célula unitária romboédrica com $a=b=23,5180 \AA$ e $c=$ 10,2 Å e grupo espacial R32.

- AB'-RIO2 (Figura 37): idem AB-RIO2, entretanto cada folha é rotacionada $180^{\circ}$ em relação a seguinte. Apresenta célula unitária romboédrica com $a=b=23,5180 \AA$ e $c=20,4 \AA$ e grupo espacial $\mathrm{P} \overline{3} \mathrm{c}$.

- S-RIO2 (Figura 38): conformação serrada, característica de materiais ortorrômbicos.

- I-RIO2 (Figura 39): conformação inclinada, característica de materiais monoclínicos.

Após a otimização da geometria de cada uma das estruturas supracitadas foi possível determinar as energias de empilhamento de cada uma delas (Tabela 2). As energias calculadas são relativas, ou seja, a conformação AA foi considerada como zero e as demais em função dela. Foi possível observar que as conformações de menor energia foram aquelas que apresentaram deslocamento entre as folhas. Entre estas, destaca-se a conformação AB'-RIO2 que contem energia de empilhamento de $-1917 \mathrm{kcal} \mathrm{mol}^{-1}$ em relação a AA'. A tentativa de cancelar os momentos de dipolo das ligações $\mathrm{N}-\mathrm{H}$ do carbazol pode ser uma explicação para esse deslocamento. Desta forma, segundo os cálculos, o material apresentaria poros, mas estes não estariam disponíveis, como mostrado na Figura 37. Resultados semelhantes foram obtidos por cálculos teóricos para empilhamento $\pi$ de compostos heterocíclicos contendo nitrogênio. Em estudo teórico em nível MP2/6-311++G** com 100\% de correção BSSE, Mishra e Sathyamurthy (2005) mostraram que dímeros e trímeros de piridina tendem a apresentar conformação antiparalela-deslocadas devido ao momento de dipolo permanente do composto. Para o trímero, foi obtido $8,04 \mathrm{kcal} \mathrm{mol}^{-1}$ de energia de 
empilhamento para essa conformação, que foi coerente com a energia de vaporização obtida experimentalmente $\left(8,48 \mathrm{kcal} \mathrm{mol}^{-1}\right)$.

Tabela 2: Energias de empilhamento para as conformações do RIO2.

\begin{tabular}{cc}
\hline Conformação & Energia de empilhamento $\left(\mathrm{kcal} \mathrm{mol}^{-1}\right)$ \\
AA-RIO2 & 0,0 \\
AA'-RIO2 & $-1788,4$ \\
AB-RIO2 & $-1844,9$ \\
AB'-RIO2 & $-1917,0$ \\
S-RIO2 & $-1813,5$ \\
I-RIO2 & $-1910,8$ \\
\hline
\end{tabular}

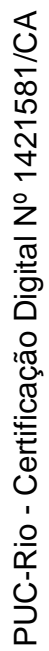

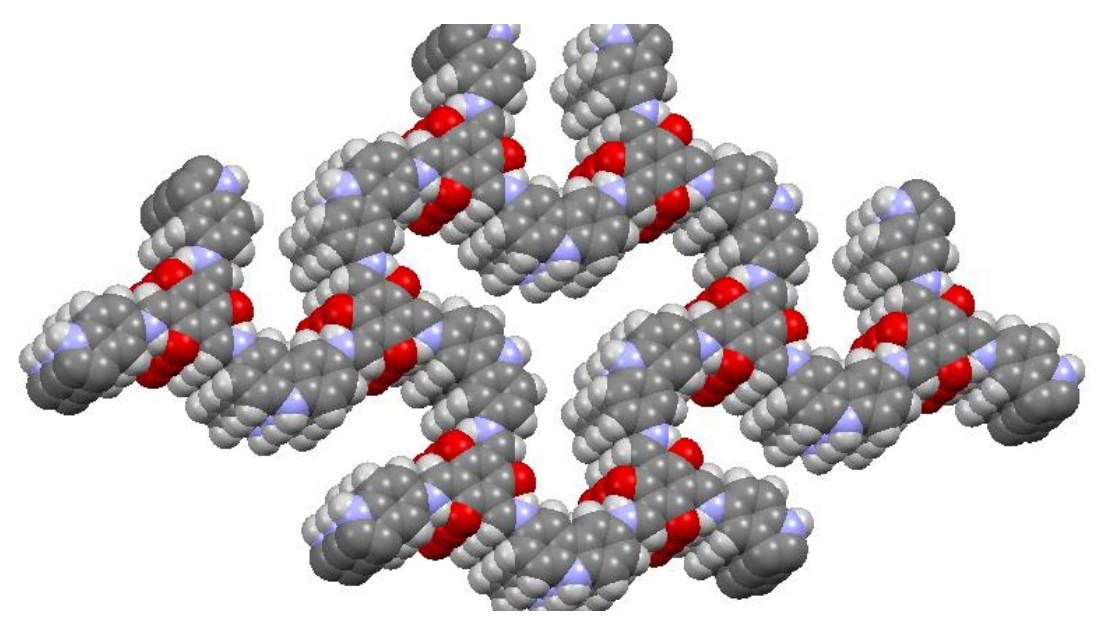

Figura 34: RIO2 em conformação AA.

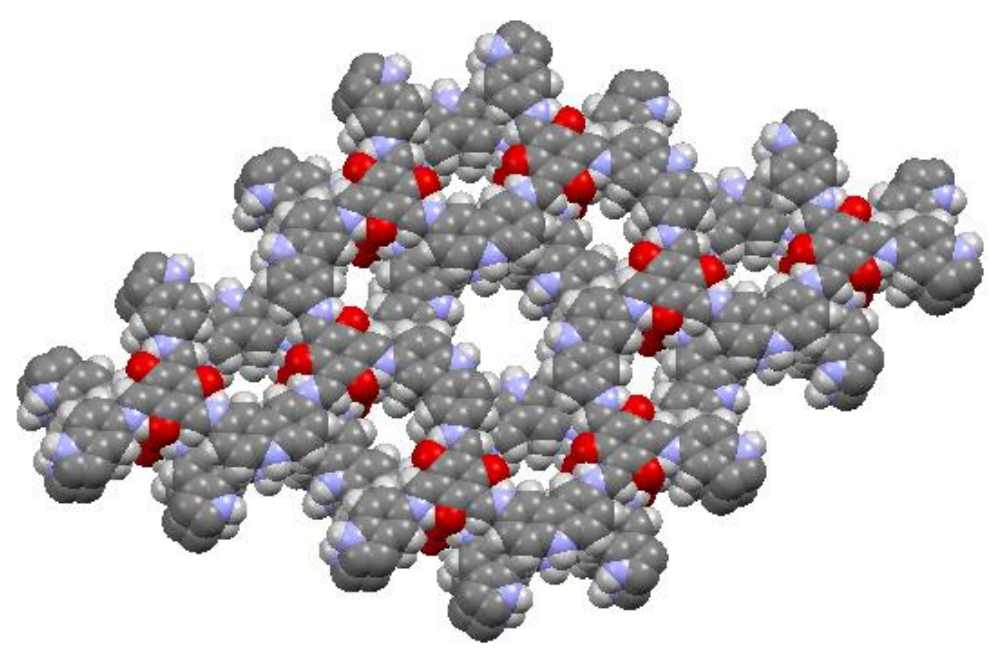

Figura 35: RIO2 em conformação AA'. 


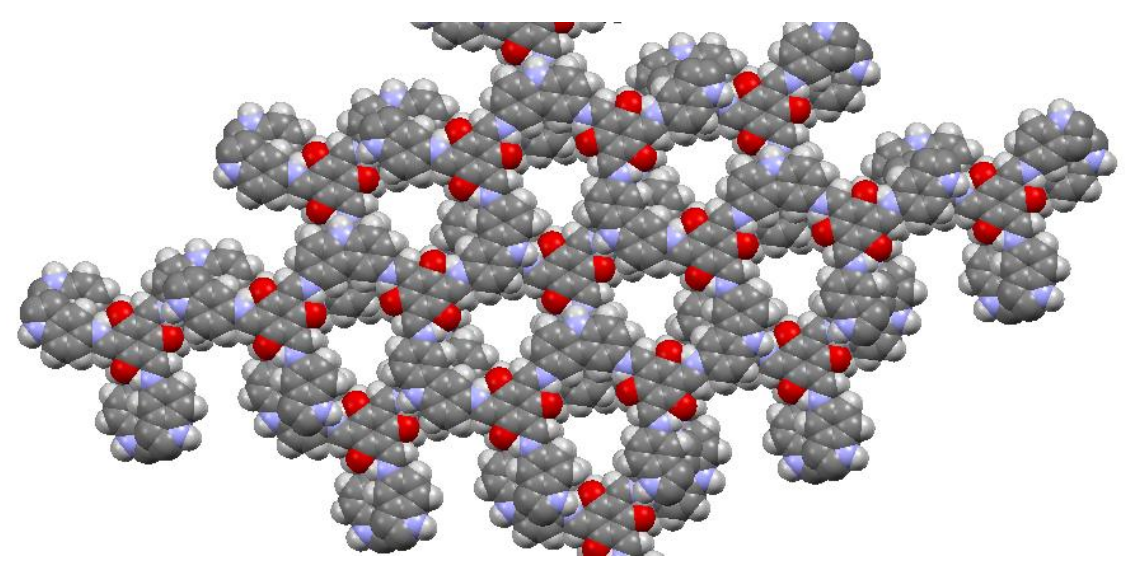

Figura 36: RIO2 em conformação AB.

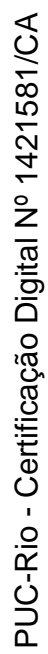

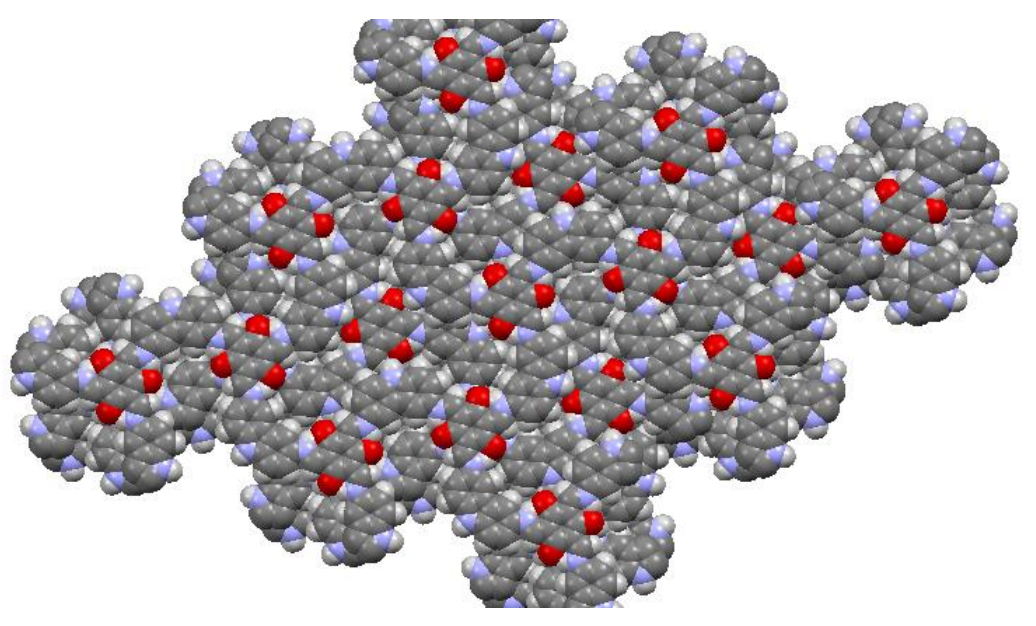

Figura 37: RIO2 em conformação AB'.

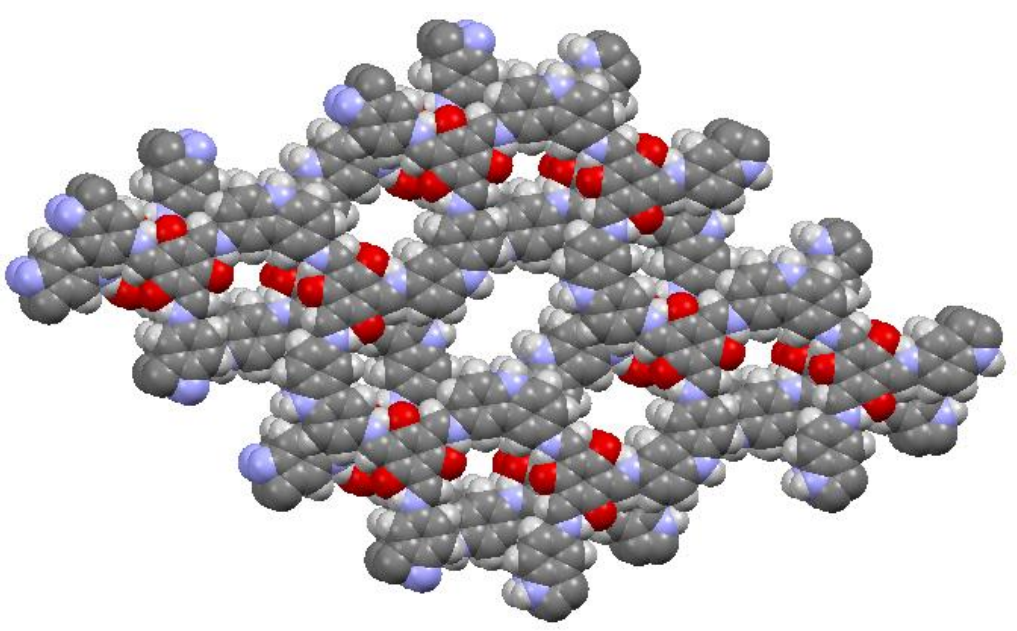

Figura 38: RIO2 em conformação serrada. 


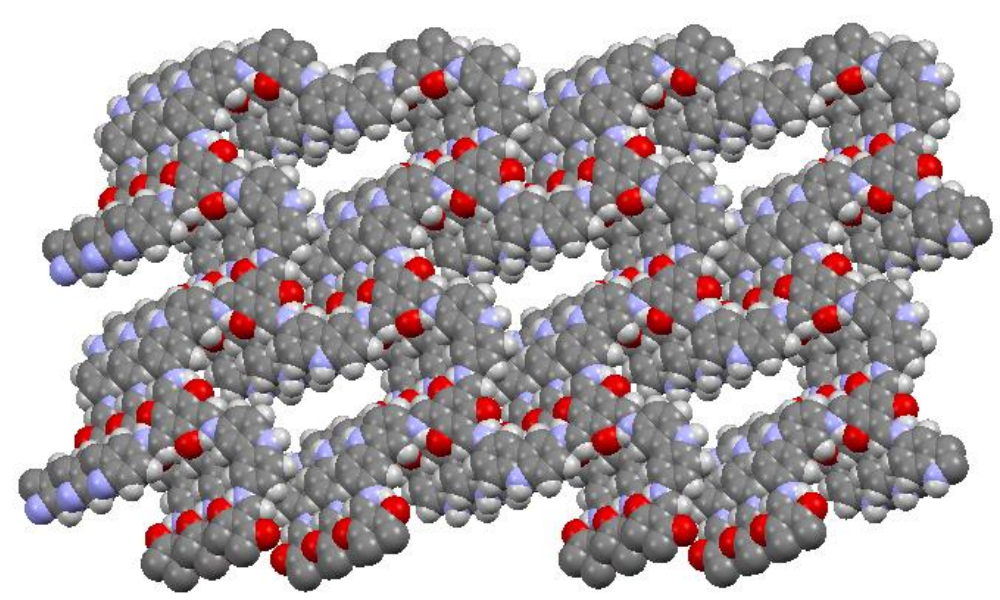

Figura 39: RIO2 em conformação inclinada.

O difratograma experimental do RIO2 apresentou picos alargados em 3,65, $8,90,17,66$ e $26,56^{\circ}$, evidenciando baixa cristalinidade do material, o que dificulta a comparação com os modelos e a aplicação de modelos de refinamento, como Rietveld e Pawley. Ao se comparar com os difratograma obtidos para os modelos teóricos (Figura 40) é possível verificar que nenhum dos modelos se adapta ao material obtido. Entretanto, pelos cálculos o melhor modelo seria o AB'-RIO2 por ser o termodinamicamente mais estável. A adoção dessas conformações pelo material pode estar relacionada com as interações eletrostáticas entre os grupos ceto. Nessas conformações deve haver o melhor balanço entre atrações e repulsões dos heteroátomos da rede do COF.

O estudo da estrutura cristalina do RIO3 seguiu a mesma abordagem do RIO2, sendo gerada inicialmente uma estrutura plana (Figura 41a) e outra enrugada (Figura 41b). Devido à baixa simetria do triformilfenol, ambos os modelos apresentaram grupo espacial $\mathrm{P} 1$, sendo a estrutura plana com célula unitária hexagonal distorcida com parâmetros de rede $a=24,20 \mathrm{~A}, \mathrm{~b}=24,15 \mathrm{~A}, \mathrm{c}$ $=5,94 \mathrm{~A}, \alpha=\beta=90^{\circ}$ e $\gamma=120,7^{\circ}$, e a estrutura enrugada com célula unitária triclínica com parâmetros $a=20,90 \mathrm{~A}, \mathrm{~b}=20,44 \mathrm{~A}, \mathrm{c}=4,50 \mathrm{~A}, \alpha=130,2^{\circ}, \beta=$ $70,8^{\circ}$ e $y=120,7^{\circ}$. 


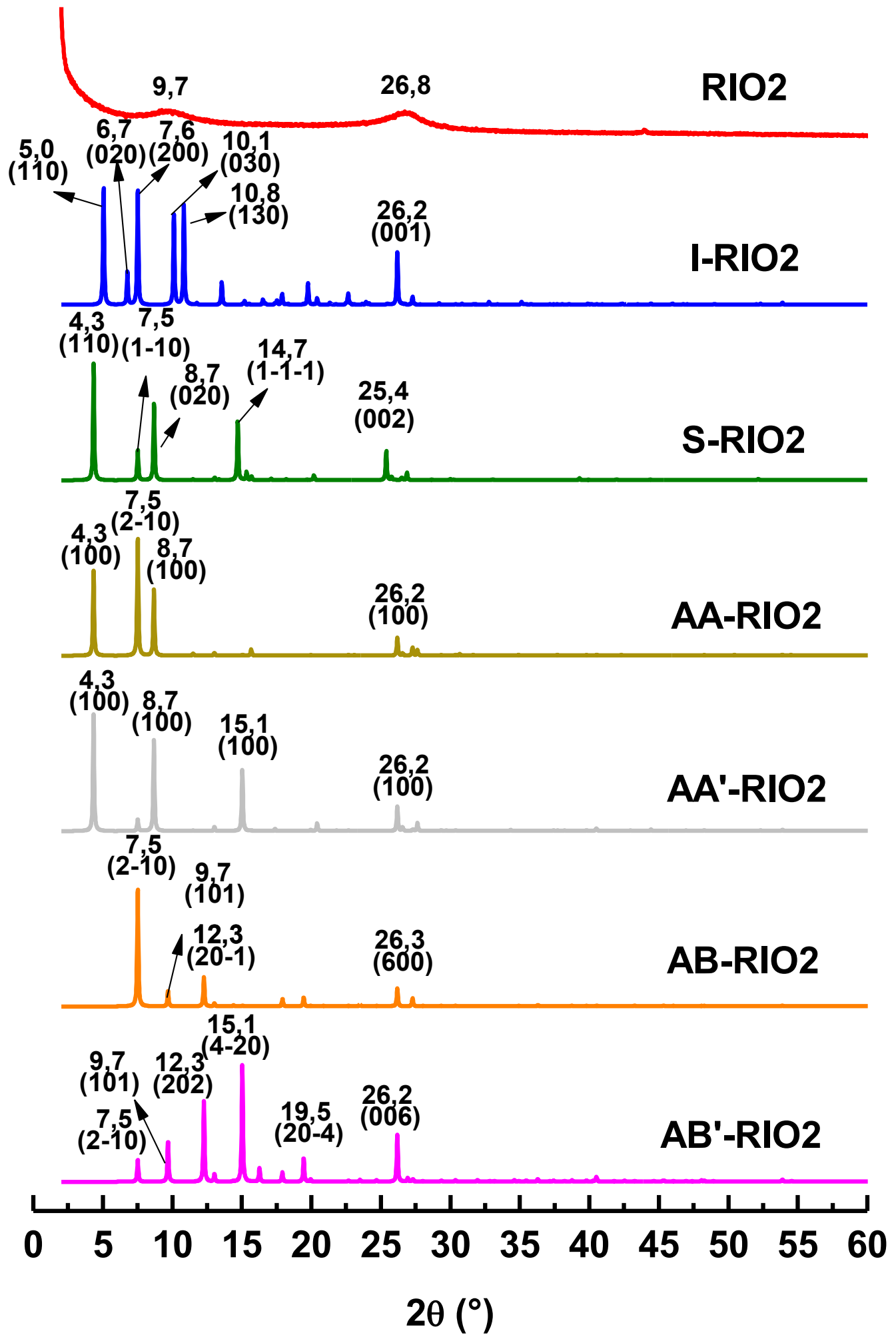

Figura 40: Difratogramas de raios-X obtido para o RIO2 e suas conformações. 
O diagrama de energia em função do espaçamento entre folhas do RIO3 (Figura 42) que foi calculado mostrou que a forma enrugada da estrutura é a termodinamicamente mais estável. Ao analisar as funções de localização eletrônica para as duas formas possíveis desse COF (Figura 41), é possível observar que a estrutura enrugada apresenta maior interação entre as folhas que a plana, entretanto essa interação é menor do que se comparada com o RIO2. Por esse motivo os parâmetros $\mathbf{a}$ e $\mathbf{b}$ da célula unitária do RIO3 são maiores que a do RIO2, apesar de serem tipos de células diferentes.

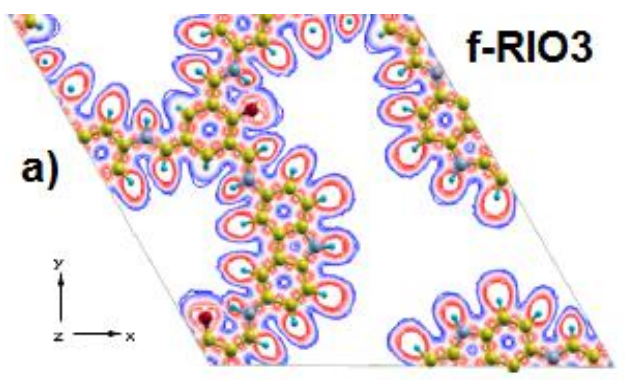

b)

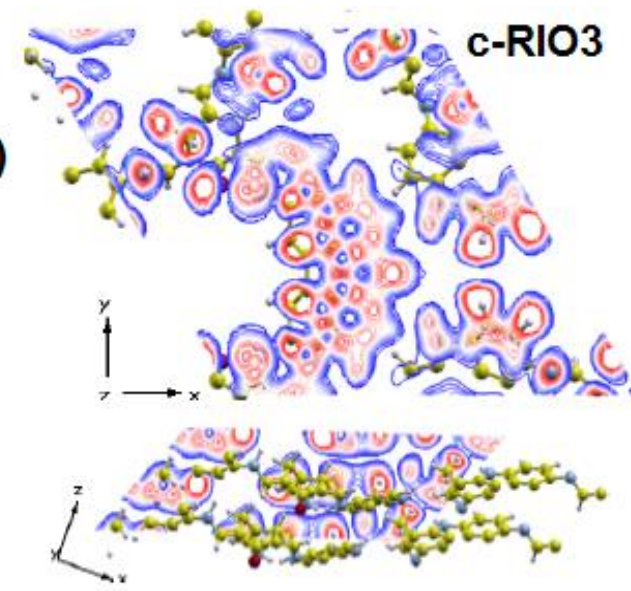

Figura 41: Função de localização eletrônica para o RIO3: a) forma plana; b) forma enrugada.

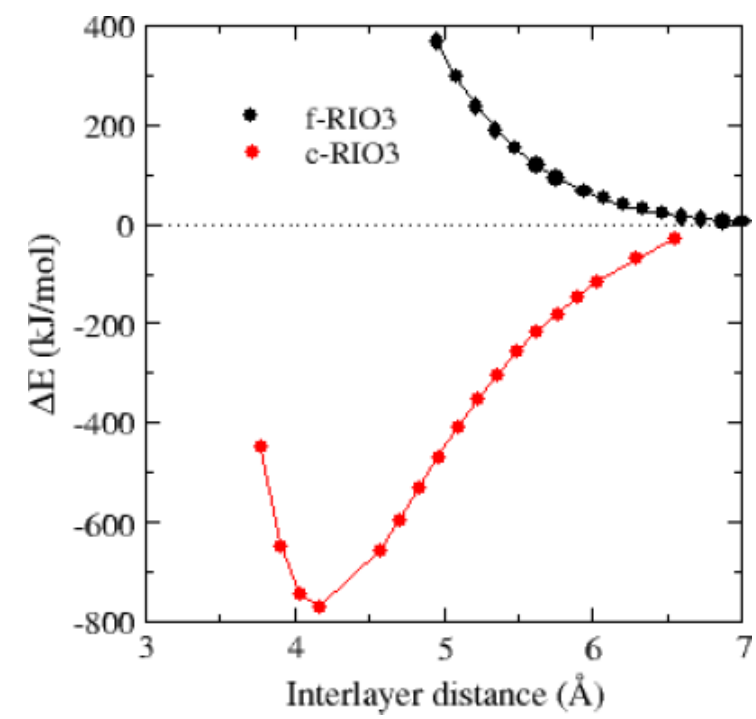

Figura 42: Diagrama de energia em função do espaçamento entre folhas de RIO3: o COF plano foi chamado de f-RIO3 e o COF enrugado de cRIO3. 
Ao se considerar que para o RIO3 também poderia haver rotação e deslocamento das folhas, novas estruturas para o COF foram geradas fixando-se o valor de c em 3,4 A de forma similar ao que foi feito para o RIO2 (Tabela 3). A conformação de menor energia obtida foi a inclinada.

Tabela 3: Energias de empilhamento para as conformações do RIO3.

\begin{tabular}{cc}
\hline Conformação & Energia de empilhamento (kcal mol ${ }^{-1}$ ) \\
AA-RIO3 (Figura 43) & 0 \\
AA'-RIO3 (Figura 44) & $-1650,4$ \\
AB-RIO3 (Figura 45) & $-1691,1$ \\
AB'-RIO3 (Figura 46) & $-1656,6$ \\
S-RIO3 (Figura 47) & $-1662,9$ \\
I-RIO3 (Figura 48) & $-1769,6$ \\
\hline
\end{tabular}

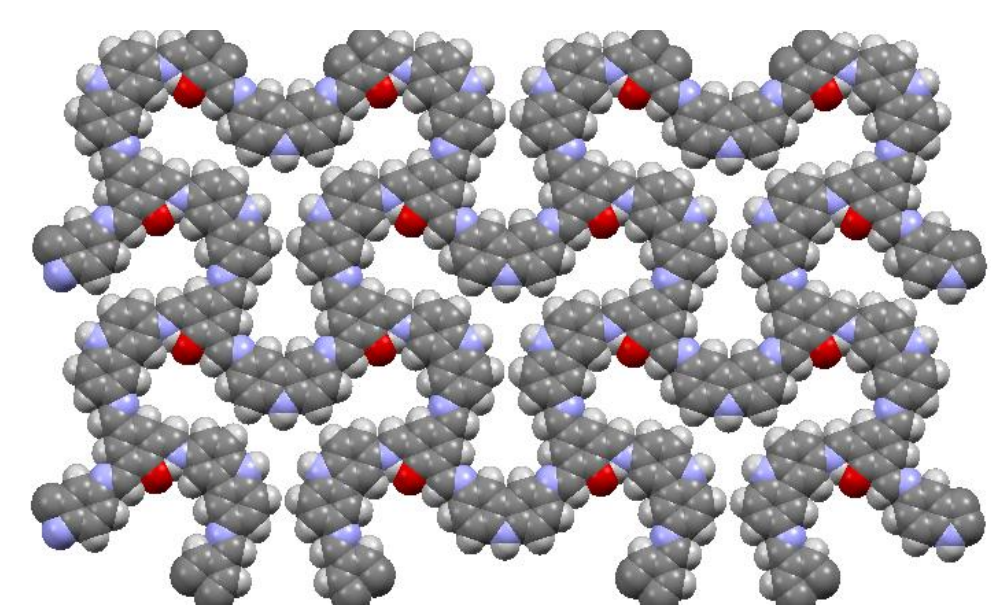

Figura 43: Conformação AA do RIO3.

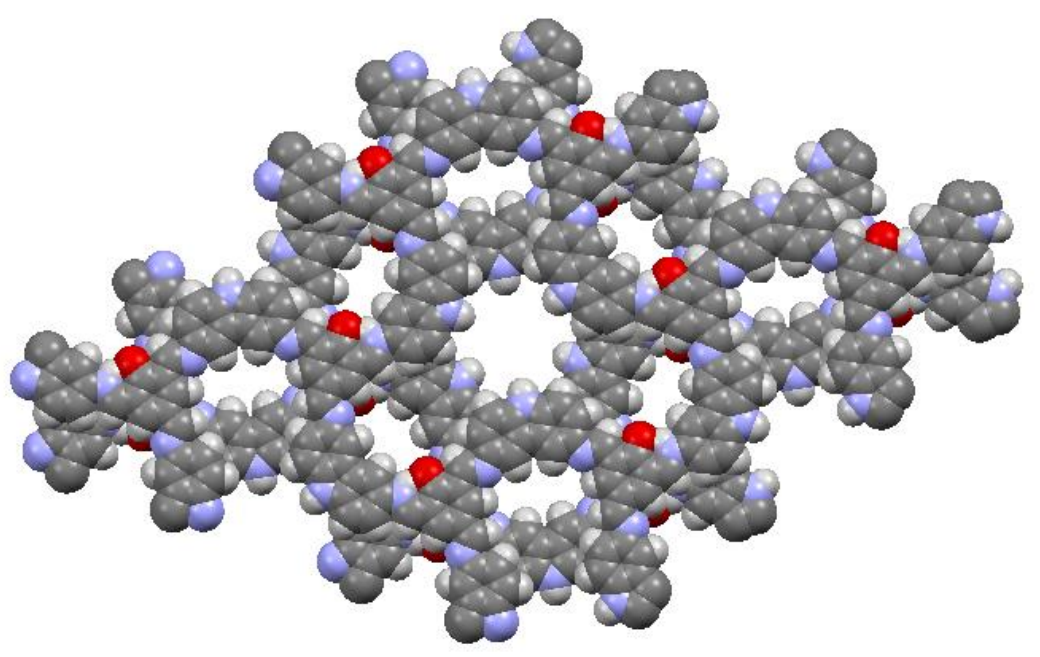

Figura 44: Conformação AA' do RIO3. 


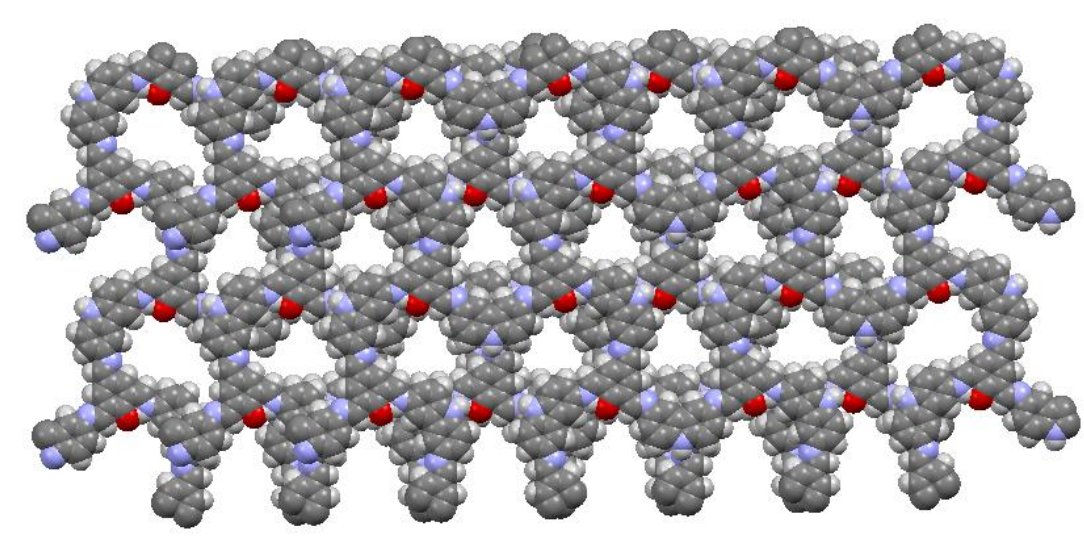

Figura 45: Conformação AB do RIO3.

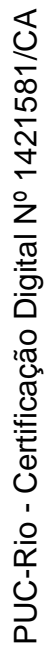

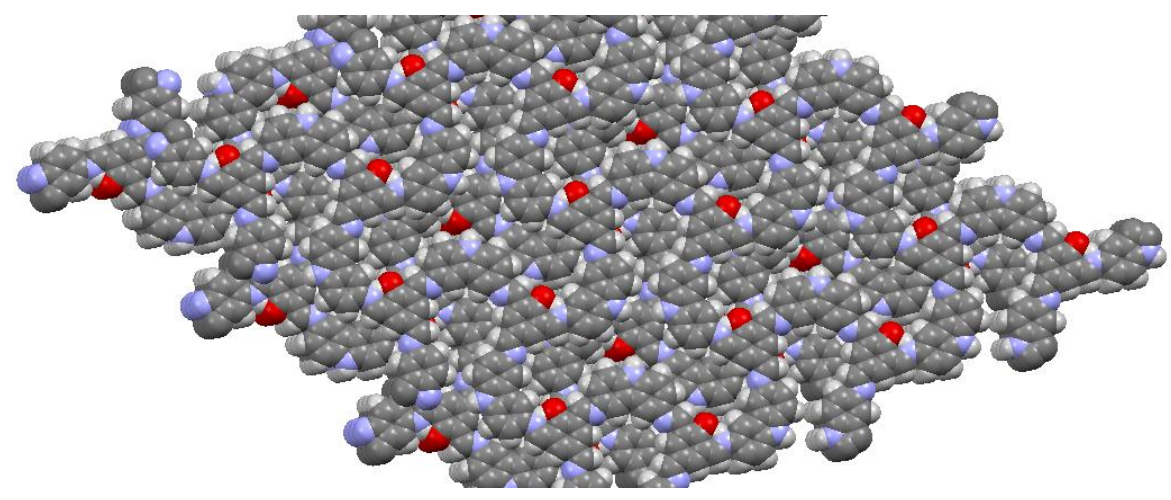

Figura 46: Conformação AB' do RIO3.

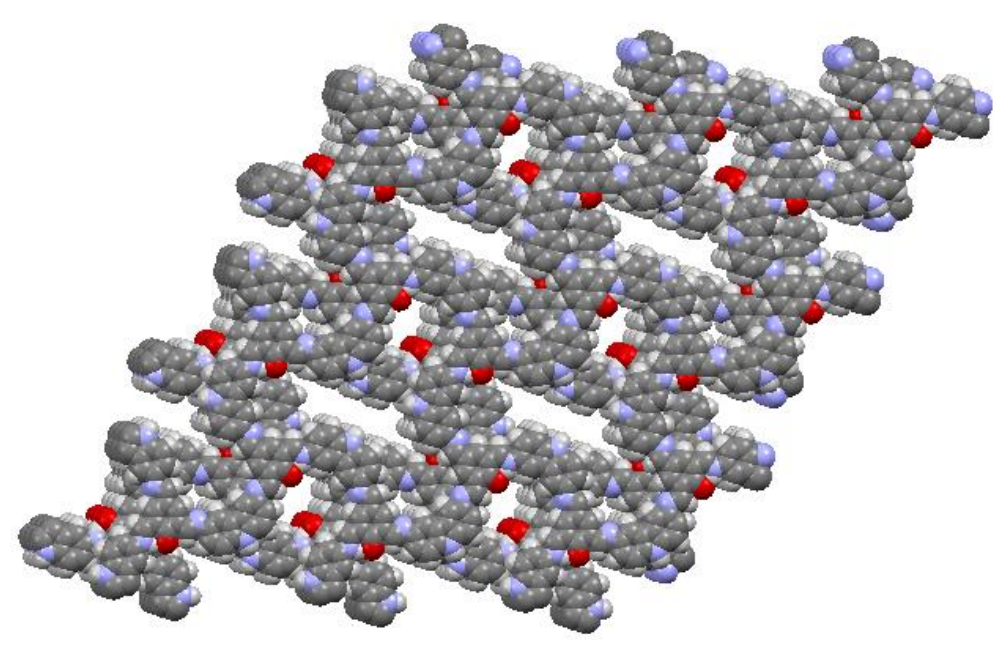

Figura 47: Conformação serrada do RIO3. 


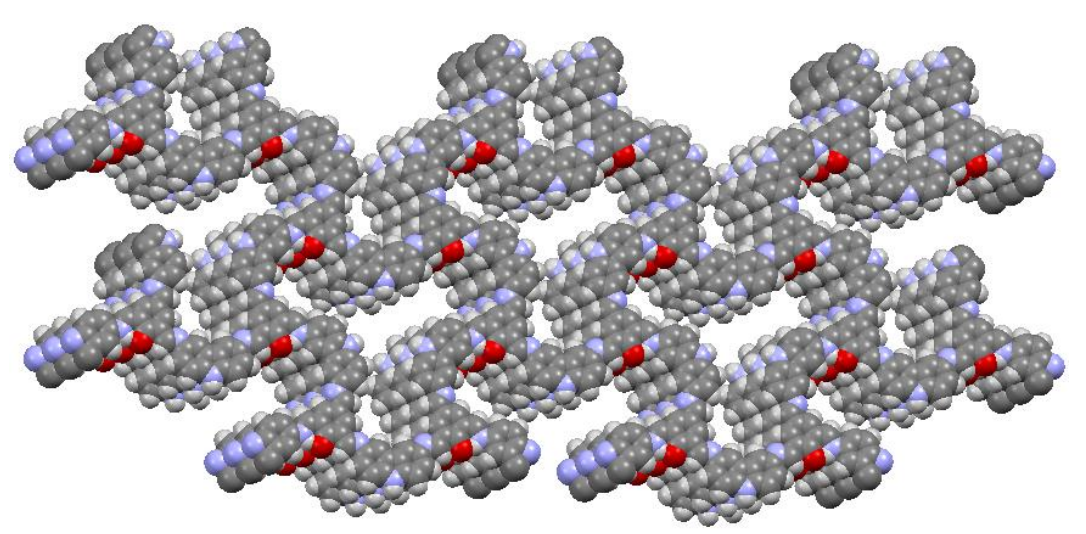

Figura 48: Conformação inclinada do RIO3.

Apesar dos resultados de energia, ao comparar o padrão de difração de rios$X$ do RIO3 com seus modelos teóricos para diferentes conformações (Figura 49), devido à baixa cristalinidade do material não foi possível dizer qual dos modelos melhor se adapta ao COF.

A baixa cristalinidade do RIO2 e RIO3 fez com que nenhum dos modelos melhor se adaptasse aos COFs. Existem outros tipos de materiais porosos como os POFs que também apresentam elevadas áreas específicas e são amorfos. A difração de raios- $X$ poderia ser um indicativo da porosidade do material, onde planos a baixo ângulo poderiam definir os poros do material e a distância entre esses planos determinaria o tamanho deles. 


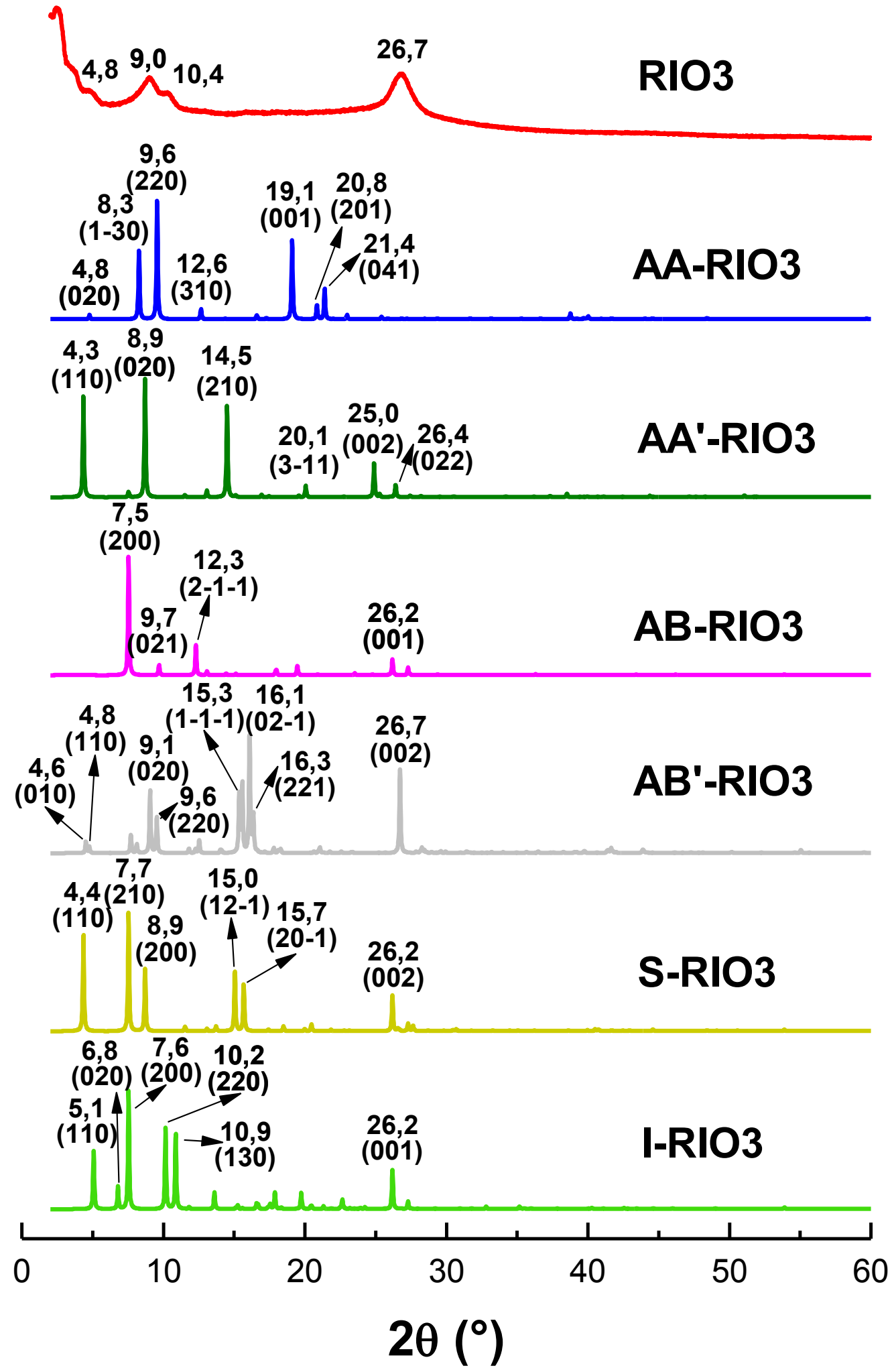

Figura 49: Difratogramas de raios-X do RIO3 comparado com seus modelos. 


\subsubsection{3.}

\section{Estrutura porosa dos materiais por isoterma de adsorção/dessorção} de nitrogênio e argônio

A próxima etapa na caracterização dos COFs foi a obtenção da isoterma de adsorção/dessorção de $\mathrm{N}_{2}$ para avaliar sua área específica e tamanho de poro. Ao se assumir o modelo AA'-RIO2, já seria possível esperar redução significativa na área específica, uma vez que o deslocamento das folhas causaria a inacessibilidade dos poros pelo fluido de análise. Pelo modelo AB'-RIO2 não haveria porosidade. A isoterma obtida foi do tipo II (Figura 50), característica de material não poroso. Através do gráfico de multi-point $\mathrm{BET}$, obtido na região 0,05 $\leq \mathrm{P} / \mathrm{P}_{0} \leq 0,3$, foi possível obter área específica de $181 \mathrm{~m}^{2} \mathrm{~g}^{-1}$. Esse tipo de isoterma, que não seria esperada para COFs por sua definição, já foi obtida previamente por Das et al. (2015). Essa isoterma, portanto, confirma a predição teórica.

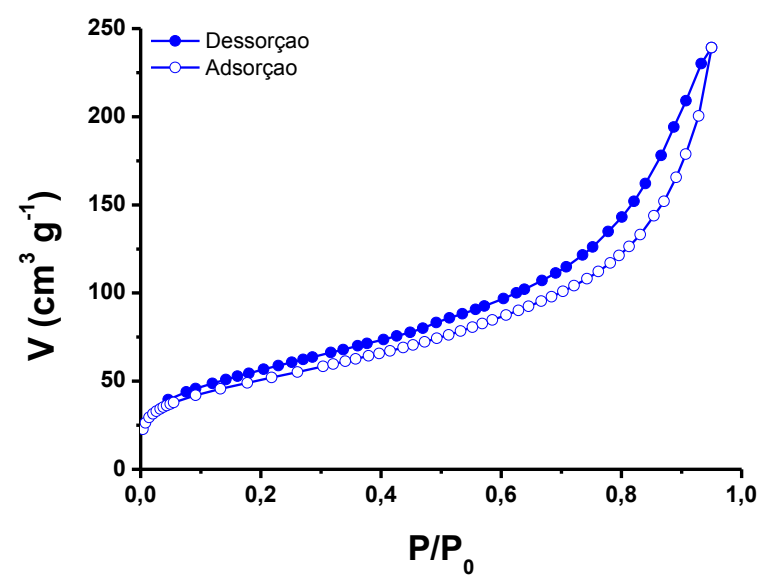

Figura 50: Isoterma de adsorção/dessorção de $\mathrm{N}_{2}$ do RIO2.

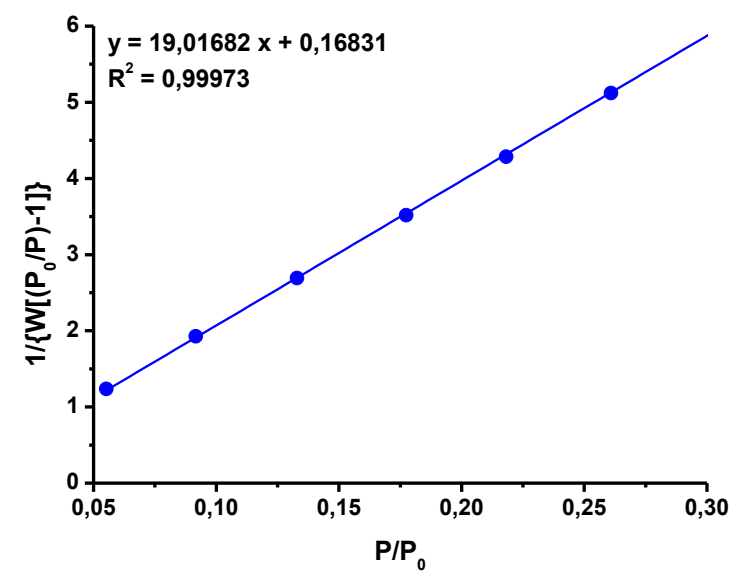

Figura 51: Gráfico multi-point BET para o RIO2. 
A distribuição de tamanho de poros foi obtida por NLDFT adotando como modelo a presença de poros cilíndricos e do tipo fenda (Figura 52), já que esse apresenta os dois tipos de poros disponíveis entre os modelos. A escolha desse método se baseou pelo fato de ser mais indicado para materiais microporosos.

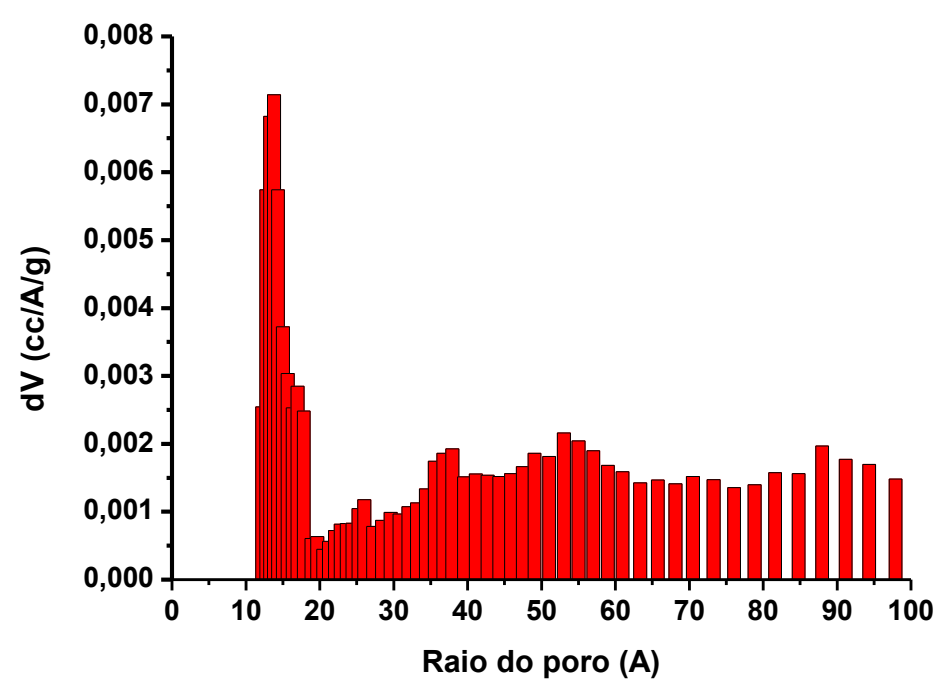

Figura 52: Distribuição de tamanho de poros do RIO2 obtida por NLDFT.

Foi possível observar no histograma obtido que o raio médio dos poros do RIO2 é de 1,38 nm, ou seja, diâmetro médio de 2,76 nm, que seria característico de material mesoporoso. A fim de se estimar esse valor a partir do modelo AA'RIO2, propôs-se uma análise de acordo com (Bertrand et al. (2013)). Eles obtiveram poros de mesma topologia para o T-COF 1 e T-COF 2 com tamanhos de 2,06 e 1,38 nm, respectivamente, admitindo modelo de poros cilíndricos, logo, as áreas dos poros seriam de 3,142 e 2,168 $\mathrm{nm}^{2}$. O fato do poro desse COF ser maior que os dos com tiofeno está baseado no fato de o carbazol ser um bloco de montagem maior que os usados pelos autores do trabalho.

Com essas evidências de rotação e deslocamento e também considerando a menor simetria desse COF devido à ausência de dois grupos hidroxila, realizouse a isoterma de adsorção/dessorção de $\mathrm{N}_{2}$ (Figura 53) esperando-se resultados semelhantes ao do COF anterior. A isoterma obtida foi do tipo II, de material não poroso, com área específica obtida foi de $32 \mathrm{~m}^{2} \mathrm{~g}^{-1}$ obtida pelo método multi-point BET. 


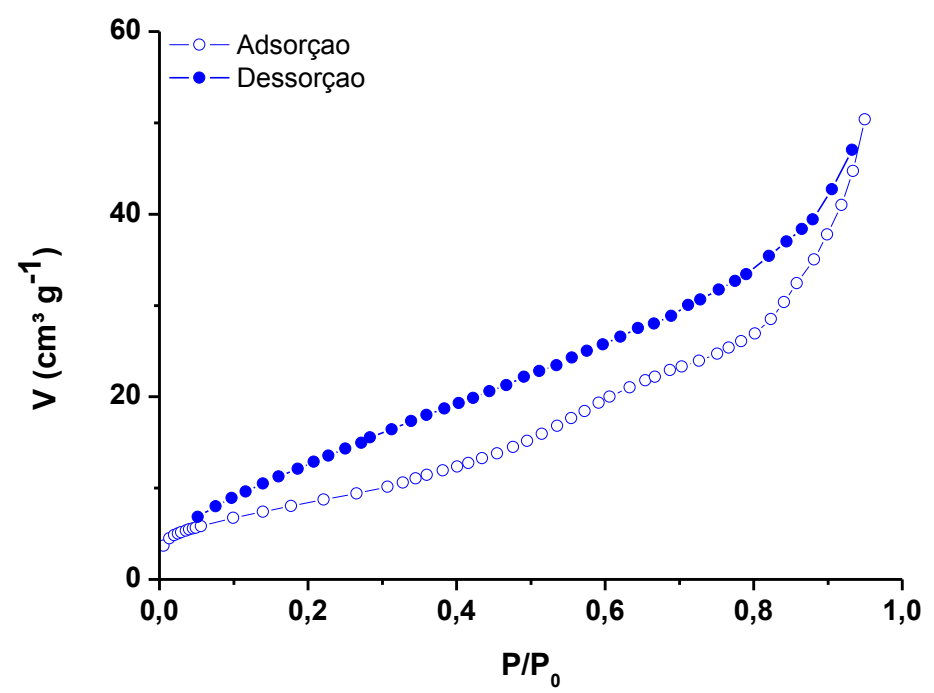

Figura 53: Isoterma de adsorção/dessorção de $\mathrm{N}_{2}$ do RIO3.

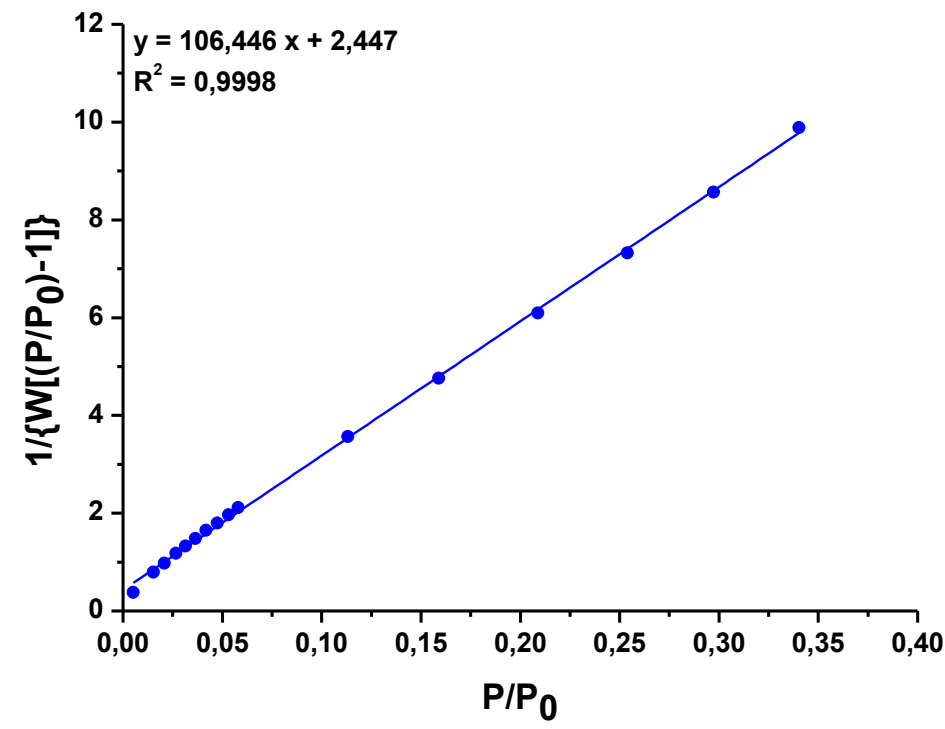

Figura 54: Gráfico multi-point BET para o RIO3.

A distribuição de tamanho de poro determinada por NLDFT, assumindo também modelo de poros cilíndricos e do tipo fenda, evidenciou o caráter microporoso do material com raio de poro de $1,70 \mathrm{~nm}$, ou seja, $3,40 \mathrm{~nm}$ de diâmetro, característico de material mesoporoso e maior que o poro do RIO2. Mais uma vez os poros apresentam-se inacessíveis ao $\mathrm{N}_{2}$, porém não necessariamente o material seria não-poroso como mostrado pela isoterma do tipo II obtida. 


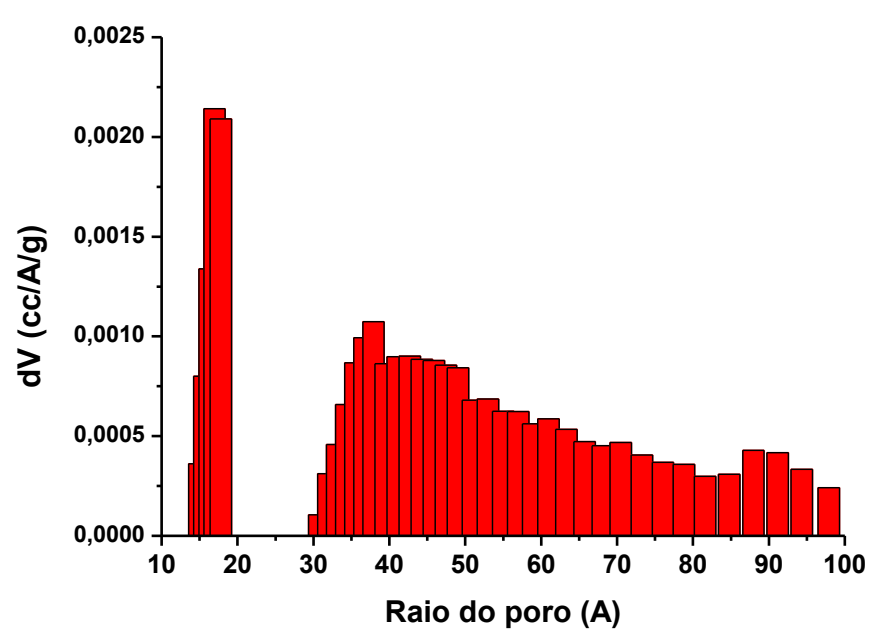

Figura 55: Distribuição de tamanho de poros do RIO3 obtida por NLDFT.

Alguns materiais porosos orgânicos já apresentaram área específica menor do que em comparação com outros COFs usando as isotermas de nitrogênio (Patel et al., 2013; Patel et al., 2014; Arab et al., 2015; Dang et al., 2015). Esses materiais são conhecidos como $\mathrm{N}_{2}$-fóbicos e apresentam elevada capacidade de adsorção de $\mathrm{CO}_{2}$. Em comum, esses materiais apresentam na parede dos poros grupos azo, - $\mathrm{N}=\mathrm{N}$-, que por apresentarem elevada densidade eletrônica causam forte interação dipolo-quadrupolo com as polarizáveis moléculas de $\mathrm{CO}_{2}$, o que não aconteceria com as de $\mathrm{N}_{2}$ (Dang et al., 2016). Para confirmar se de fato o material apresenta as áreas específicas baixas apresentadas, foi realizada também as isotermas de argônio (Figura 56), outra alternativa para se obter esse dado de materiais porosos.

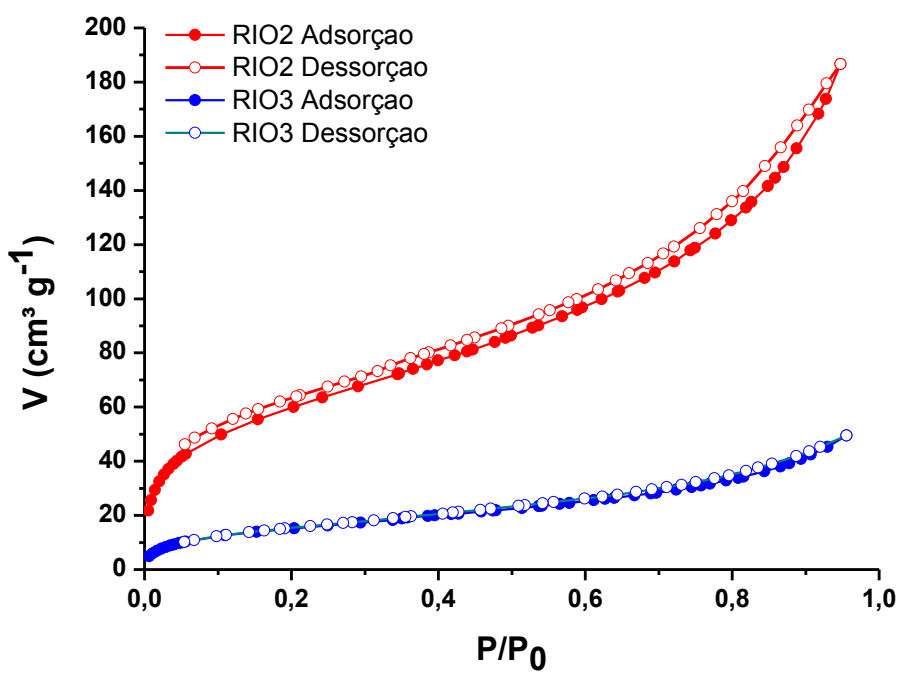

Figura 56: Isotermas de adsorção/dessorção de Ar para RIO2 e RIO3. 
As isotermas de argônio também se apresentaram como do tipo Il e através do método multi-point BET obteve-se áreas específicas de 182 e $76 \mathrm{~m}^{2} \mathrm{~g}^{-1}$ para RIO2 e RIO3, respectivamente. Esses resultados são pouco maiores que os obtidos pelas isotermas de $\mathrm{N}_{2}$. Isso indica que os poros do material não estão acessíveis aos gases usados pelo equipamento e o cálculo da área específica fica prejudicado.

\subsubsection{4.}

\section{Estrutura porosa dos materiais por SAXS}

Para um estudo mais detalhado da porosidade desses materiais realizou-se o experimento de SAXS. A curva de da intensidade de espalhamento em função do vetor espalhamento em escala logarítmica (Figura 57) foi usada para determinar o tipo de superfície dos COFs.

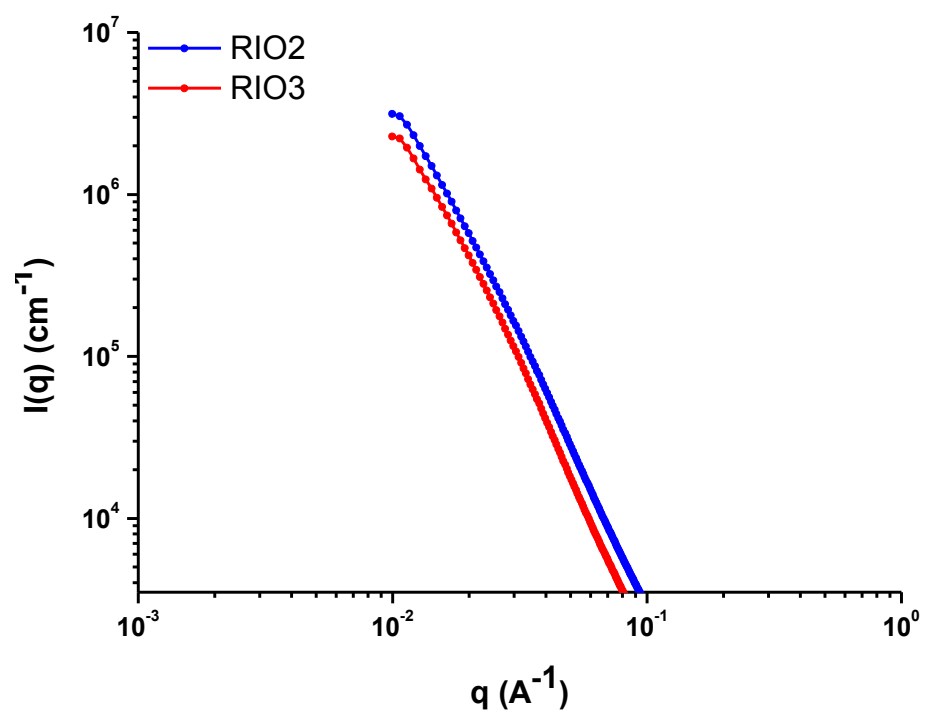

Figura 57: Perfil de SAXS do RIO2 e RIO3.

Foi possível observar na região de Porod que o espalhamento de raios-X segue a lei de potência de $\mathrm{I}(\mathrm{q}) \propto \mathrm{q}^{-3,14}$ para o RIO2 e I(q) $\propto \mathrm{q}^{-2,91}$ para o RIO3, o que os caracteriza como materiais com superfície fractal (Lifshin, 2008). Pode-se definir a dimensão fractal do material $D_{\text {SAXS }}=6$ - $\alpha$, onde $\alpha$ é o expoente de Porod. Para o RIO2 a dimensão fractal vale 2,86 e para o RIO3 é 3,09.

O estudo de superfícies fractais também pode ser realizado a partir dos dados de adsorção de $\mathrm{N}_{2}$ utilizando o método de Frenkel-Halsey Hill (FHH) (Halsey, 1948) modificado por Pfeifer (Pfeifer et al., 1989; Pfeifer e Liu, 1997). 
Nesse método, a dimensão fractal $D_{\mathrm{FHH}}$ pode ser definida a partir da equação 13 , onde $\mathrm{V}$ é o volume de gás adsorvido, $\mathrm{V}_{\text {mono }}$ é o volume coberto por uma monocamada e A é uma constante.

$$
\ln \left(\frac{\mathrm{V}}{\mathrm{V}_{\text {mono }}}\right)=\text { constante }+\mathrm{A}\left\{\ln \left[\ln \left(\frac{\mathrm{P}_{0}}{\mathrm{P}}\right)\right]\right\}
$$

A constante $A$ é a inclinação da reta obtida no gráfico $\ln \left(\frac{V}{V_{\text {mono }}}\right) \times \ln \left[\ln \left(\frac{P_{0}}{P}\right)\right]$ e está relacionada com a dimensão fractal. Entretanto, o valor de $D_{\mathrm{FHH}}$ é obtido corretamente na região do gráfico que representa o recobrimento por uma monocamada. Ao definir $\mathrm{n}$ como sendo o número de camadas de gas adsorvida através da equação \#, para todo $1,0 \pm 0,5<\mathrm{n}<2,0 \pm 0,5$ o valor de $D_{F H H}$ é correto.

$$
\mathrm{n}=\left(\frac{\mathrm{V}}{\mathrm{V}_{\mathrm{mono}}}\right)^{1 /\left(3-\mathrm{D}_{\mathrm{FFH}}\right)}
$$

A partir do resultado do SAXS indicativo de que os COFs apresentam superfície fractal, construiu-se o gráfico $\ln \left[\ln \left(\mathrm{P}_{0} / \mathrm{P}\right)\right] \times \ln \left(\mathrm{V} / \mathrm{V}_{\text {mono }}\right)$ na região indicada pelo equipamento como sendo de monocamada (Figura 58). A curva obtida para o RIO2 apresentou equação y $=-0,472 x+1,618$ com $R^{2}=0,997$ e o valor de $D_{F H H}$ encontrado foi de 2,5278. Para o RIO3, a equação obtida foi $y=-0,583 x+0,8472$ com $R^{2}=0,991$ e $D_{F H H}=2,4169$. Assim, os resultados obtidos pelo BET mostram também que os COFs apresentam estrutura fractal.

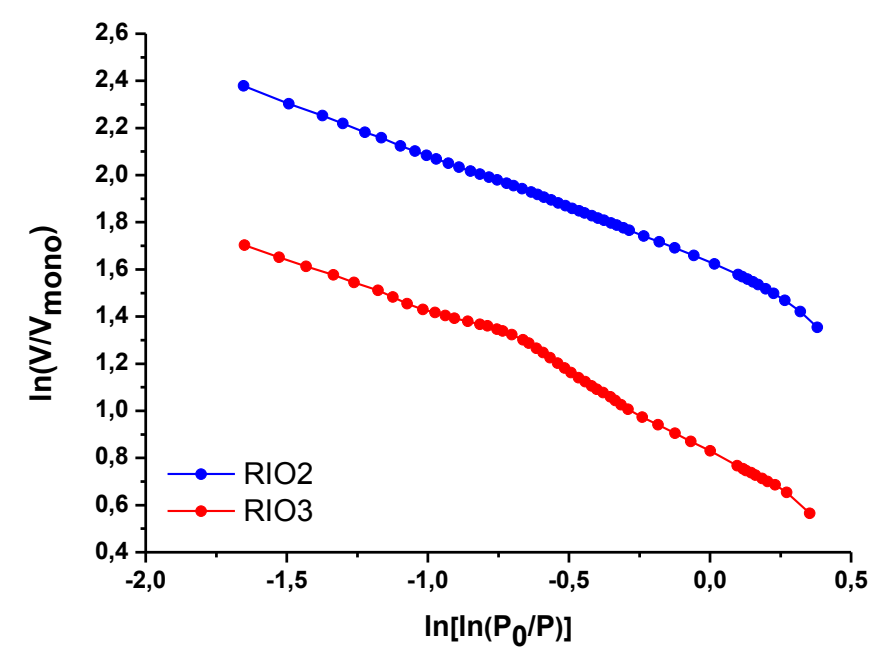

Figura 58: Gráfico $\ln \left[\ln \left(\mathrm{P}_{0} / \mathrm{P}\right)\right]$ x $\ln \left(\mathrm{V} / \mathrm{V}_{\text {mono }}\right)$ para o RIO2 (azul) e RIO3 (vermelho). 
Tsao et al. (2007) estudaram a estrutura dos poros do MOF-5 por SAXS. Eles observaram que para taxas mais lentas de resfriamento do material, sua tendência é assumir características de material fractal, apresentando valores de dimensão fractal entre 2,8 e 2,9. Nesse caso, os poros tendem a se agregar formando poros maiores, na escala de mesoporos, que foram chamados de rede fractal. Segundo os autores, esse fenômeno poderia ser explicado pelo envelhecimento de Ostwald, que se baseia na redução da energia livre da superfície do poro através da coalescência de poros menores vizinhos. Ao analisar a distribuição de tamanho de poros é possível observar que existem poros entre 4 e $20 \mathrm{~nm}$, que podem então ser oriundos de fenômeno semelhante ao do MOF5.

A partir dos dados do SAXS pôde-se ser gerado a curva de $P(r)$ (Figura 59), que corresponde à função de distribuição de distâncias. Esse gráfico foi usado como análogo da distribuição de tamanho de poros. Tanto para o RIO2 e o RIO3 as distribuições apresentaram curvas com perfil de gaussiana centradas em $19 \mathrm{e}$ $17 \mathrm{~nm}$, respectivamente. Esse pode ser mais um indicativo do envelhecimento de Ostwald dos poros e da característica fractal da superfície.

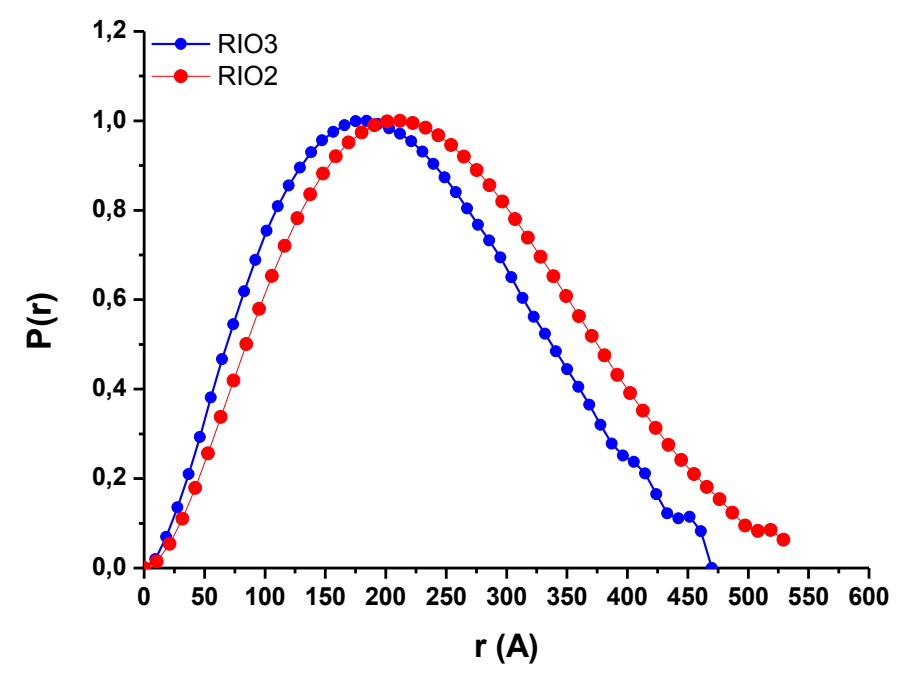

Figura 59: Distribuição P(r) para o RIO2 e RIO3.

\subsubsection{5.}

\section{Estabilidade térmica}

Para avaliar a estabilidade térmica dos materiais, foi realizada a termogravimetria. O termograma obtido para o RIO2 (Figura 60) mostrou perda 
inicial de $8,8930 \%$ de massa até $200{ }^{\circ} \mathrm{C}$ e após $350{ }^{\circ} \mathrm{C}$ perda de $43,2223 \%$, indicando que o material apresenta estabilidade até essa temperatura.

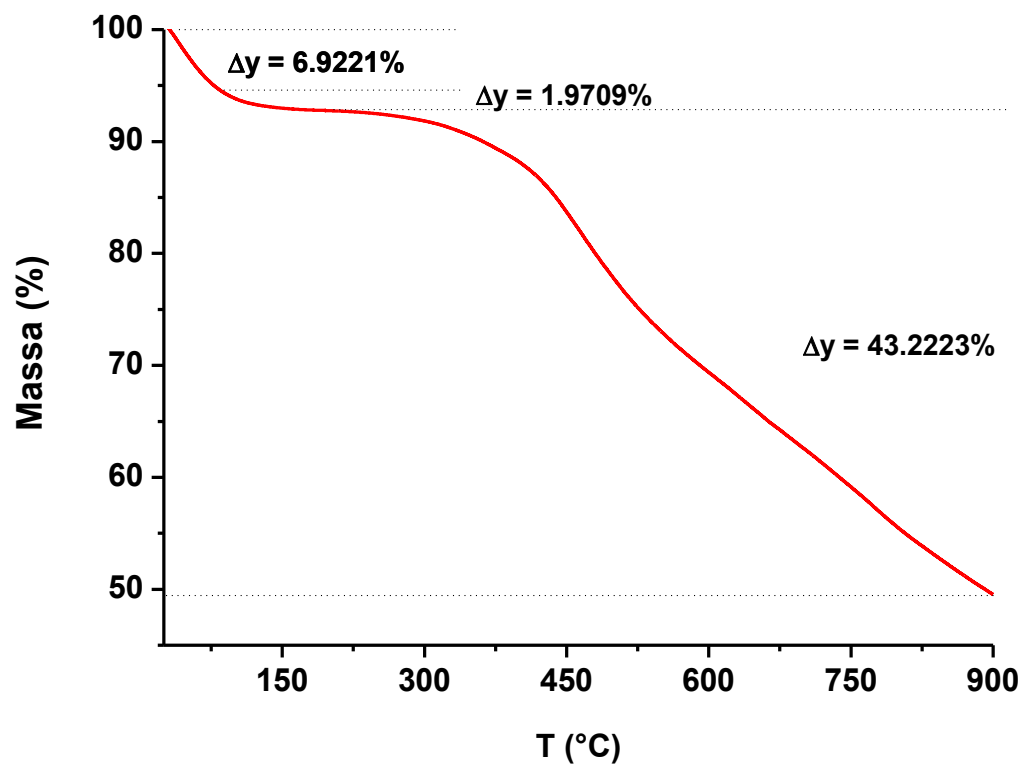

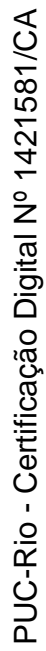

Figura 60: Termograma do RIO2.

Para o RIO3, o termograma obtido (Figura 61) mostrou perda inicial de $0,8880 \%$ de massa até $200{ }^{\circ} \mathrm{C}$ e outra de $29,6053 \%$ acima de $300{ }^{\circ} \mathrm{C}$, indicando também elevada estabilidade térmica.

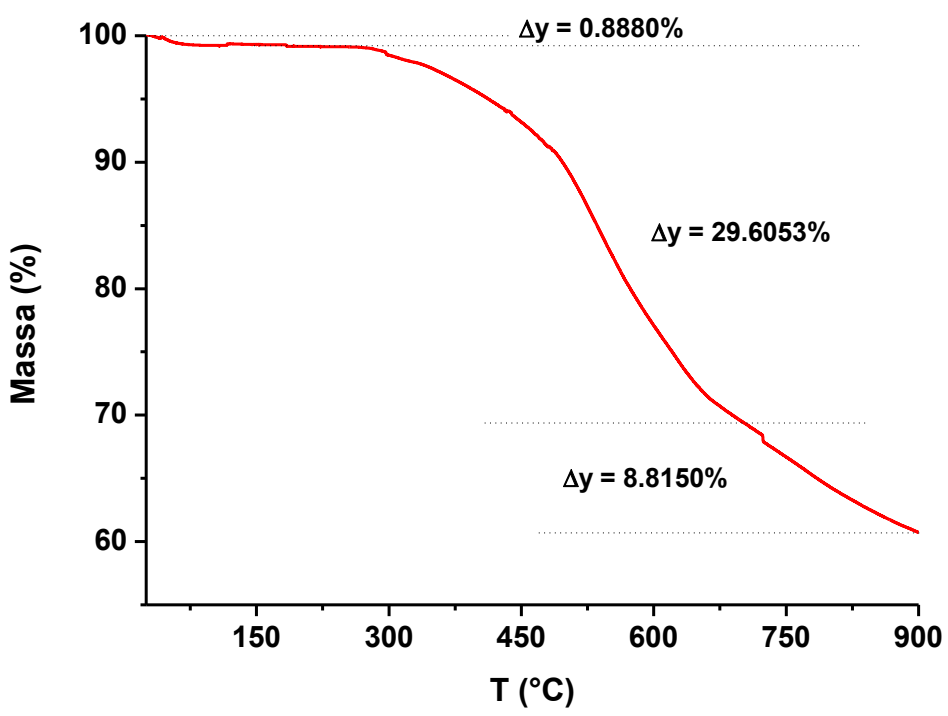

Figura 61: Termograma do RIO3. 


\section{3.}

\section{Estrutura lamelar do RIO3.}

. Materiais bidimensionais lamelares apresentam interações fracas entre suas folhas. Estruturas lamelares são tipicamente esfoliadas para que suas folhas possam ser liberadas e, com isso, terem sua área específica aumentada (Nicolosi et al., 2013). O difratograma de raios-X do RIO3 apresentou um pico de difração em 26,8 $8^{\circ}$, semelhante ao grafite (Figura 62) (Kukesh e Pauling, 1950), material que pode ser esfoliado para obtenção do grafeno. Banhos de ultrassom são suficientes para que, por ação mecânica, as forças de Van der Waals que as unem possam ser rompidas. Alguns trabalhos já foram descritos para esfoliação de COFs (Berlanga et al., 2011; Berlanga et al., 2012; Bunck e Dichtel, 2013; Gallego et al., 2013; Stegbauer et al., 2014).

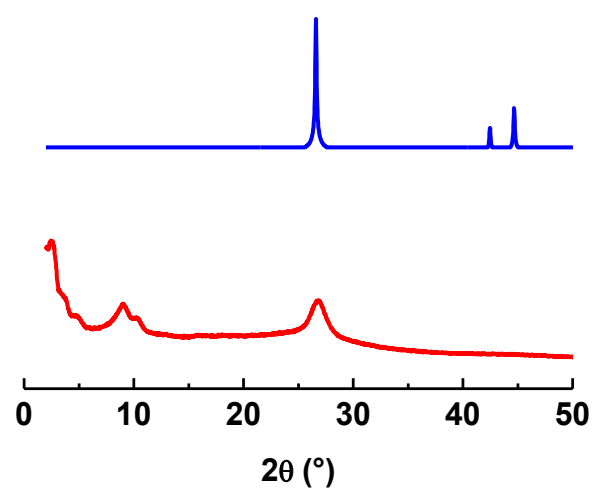

\section{Figura 62: Comparação dos padrões de difração de raios-X entre grafite (azul) e RIO3 (vermelho).}

A esfoliação do RIO3 gerou uma suspensão que foi então visualizada no MET. Foi possível confirmar a formação das nanofolhas de COF (Figura 63a), nesse caso com até cinco folhas empilhadas, observadas pela diferença de contras de massa/espessura. Entretanto, o padrão de difração de elétrons (Figura 63b) mostrou que algumas regiões analisadas, como as da figura Figura 63a, se comportaram como material amorfo com alguns spots de material cristalino. Uma imagem do spot indicado em campo escuro (Figura 63c) indicou que as regiões são discretas. Esse comportamento amorfo difere do difratograma de raios- $X$ obtido e possivelmente $\mathrm{o}$ solvente de esfoliação, diclorometano, pode ter provocado a perda de cristalinidade do material ou mesmo o material necessitava de maior tempo de síntese para que o equilíbrio termodinâmico da reação corrigisse as regiões amorfas. 


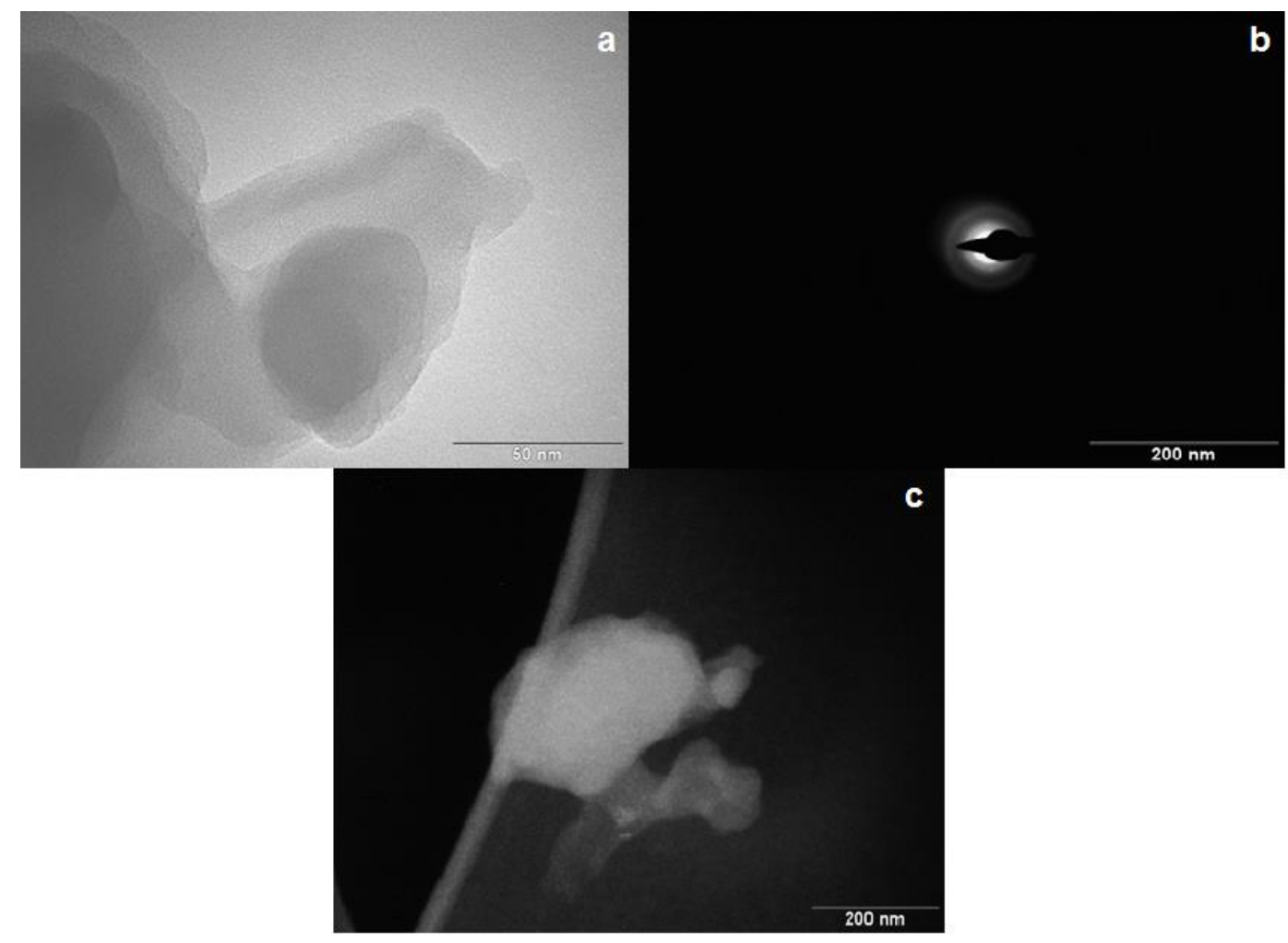

Figura 63: Imagens de HRTEM do RIO3: a) imagem em campo claro de nanofolhas empilhadas; b) padrão de difração de elétrons da região da foto (a); c) imagem em campo escuro de um spot da imagem (b).

Em outra região da amostra (Figura 64a) foi possível observar a presença de franjas de Moiré. Esse tipo de estrutura é comumente encontrada ao analisar grafite (Xu et al., 2014). O padrão de difração (Figura 64b) apresentou círculos concêntricos com spots. Isso é indicativo de que a amostra era policristalina com algumas regiões monocristalinas, ou seja, provavelmente com o tempo maior de síntese, esse material tenderia a formação de monocristais. Uma imagem em campo escuro de um dos spots internos ao primeiro círculo da difração (Figura 64c) mostra regiões mais claras, típicas de regiões cristalinas. A imagem do primeiro círculo da difração em campo escuro (Figura 64d) mostra as franjas de Moiré, indicando a presença de planos atômicos separados por distância 3,6 ̊̊. 


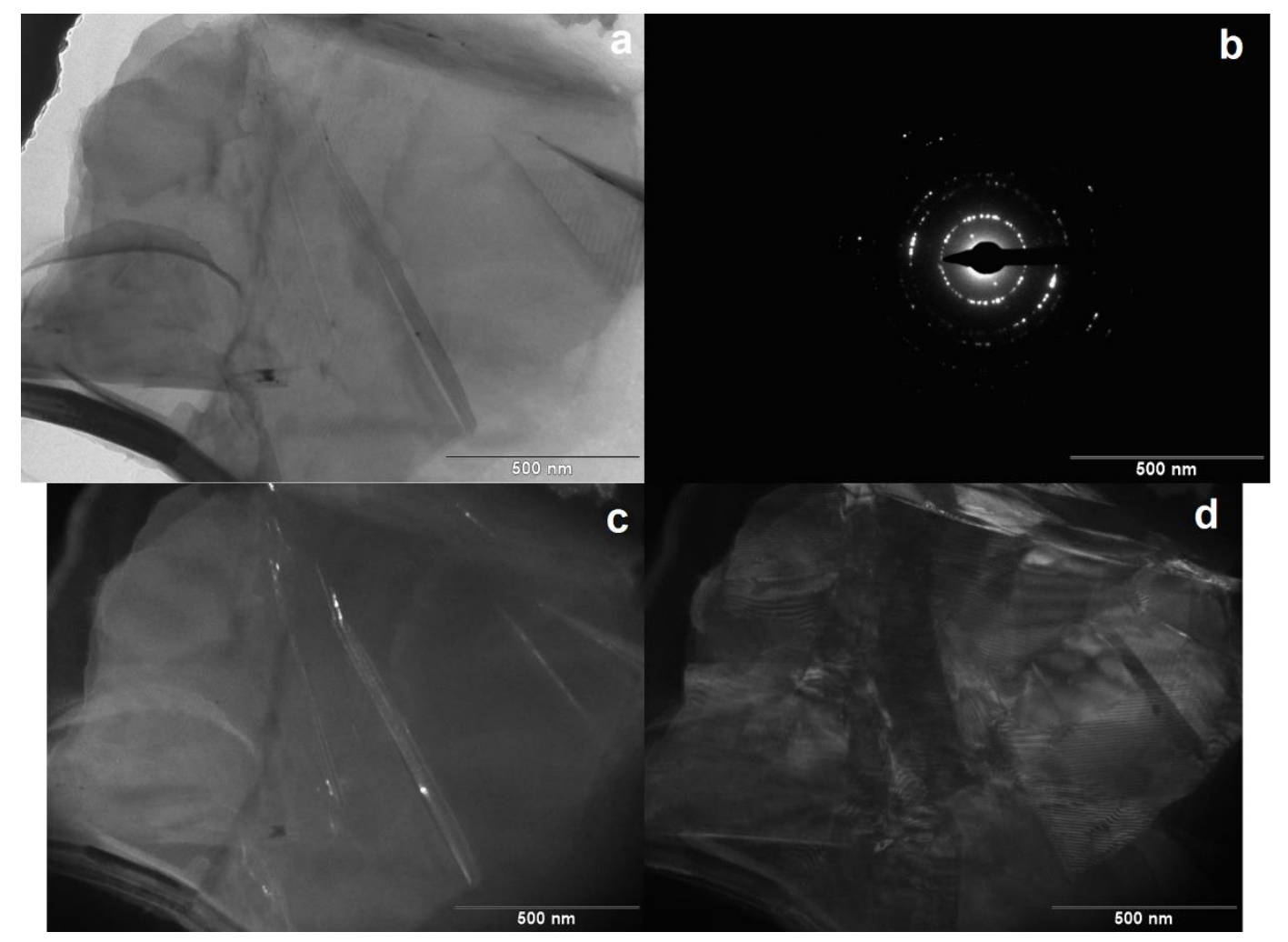

Figura 64: Imagens em TEM do RIO3: (a) nova região da amostra em campo claro; (b) padrão de difração de elétrons dessa região; (c) imagem de um dos spots internos em campo escuro; (d) imagem do primeiro círculo de difração em campo escuro.

Lino (2007) em sua dissertação de mestrado, apresentou dados teóricos mostrando que a formação de nanotubos e fulerenos de COF são energeticamente possíveis [ref]. Em especial, a energia de formação de fulerenos de COF-1 obtida foi de $0,15 \mathrm{eV}$, utilizando uma base SZ para o cálculo. Esse valor, segundo Lino, é menor do que para $\mathrm{C}_{60}$, ou seja, seria energeticamente mais favorável fazer fulerenos de COF do que puramente de carbonos.

Ao se analisar o RIO3 no HRTEM foi possível observar a presença de estruturas híbridas entre fulerenos e nanotubos com multi-paredes: as nanocebolas' (Figura 65), basicamente formada por estruturas circulares, como fulerenos, dispostas concentricamente uma dentro das outras (Han et al., 2011). É importante salientar que a quantidade de nano-cebolas obtidas não foi estatisticamente representativa na amostra, entretanto observá-las sendo formadas a partir do RIO3 pode abrir uma importante janela de pesquisa sobre como ajustar a síntese do COF de forma que haja a formação dessas nano-

\footnotetext{
' Do inglês, nano onions.
} 
cebolas. A possibilidade de funcionalização desse tipo de estrutura a partir da adição de grupos funcionais permite novas aplicações para ela (Bartelmess e Giordani, 2014).

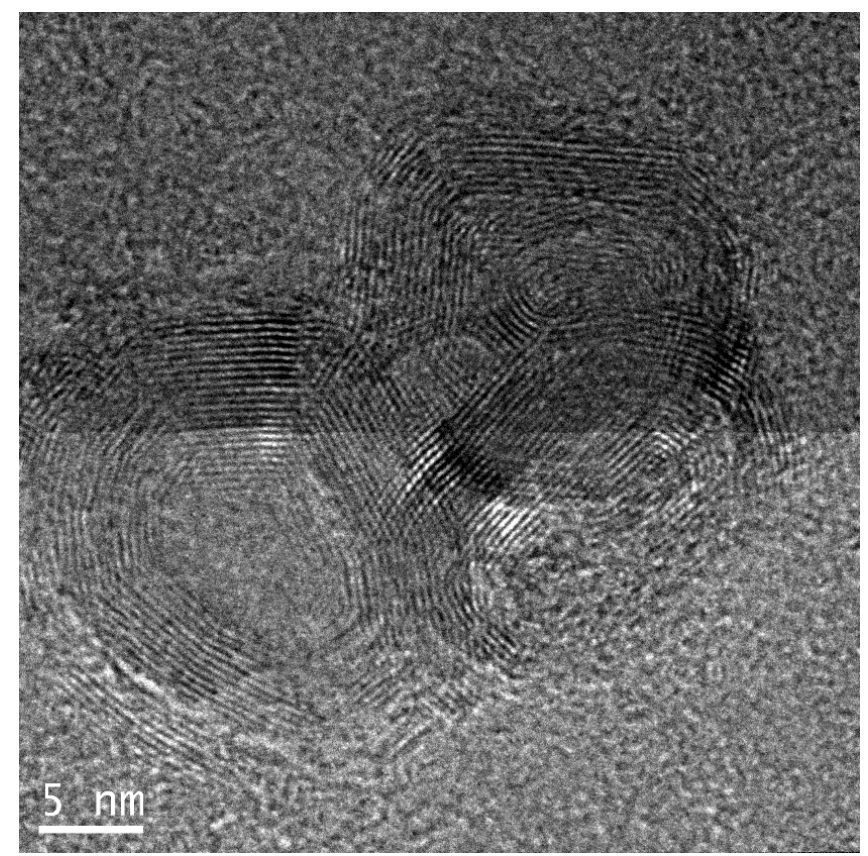

Figura 65: Nano-cebolas formadas a partir do RIO3.

\subsection{1. \\ Síntese e caracterização do RIO5 e RIO6}

Como os COFs são caracterizados por suas altas áreas específicas, foram sintetizados dois outros materiais para tentar contornar os problemas de rotação e deslocamento das folhas que poderiam indisponiblizar o acesso aos poros como evidenciado para o RIO2 e RIO3. Para tanto, foi mantido o composto 3 e utilizouse duas outras fontes de aldeído, o 8 e o triformilbenzeno (15), para obter o RIO5 e RIO6, respectivamente. A escolha desses blocos de montagem deveu-se por o primeiro ser uma molécula maior em comparação com os blocos usados anteriormente e que poderia gerar poros maiores, e o segundo não apresentar grupos hidroxila que poderiam ser novos sítios de interações inter e intramoleculares. O RIO5 foi obtido como um sólido amarelo escuro em rendimento de $77 \%$ e o RIO6 como um sólido verde escuro em rendimento de $80 \%$.

Os espectros de IV dos dois COFs são comparados. Era esperado que apresentassem espectros semelhantes, uma vez que somente apresentam como grupos funcionais as iminas e os grupos $\mathrm{N}-\mathrm{H}$ dos carbazóis. Foi possível observar 
a ausência de bandas relativas a aminas primárias e aldeídos, o que indicou que a reação foi concluída. A confirmação da formação da imina foi feita com a atribuição das bandas em 1683 e $1693 \mathrm{~cm}^{-1}$ para RIO5 e RIO6, respectivamente, que correspondem ao estiramento de $\mathrm{C}=\mathrm{N}$ de iminas. As bandas de $\mathrm{N}-\mathrm{H}$ do carbazol estão em 3379 e 3389 para RIO5 e RIO6, respectivamente. Por fim, bandas relativas aos estiramentos $\mathrm{C}-\mathrm{H}$ dos anéis aromáticos para o RIO5 aparecem em 2928, 2873, 1601 e 1488 cm$^{-1}$, enquanto que para o RIO6 aparecem em 2926, 2871, 1598 e $1940 \mathrm{~cm}^{-1}$.

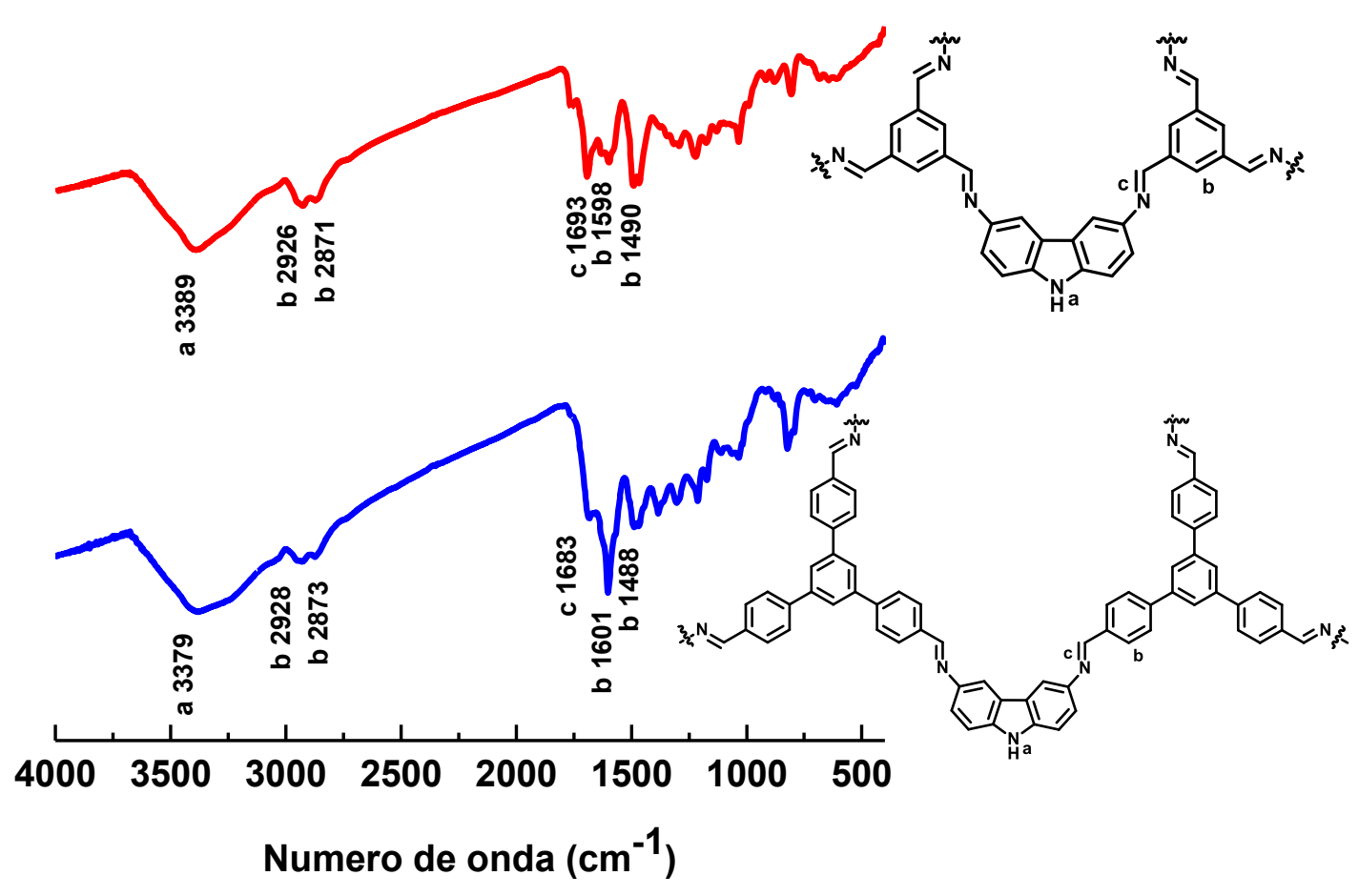

Figura 66: Espectros de IV do RIO5 (azul) e RIO6 (vermelho).

Os padrões de difração de raios- $X$ indicaram perfis distintos entre esses COFs. O RIO5 apresentou baixa cristalinidade, entretanto picos em 16,1 $1^{\circ}, 18,7^{\circ}$, $26,2^{\circ}$ e $29,4^{\circ}$ aparecem finos e com baixa intensidade, indicando que o material pode ter tendência a ser cristalino com mais tempo de síntese. O RIO6 apresentou perfil de material amorfo. Comparando-se com RIO2 e RIO3, seria esperado que esses materiais apresentassem algum grau de cristalinidade, entretanto o RIO6 contrariou as expectativas. 


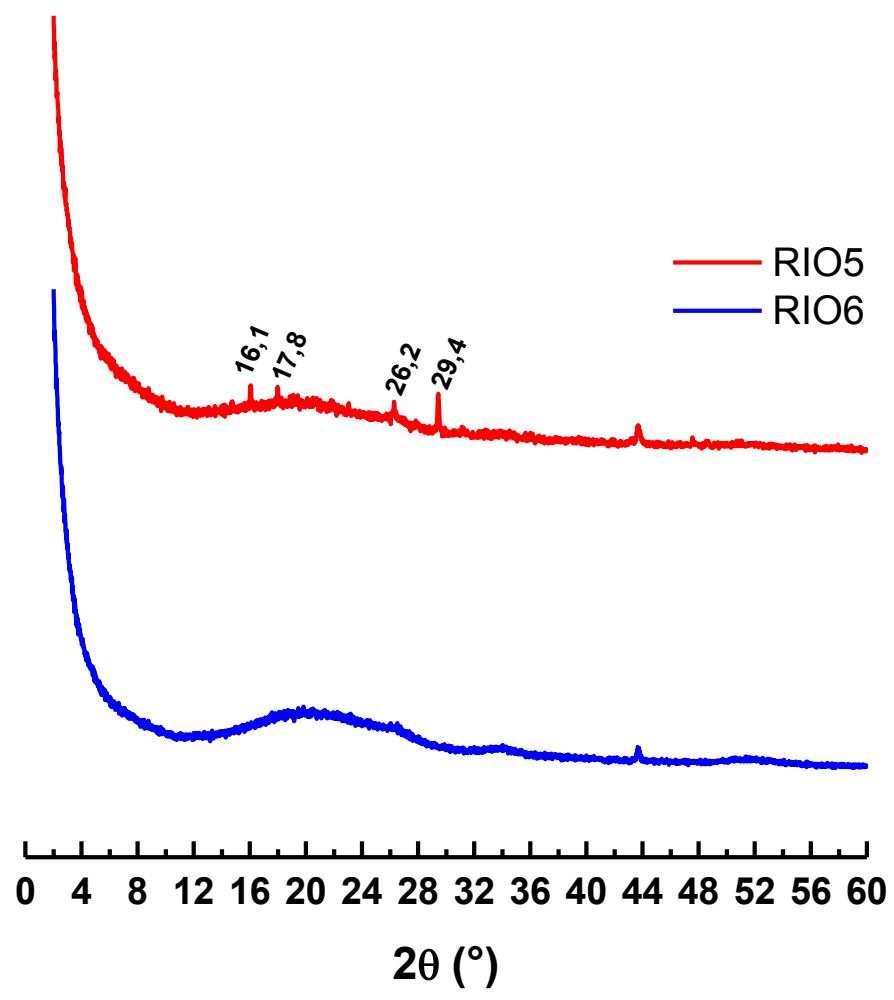

Figura 67: Difratogramas de raios-X do RIO5 e RIO6.

Para verificar o efeito da presença de hidroxilas no bloco de montagem, o RIO6 foi sintetizado com o 15. Foram calculadas seis novas estruturas cristalinas para ele, seguindo os mesmos padrões de deslocamento e rotação do RIO2 e RIO3, sendo assim denominados: AA-RIO6, AA'-RIO6, AB-RIO6, AB'-RIO6, SRIO6 e I-RIO6. A partir das energias de empilhamento (Tabela 4) foi possível verificar que a estrutura mais estável era a AB-RIO6 (Figura 68).

Tabela 4: Energias de empilhamento para as conformações do RIO6.

\begin{tabular}{cc}
\hline Conformação & Energia de empilhamento (kcal mol ${ }^{-1}$ ) \\
AA-RIO6 & 0 \\
AA'-RIO6 & $-1568,8$ \\
AB-RIO6 & $-1615,8$ \\
AB'-RIO6 & $-1593,9$ \\
S-RIO6 & $-1584,5$ \\
I-RIO6 & $-1600,1$ \\
\hline
\end{tabular}




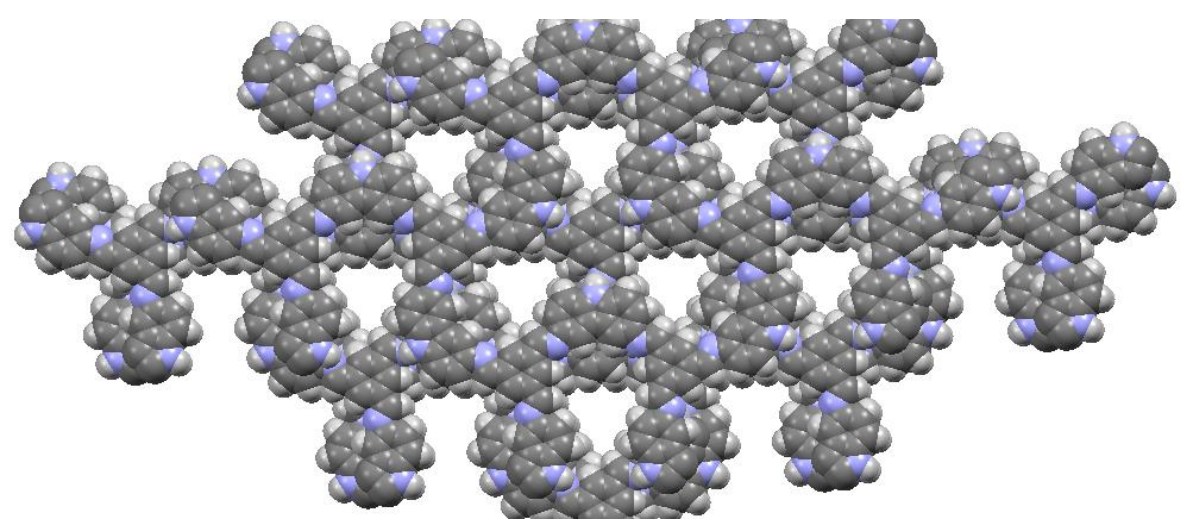

Figura 68: Estrutura do AB-RIO6.

A estrutura AB-RIO6 consiste nos grupos 15 empilhados com conformação estrelada, sendo os átomos de hidrogênio de uma folha alinhados aos grupos imina da folha seguinte. A conformação apresenta os grupos imina alinhados de forma que seus momentos de dipolo se cancelam (Figura 69).

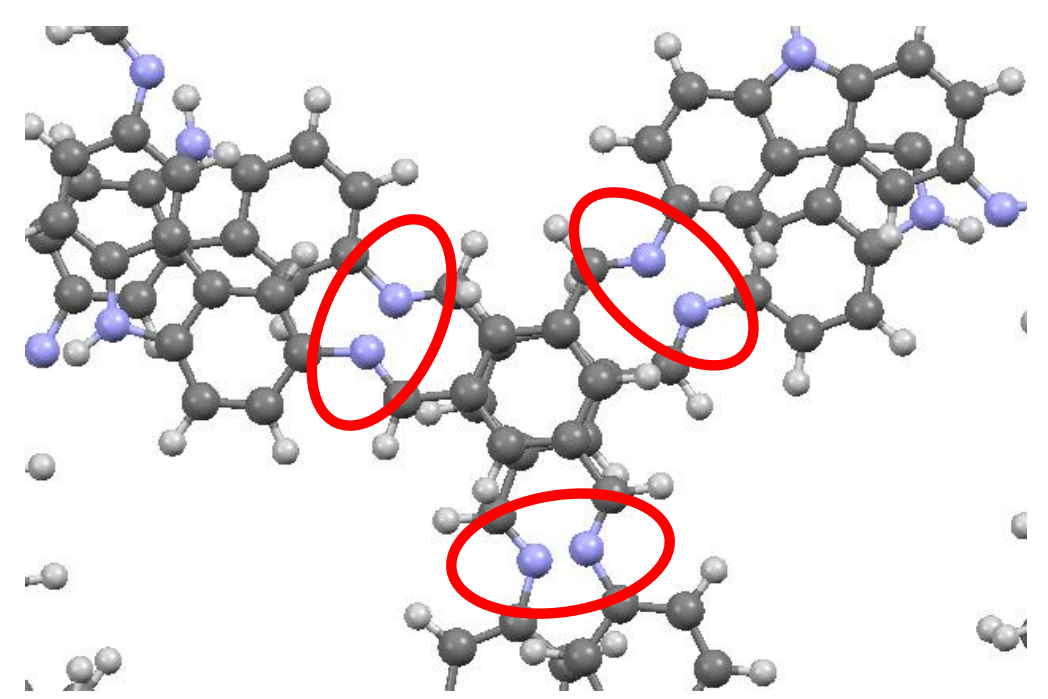

Figura 69: Grupos imina alinhados para cancelar os momentos de dipolo na conformação AB-RIO6.

Por fim, os COFs foram avaliados quanto à porosidade. As isotermas de adsorção/dessorção de $\mathrm{N}_{2}$ mostraram novamente o perfil de material não-poroso com isoterma do tipo II para o RIO5 (Figura 70) e RIO6 (Figura 71). A partir da análise feita pelo método multi-point BET, as áreas específicas obtidas para os materiais foram 186 e $12 \mathrm{~m}^{2} \mathrm{~g}^{-1}$ para RIO5 e RIO6, respectivamente. 


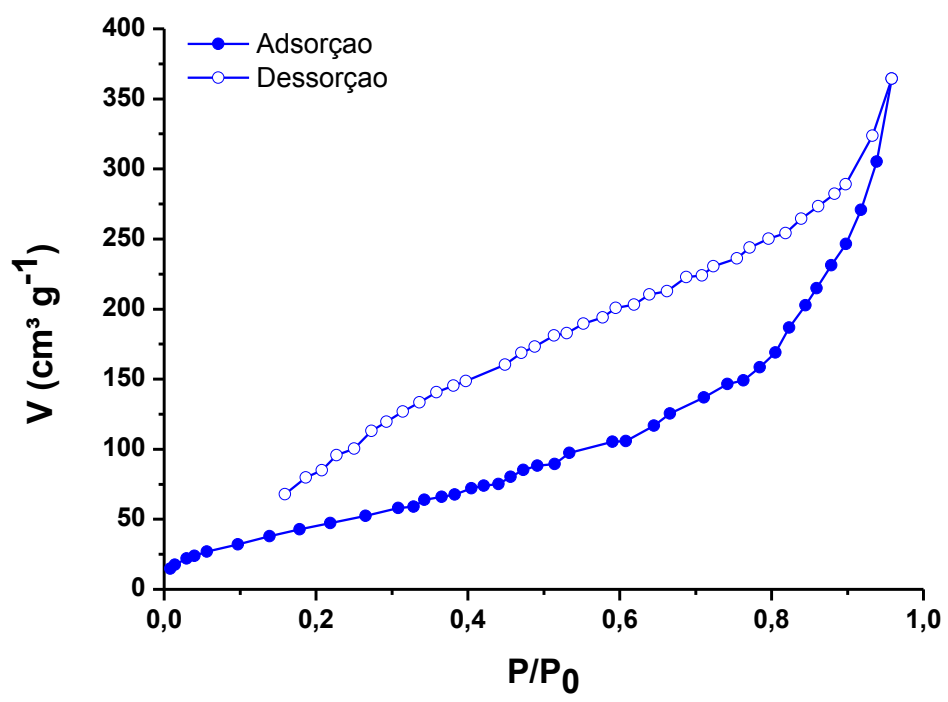

Figura 70: Isoterma de adsorção/dessorção de $\mathrm{N}_{2}$ do RIO5.

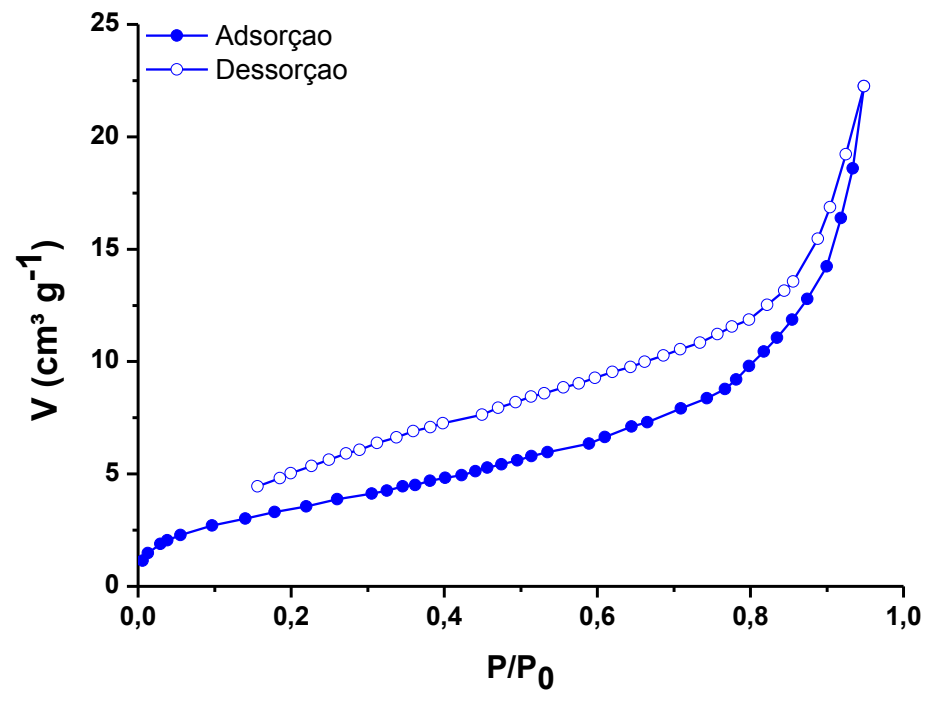

Figura 71: Isoterma de adsorção/dessorção de $\mathrm{N}_{2}$ do RIO6. 


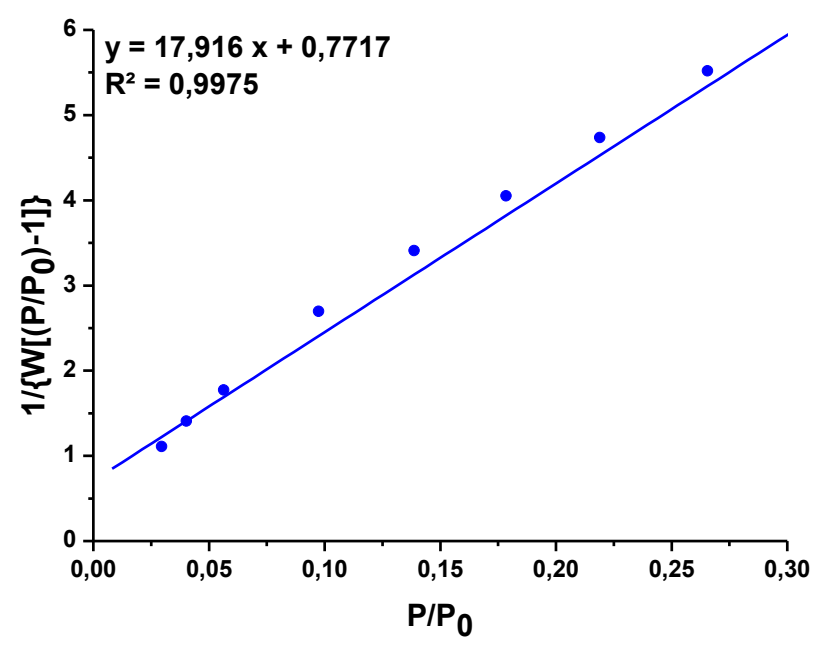

Figura 72: Gráfico multi-point BET para o RIO5.

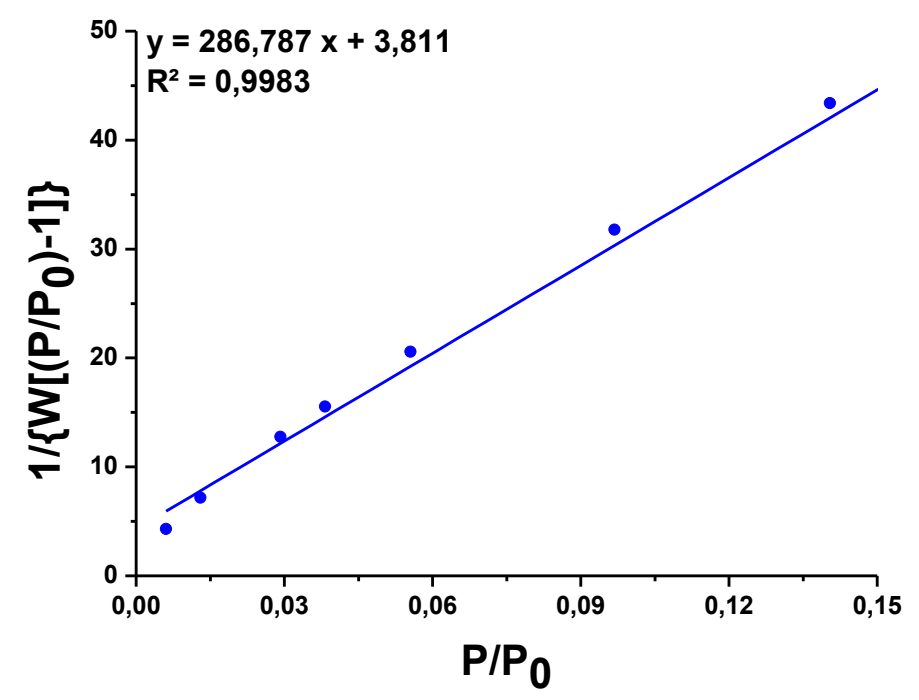

Figura 73: Gráfico multi-point BET para o RIO6.

A escolha desses blocos de montagem com aldeídos não resolveu o problema de inacessibilidade dos poros dos COFs. Para o RIO5 foi obtido um material com poros de tamanho médio de 1,78 nm (Figura 74) e para o RIO6 poros de 1,7 nm de diâmetro (Figura 75). O valor obtido para o RIO5 não era esperado. Alguns COFs já foram sintetizados com o bloco de montagem 8, como o COF-43 obtido por Uribe-Romo et al. (2011) que apresentou diâmetro de poro de 3,8 nm. Nesse mesmo trabalho os pesquisadores obtiveram o COF-42 usando o bloco 15. $\mathrm{O}$ diâmetro de poro obtido foi de $2,8 \mathrm{~nm}$, maior que o encontrado para o RIO6. Ao 
se comparar esse exemplo já publicado com os cálculos teóricos, também é suspeito que os poros do RIO6 estejam inacessíveis para a análise das isotermas de adsorção/dessorção, e essa conclusão pode ser estendida ao RIO5.

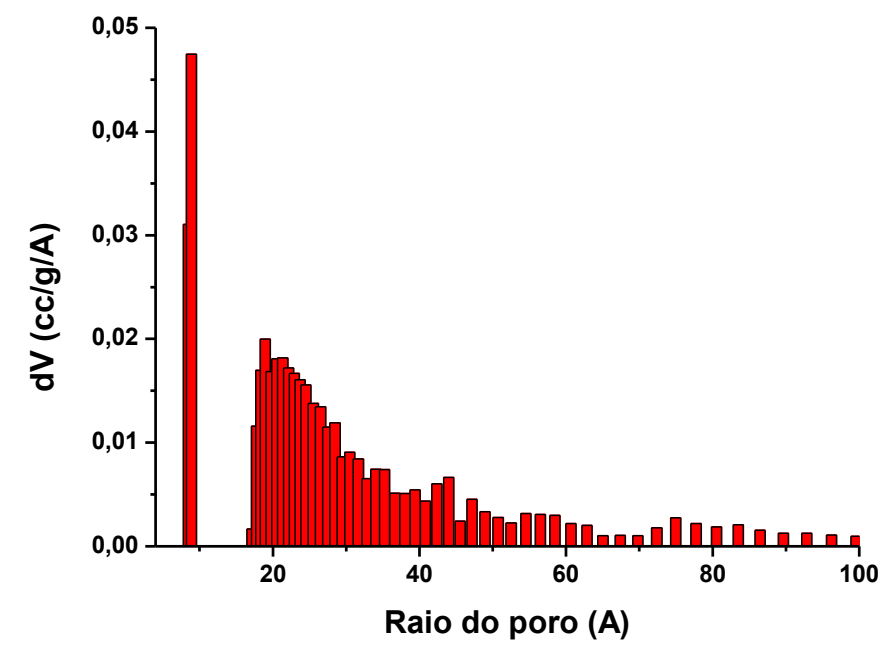

Figura 74: Distribuição de tamanho de poros do RIO5 por NLDFT.

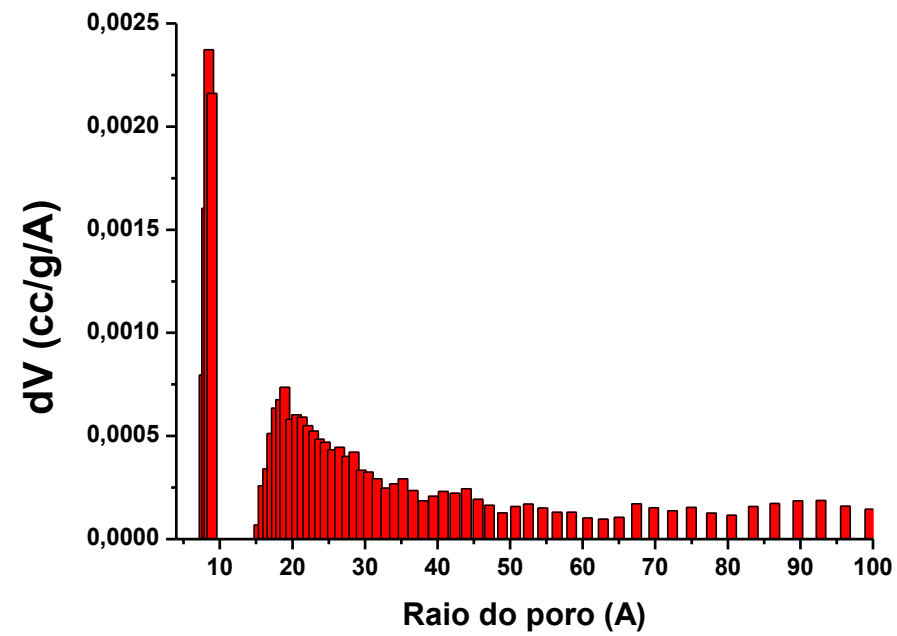

Figura 75: Distribuição de tamanho de poros do RIO6 por NLDFT. 


\section{4 \\ Conclusão}

Nesse trabalho foram sintetizados quatro novos materiais orgânicos baseados em carbazóis: RIO2, RIO3, RIO5 e RIO6. Esses materiais apresentaram perfil de materiais não-porosos com isotermas do tipo II de $\mathrm{N}_{2}$ contrariando as expectativas. De acordo com os cálculos teóricos, esses materiais apresentam conformações que não consistem no alinhamento dos poros, o que impedem a acessibilidade dos poros a fim de minimizar interações eletrostáticas e anular momentos de dipolo entre os heteroátomos. Isso vai de encontro com os resultados obtidos para todos os COFs bidimensionais já publicados, que apresentam COFs com poros perfeitamente empilhados mesmo com a presença de átomos de nitrogênio e oxigênio ao longo da rede.

Esse resultado, no entanto, não impede que o material possa ser aplicado onde a presença de poros não se faz tão importante, como na fabricação de dispositivos eletrônicos. A estrutura desses COFs apresenta sistema m-n-m que pode ser explorado como materiais semicondutores ou condutores.

Por fim, ressalta-se a importância da contribuição do trabalho à química reticular. Esse é o segundo trabalho com poros com o formato apresentado. Aparentemente esse tipo de poro não é interessante para se ter no material quando o mesmo sofre deslocamentos ou rotações de suas folhas. Além disso, a ausência de modelos teóricos para NLDFT prejudica a análise do mesmo, pois poros do tipo fenda ou cilíndricos não são o melhor modelo para esse caso. 


\section{5 \\ Perspectivas futuras}

Tendo em vista os resultados e conclusões obtidos, as próximas etapas desse trabalho seguem três caminhos. O primeiro vai se basear no princípio de que os átomos de nitrogênio dos carbazóis contribuem para o deslocamento e rotação dos poros dos COFs. Para isso, COFs baseados em fluorenos podem ser interessantes por esse composto apresentar apenas carbonos e hidrogênios em sua estrutura. Entretanto, a obtenção do 3,6-diaminofluoreno requer uma rota sintética mais complexa que para o composto 3, uma vez que as posições preferenciais para entrada dos grupos amino seriam nos carbonos 2 e 7.

Conforme citado nas análises da isoterma de adsorção/dessorção de $\mathrm{N}_{2}$, alguns trabalhos mostram que materiais que tendem a ser $\mathrm{N}_{2}$-fóbicos apresentam boa capacidade de adsorção de $\mathrm{CO}_{2}$. Numa próxima etapa, esses materiais sintetizados nesse trabalho serão testados quanto a essa capacidade como uma possível aplicação. No caso desses COFs, o uso de blocos de montagem a partir de carbazol pode ter apelo industrial em caso de resultados satisfatórios, por ser um produto natural barato. Outros materiais porosos orgânicos feitos a partir de carbazol apresentaram boa capacidade de adsorção, como descrito por Liu, Y. et al. (2014)

Confirmado que o material apresenta poros inacessíveis, aplicações onde não há necessidade de porosidade no material podem ser testadas. A obtenção de materiais orgânicos optoeletrônicos pode ser realizada uma vez que, como citado na Introdução desse trabalho, carbazóis são comumente usados na síntese de polímeros condutores e semicondutores. Para isso, a obtenção de filmes finos desses materiais é imprescindível. Alguns trabalhos já obtiveram filmes finos a partir de COFs (Colson et al., 2011; Colson et al., 2015; Deblase et al., 2015; Medina et al., 2015). 


\section{6 \\ Procedimento experimental}

\section{1. Materiais e métodos}

Os reagentes e solventes utilizados foram adquiridos da Sigma-Aldrich Co. ou Vetec Química Fina Ltda. O composto triformilfenol foi sintetizado por outros integrantes do grupo de pesquisa da professora Camilla Buarque. Os solventes mesitileno e 1,4-dioxana foram usados após secagem com sódio metálico seguida de destilação. Os demais foram usados assim como foram adquiridos.

O acompanhamento das reações foi feito através da técnica de cromatografia em camada fina usando placas de alumínio com gel sílica 60-F254 da marca SiliCycle Inc.

Para identificação dos compostos sintetizados, os espectros de IV foram obtidos em espectrômetro FTLA-2000, no aparelho da Central Analítica do Departamento de Química Inorgânica do IQ-UFRJ, cobrindo a faixa de 400 a 4000 $\mathrm{cm}^{-1}$ e a amostra foi lida em uma pastilha de $\mathrm{KBr}$. Os espectros de $\mathrm{RMN}-{ }^{1} \mathrm{H}$ em solução foram obtidos em espectrômetro Bruker Avance III HD-400 MHz com 9,4 T de campo magnético, da Central Analítica do Departamento de Química da PUC-Rio. Cerca de $1 \mathrm{mg}$ do composto foi dissolvido em $\mathrm{CDCl}_{3}$, acetona- $d_{6}$ ou DMSO- $d_{6}$ num tubo de $5 \mathrm{~mm}$ o.d. Os espectros de massas de alta resolução foram obtidos em espectrômetro Bruker micrOTOF-QII com uso de formato de sódio como padrão de calibração, disponível no NPPN-UFRJ.

Para a caracterização dos COFs, os espectros de IV foram adquiridos no mesmo equipamento e nas mesmas condições dos blocos de montagem, como descrito acima. O espectro de ressonância magnética nuclear de ${ }^{13} \mathrm{C}$ em estado sólido por polarização cruzada com rotação em torno do ângulo mágico (CP/MAS $\mathrm{RMN}-{ }^{13} \mathrm{C}$ ) foi obtido em equipamento Bruker Avance III, disponível no Instituto de Química da UFRJ, operando a 9,4 T, tempo de contato de $3 \mathrm{~ms}$, frequência de Larmor de 100,3 MHz e delay de 4 s. A amostra foi colocada em rotor de $\mathrm{ZrO}_{2}$ e a temperatura de análise foi ambiente.

A obtenção da isoterma de adsorção/dessorção de $\mathrm{N}_{2}$, que avalia a porosidade do material, foi realizada em equipamento Quantachrome NOVA 1200. 
Pesou-se cerca de $30 \mathrm{mg}$ do COF em um tubo de BET com $9 \mathrm{~mm}$ o.d. A amostra foi inicialmente seca usando bomba de vácuo dinâmico à $10^{-3}$ Torr e aquecida utilizando as seguintes rampas de temperatura: $60^{\circ} \mathrm{C}$ por $30 \mathrm{~min}, 80^{\circ} \mathrm{C}$ por 30 $\min , 100^{\circ} \mathrm{C}$ por $30 \mathrm{~min}, 130^{\circ} \mathrm{C}$ por $30 \mathrm{~min}, 160^{\circ} \mathrm{C}$ por $30 \mathrm{~min}, 180^{\circ} \mathrm{C}$ por $12 \mathrm{~h}$. A amostra foi então colocada à $77 \mathrm{~K}$, sendo a temperatura mantida em banho de nitrogênio líquido, e 1 atm para proceder com a obtenção das isotermas. A área específica foi obtida pelo método multi-point BET, enquanto que o volume dos poros e a distribuição de tamanho dos poros foram obtidos pelo método DFT.

Para avaliar a estrutura cristalina dos materiais foi realizada a Difração de Raios-X pelo método do pó utilizando um difratômetro D8 Discover da Bruker com detector LynxEye, tubo de cobre operando a $40 \mathrm{kV}$ e $40 \mathrm{~mA}$, tempo de 1,5 s e passo de $0,02^{\circ}$, disponível no Departamento de Engenharia Química e de Materiais da PUC-Rio. As análises de SAXS foram realizadas em difratômetro Nanostar da Bruker equipado com detector Vantec 2000 e fonte de raios-X um tubo de Cu-Ka operando a $40 \mathrm{kV}$ e $35 \mathrm{~mA}$. As amostras foram previamente submetidas a vácuo por $2 \mathrm{~h}$ e introduzidas no porta-amostras entre dois filmes finos de kapton.

As análises morfológicas e difração de elétrons foram realizadas em Microscópio Eletrônico de Transmissão de Alta Resolução (HRTEM) FEI Titan G2 80-300, disponível no INMETRO, operando a $300 \mathrm{keV}$ equipado com filtro de imagem Gatan (GIF), modo microscopia eletrônica de varredura por transmissão (STEM) e espectrômetro de raios-X por dispersão de energia (EDX).

As análises termogravimétricas foram realizadas em equipamento Pyris 1 TGA da Perkin Elmer, disponível no Departamento de Química da PUC-Rio, com faixa de trabalho de 20 a $900{ }^{\circ} \mathrm{C}$ e taxa de aquecimento de $10^{\circ} \mathrm{C} \mathrm{min}{ }^{-1}$. 


\section{2. \\ Obtenção dos blocos de montagem e compostos modelo}

\subsection{1.}

Síntese do 3,6-dinitro-9H-carbazol (2)

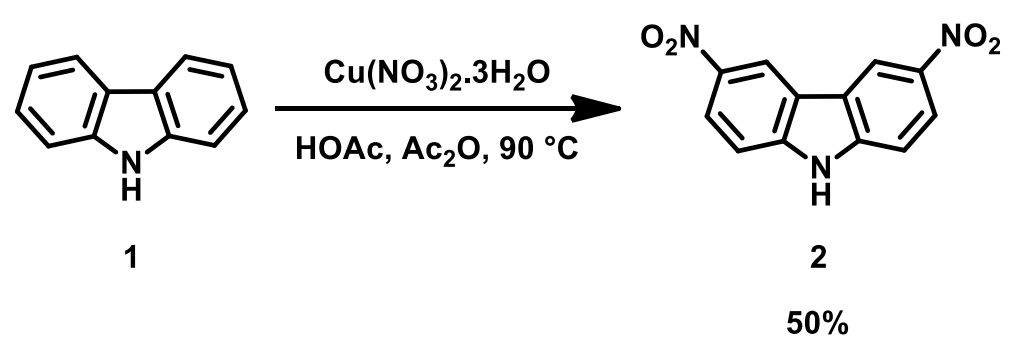

Em um balão de $100 \mathrm{~mL}$ pesou-se $9,7958 \mathrm{~g}(40,5 \mathrm{mmol})$ de $\mathrm{Cu}\left(\mathrm{NO}_{3}\right)_{2} \cdot 3 \mathrm{H}_{2} \mathrm{O}$ e adicionou-se uma mistura contendo $30 \mathrm{~mL}$ de anidrido acético e $20 \mathrm{~mL}$ de ácido acético glacial. A suspensão formada permaneceu sob agitação por 5 min à temperatura ambiente. Em seguida, a suspensão foi colocada em banho de gelo, água e $\mathrm{NaCl}$ à $-5^{\circ} \mathrm{C}$ e $4,1868 \mathrm{~g}(25,1 \mathrm{mmol})$ de $9 \mathrm{H}$-carbazol foram adicionados em pequenas porções ao longo de $10 \mathrm{~min}$, sob agitação. A adição lenta garantiu que a temperatura não aumentasse rapidamente e que o meio reacional não projetasse para fora do balão. A reação permaneceu sob agitação constante por $30 \mathrm{~min}$ até alcançar a temperatura ambiente. Após esse tempo, a temperatura foi aumentada para $90^{\circ} \mathrm{C}$ por mais $30 \mathrm{~min}$.

Após o fim da reação, o conteúdo do balão da reação foi vertido em $500 \mathrm{~mL}$ de água destilada, sendo observada a formação de um precipitado amarelo que foi filtrado a vácuo e lavado com cerca de $300 \mathrm{~mL}$ de água destilada. $O$ sólido foi, então, dissolvido em solução contendo $25,3218 \mathrm{~g}$ de $\mathrm{KOH}, 250 \mathrm{~mL}$ de água destilada e $250 \mathrm{~mL}$ de etanol. A mistura obtida, de coloração vermelha, foi mantida sob agitação constante à temperatura ambiente por $1 \mathrm{~h}$, sendo em seguida filtrada e recolhida a solução obtida no kitassato. A solução foi acidificada com $\mathrm{HCl}$ concentrado até mudança de cor para amarelo. Observou-se a formação de um precipitado amarelo que foi filtrado, lavado três vezes com $200 \mathrm{~mL}$ de água destilada e seco em estufa a $100{ }^{\circ} \mathrm{C}$. O sólido foi transferido para o balão, adicionado cerca de $20 \mathrm{~mL}$ de acetona, o solvente evaporado no rotaevaporador e os resquícios de solvente foram eliminados sob alto vácuo. Foram obtidos 3,2360 g de 3,6-dinitro-9H-carbazol, em rendimento de 50\%.

Características do produto obtido: 
- Ponto de fusão: $385^{\circ} \mathrm{C}$

- $\mathrm{RMN}-{ }^{1} \mathrm{H}$ (acetona- $d_{6}$, em ppm): 12,08 (s, 1H); 9,46 (d, 2,2 Hz, 2H); 8,49 (dd, 2,3 e 9,0 Hz, 2H); 7,88 (d, 9,0 Hz, 2H).

- MS: valor calculado de $[\mathrm{M}+\mathrm{Na}]=280,032876$; valor obtido de $[\mathrm{M}+\mathrm{Na}]$ $=280,0329$.

\subsection{2.}

Síntese do 3,6-diamino-9H-carbazol (3)<smiles>O=[N+]([O-])c1ccc2[nH]c3ccc([N+](=O)[O-])cc3c2c1</smiles>

2

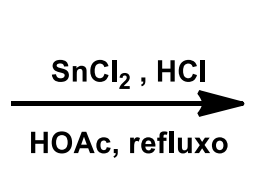

HOAc, refluxo<smiles>Nc1ccc2[nH]c3ccc(N)cc3c2c1</smiles>

3

$71 \%$

Em um balão de $100 \mathrm{~mL}$ pesou-se 1,9980 g de 3,6-dinitro-9H-carbazol (7,8 mmol) e 15,4365 $\mathrm{g}$ de $\mathrm{SnCl}_{2}$ anidro. Adicionou-se $48 \mathrm{~mL}$ de $\mathrm{HOAc}$ e $8 \mathrm{~mL}$ de $\mathrm{HCl}$ concentrado. A reação foi deixada sob refluxo com atmosfera de $\mathrm{N}_{2}$ e agitação constante por $24 \mathrm{~h}$. Após esse tempo, o meio reacional foi vertido em $400 \mathrm{~mL}$ de solução de $\mathrm{NaOH} 20 \%$ e observou-se a formação de um precipitado marrom claro, que foi filtrado à vácuo e lavado com água destilada. O produto foi seco na linha de vácuo com aquecimento a $100{ }^{\circ} \mathrm{C}$ obtendo-se 1,0796 g de sólido cinza, em rendimento de $71 \%$.

Características do produto obtido:

- $\mathrm{RMN}-{ }^{1} \mathrm{H}$ (DMSO- $d_{6}$, em ppm): 10,11 (s, 1H); 7,08 (d, 2,2 Hz, 2H); 6,67 (dd; 9,0 e 2,3 Hz, 2H); 4,57 (br, 2H).

- MS: valor calculado de $[\mathrm{M}+\mathrm{H}]=198,102574$; valor obtido de $[\mathrm{M}+\mathrm{Na}]$ $=198,102574$. 


\subsection{3.}

\section{Síntese do triformilfloroglucinol (4)}<smiles>Oc1cc(O)cc(O)c1</smiles>

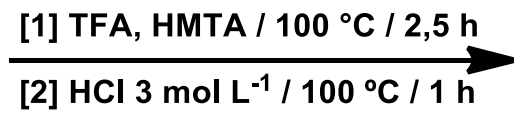<smiles>O=Cc1c(O)c(C=O)c(O)c(C=O)c1O</smiles>

$20 \%$

Em um balão de $500 \mathrm{~mL}$ pesou-se $6,0114 \mathrm{~g}$ de floroglucinol $(47,7 \mathrm{mmol}) \mathrm{e}$ adicionou-se $90 \mathrm{~mL}$ de ácido trifluoroacético, formando uma suspensão que foi colocada sob agitação constante. Em um bécher de $50 \mathrm{~mL}$ pesou-se $15,1882 \mathrm{~g}$ de hMTA (108 mmol) que foi adicionado à suspensão em pequenas porções, observando liberação de gás e mudança de cor para amarelo. Após o fim de sua adição, a reação foi mantida sob agitação constante, à $100{ }^{\circ} \mathrm{C}$ por $2,5 \mathrm{~h}$ sob atmosfera de argônio.

Após esse tempo, adicionou-se $150 \mathrm{~mL}$ de $\mathrm{HCl} 3 \mathrm{~mol} \mathrm{~L}^{-1}$ lentamente e a reação continuou por mais $1 \mathrm{~h}$ sem a atomosfera de argônio. A cor da solução ficou castanha. Após o fim da reação, dividiu-se o conteúdo do balão em duas partes iguais e cada uma foi extraída com diclorometano $(4 \times 50 \mathrm{~mL})$. As fases orgânicas foram secas com $\mathrm{Na}_{2} \mathrm{SO}_{4}$ anidro e após filtração utilizando papel de filtro, esta foi evaporada em rotaevaporador e os resquícios de solvente foram eliminados sob alto vácuo, obtendo $1,9851 \mathrm{~g}$ de sólido de cor amarela com rendimento de $20 \%$.

Características do produto obtido:

- Ponto de fusão: $185^{\circ} \mathrm{C}$

- $\mathrm{RMN}-{ }^{-1} \mathrm{H}\left(\mathrm{CDCl}_{3}-d_{6}\right.$, em ppm): 14,14 (s, 3H); 10,18 (s, 3H). 
6.2.4.

Síntese do 2,4,6-tris((fenilamino)metileno)cicloex-1,3,5-triona (9)

3<smiles>Nc1ccccc1</smiles><smiles>O=Cc1c(O)c(C=O)c(O)c(C=O)c1O</smiles>

4

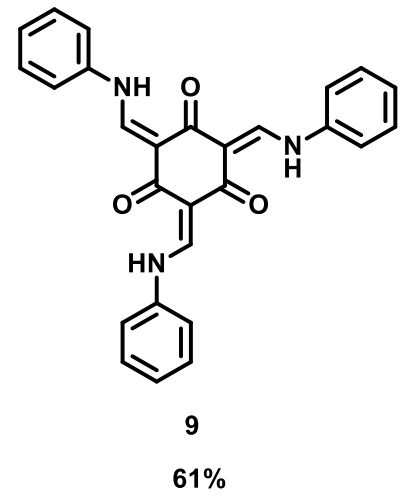

Em balão de $100 \mathrm{~mL}$, pesou-se $0,1631 \mathrm{~g}(0,76 \mathrm{mmol})$ de triformilfenol e adicionou-se $50 \mathrm{~mL}$ de etanol. Em um bécher pesou-se 0,5238 g (5,6 mmol) de anilina e adicionou-se $20 \mathrm{~mL}$ de etanol. Essa solução foi adicionada ao balão da reação e a reação foi deixada sob refluxo por 24 h. Após esse tempo, a reação foi resfriada à temperatura ambiente e o sólido formado foi filtrado e lavado com etanol ( $3 \times 20 \mathrm{~mL}$ ). Após secagem em alto vácuo, foi obtido 0,2073 g de sólido vermelho, em $61 \%$ de rendimento.

Características do produto obtido:

- $\quad$ CP/MAS RMN $-{ }^{13} \mathrm{C}$ (ppm): 185, 150, 139, 130, 125, 120, 117, 106. 


\subsection{5.}

Síntese do 2,4,6-tris((3-aminocarbazol)metileno)fenol (10)

3
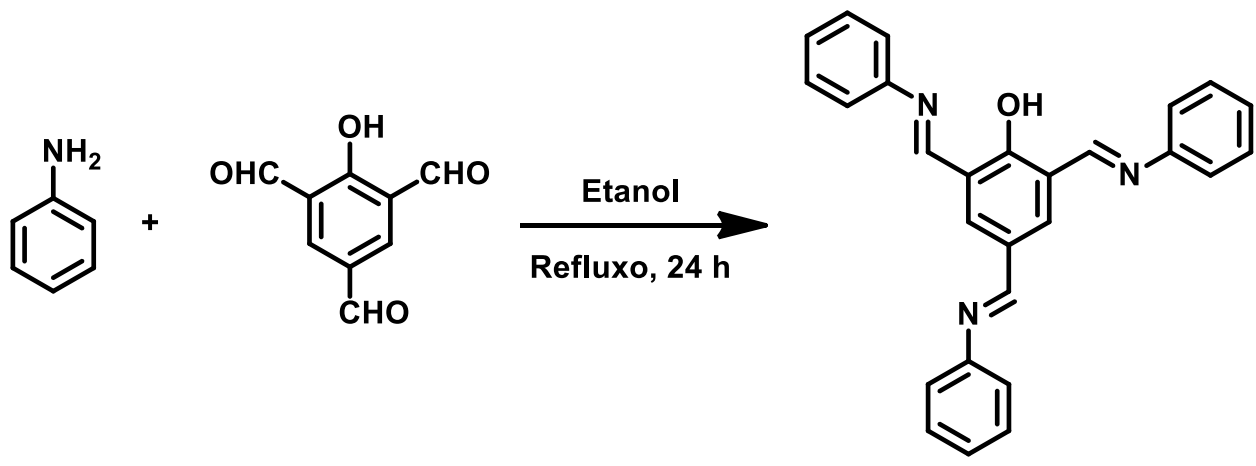

10

$43 \%$

O composto foi sintetizado de forma similar ao 9 sando-se $0,1418 \mathrm{~g}(0,80$ $\mathrm{mmol})$ de triformilfenol e $0,5163 \mathrm{~g}(5,4 \mathrm{mmol})$ de anilina para obter um sólido vermelho em $43 \%$ de rendimento.

Características do produto obtido:

- CP/MAS RMN- ${ }^{13} \mathrm{C}: 162,160,156,146,139,129,126,123,118$. 


\subsection{6.}

Síntese do 2,4,6-tribromoanilina (5)

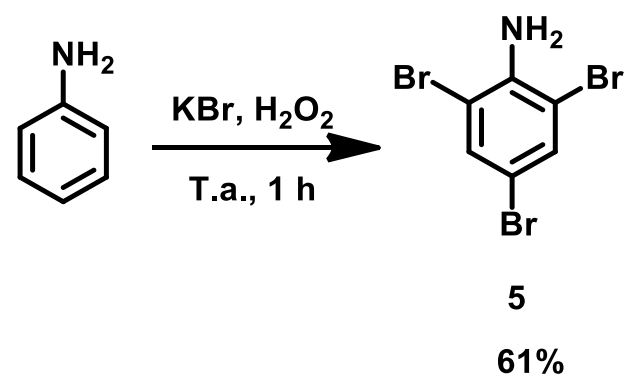

Em um balão de $100 \mathrm{~mL}$ pesou-se $1,1420 \mathrm{~g}(12,3 \mathrm{mmol})$ de anilina e adicionou-se $30 \mathrm{~mL}$ de solução aquosa de $\mathrm{HCl} 6 \%$ e ficou mantido a aproximadamente $15{ }^{\circ} \mathrm{C}$. Separadamente preparou-se uma solução contendo $5,2606 \mathrm{~g}$ (44,2 mmol) de $\mathrm{KBr}$ e $6,5 \mathrm{~mL}$ de $\mathrm{H}_{2} \mathrm{O}_{2}$. Essa solução foi adicionada ao balão da reação, gota a gota e a reação foi deixada sob agitação por $1 \mathrm{~h}$. Depois desse tempo, o produto foi filtrado e lavado com água. O sólido branco obtido foi seco na linha de vácuo por algumas horas em rendimento de $61 \%$.

Características do produto obtido:

- Ponto de fusão: $120^{\circ} \mathrm{C}$

- $\mathrm{RMN}-{ }^{1} \mathrm{H}\left(\mathrm{CDCl}_{3}-d_{6}\right.$, em ppm): 7,51 (s, 2H); 4,57 (s, 2H). 


\subsection{7.}

Síntese do 1,3,5-tribromobenzeno (6)

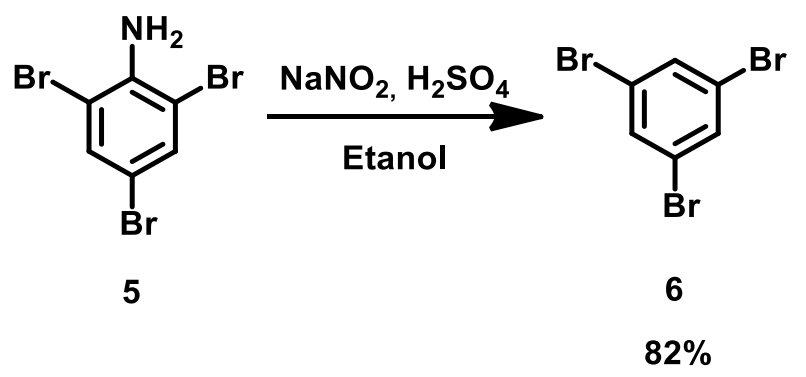

Em um balão de $10 \mathrm{~mL}$ pesou-se 1,0006 $\mathrm{g}$ de 2,4,6-tribromoanilina e foi adicionado $3,5 \mathrm{~mL}$ de etanol e $0,8 \mathrm{~mL}$ de benzeno. $O$ balão foi mantido num banho de água em ebulição até completa dissolução do material de partida. Em seguida foi adicionado 0,2 $\mathrm{mL}$ de $\mathrm{H}_{2} \mathrm{SO}_{4}$ e aqueceu-se o balão com condensador conectado até ebulição, quando em seguida foi retirado do aquecimento e adicionado $0,1001 \mathrm{~g}$ de $\mathrm{NaNO}_{2}$. O condensador foi conectado novamente ao balão e sob agitação vigorosa foi adicionado mais $0,1000 \mathrm{~g}$ de $\mathrm{NaNO}_{2}$. Por fim a reação ficou sob refluxo por 1,5 h. Após esse tempo, o balão foi resfriado e colocado em banho de água e gelo por $20 \mathrm{~min}$. O produto foi filtrado e lavado com cerca de 200 $\mathrm{mL}$ de água e seco na linha de vácuo por 24 h, obtendo-se assim um sólido vermelho em rendimento de $82 \%$.

Características do produto obtido:

- Ponto de fusão: $121^{\circ} \mathrm{C}$.

- $\mathrm{RMN}-{ }^{1} \mathrm{H}\left(\mathrm{CDCl}_{3}-d_{6}\right.$, em ppm): 7,62 (s, 3H). 


\subsection{8.}

Síntese do 1,3,5-tri(4-formilfenil)benzeno (8)
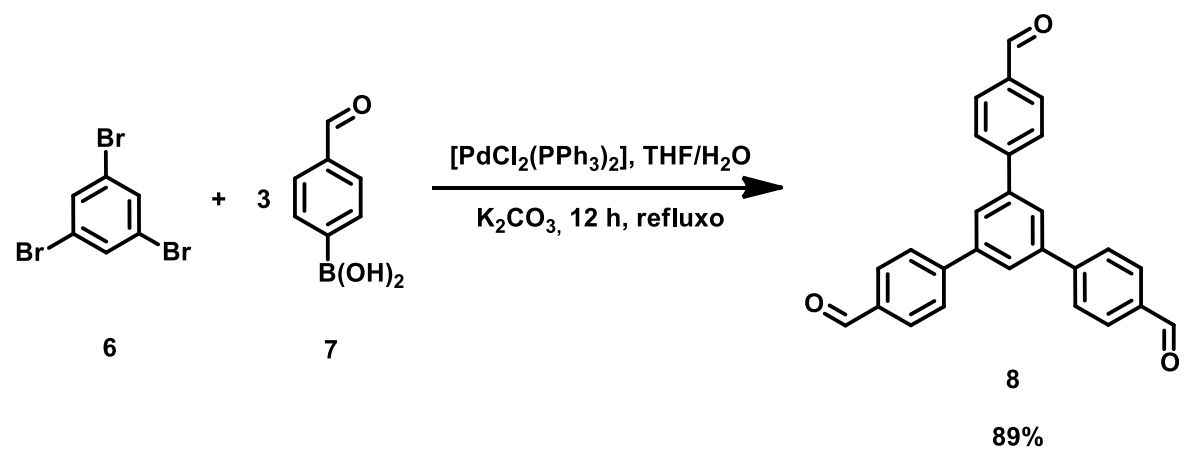

Em um balão de $25 \mathrm{~mL}$ pesou-se 0,2042 $\mathrm{g}(0,65 \mathrm{mmol})$ de tribromobenzeno e 0,3016 g (2,01 mmol) de ácido 4-formilborônico e em seguida foi adicionado 10 $\mathrm{mL}$ de THF. O balão foi conectado ao condensador e atmosfera modificada com $\mathrm{N}_{2}$. Em seguida foi adicionado $5 \mathrm{~mL}$ de solução aquosa $2 \mathrm{~mol} \mathrm{~L}^{-1}$ de $\mathrm{K}_{2} \mathrm{CO}_{3} \mathrm{e}$, por fim, $0,1863 \mathrm{~g}$ de $\left[\mathrm{PdCl}_{2}\left(\mathrm{PPh}_{3}\right)_{2}\right]$. A reação foi mantida sob refluxo por $14 \mathrm{~h}$. Após esse tempo o produto foi extraído com diclorometano $(4 \times 50 \mathrm{~mL})$. A fase orgânica foi seca com $\mathrm{NaSO}_{4}$ anidro, filtrada e evaporada em rotaevaporador. Após secagem em alto vácuo, foi obtido um sólido branco em $89 \%$ de rendimento.

Características do produto obtido:

- Ponto de fusão: $232-233^{\circ} \mathrm{C}$

- $\mathrm{RMN}-{ }^{1} \mathrm{H}\left(\mathrm{CDCl}_{3}-d_{6}\right.$, em ppm): 10,11 (s, 3H); 8,02 (d, 8,02 Hz, 6H), $7,91 \mathrm{H}(\mathrm{s}, 3 \mathrm{H}), 7,87(\mathrm{~d}, 8,02 \mathrm{~Hz}, 3 \mathrm{H})$. 


\section{3.}

\section{Obtenção dos COFs}

\subsection{1.}

\section{Síntese do RIO2}

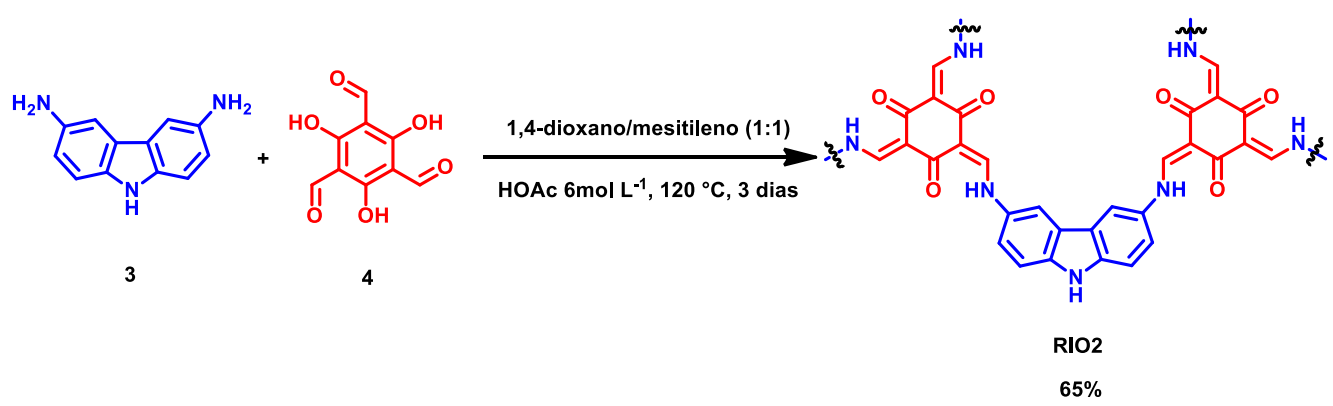

$0,1065 \mathrm{~g}(0,51 \mathrm{mmol})$ de triformilfloroglucinol e $0,1504 \mathrm{~g}(0,76 \mathrm{mmol})$ de 3,6diamino-9H-carbazol foram transferidos para um reator com $21,6 \mathrm{~mL}$ de uma mistura 1:1 de mesitileno e 1,4-dioxana, ambos destilados. $O$ reator foi colocado em banho de ultrassom por 5 min. Em seguida foi adicionado 4,2 $\mathrm{mL}$ de HOAc 6 mol L-1 , seguido de banho de ultrassom por $5 \mathrm{~min}$. $O$ reator foi fechado e a reação procedeu-se por 3 dias, sem agitação, em banho de óleo à $120^{\circ} \mathrm{C}$. Após esse tempo, o sólido marrom obtido foi filtrado ainda quente e lavado com clorofórmio ( $3 \times 10$ mL). O RIO2 foi, então, seco na linha de vácuo por 24 h, obtendo-se 0,1492 $\mathrm{g}$ de sólido marrom com $65 \%$ de rendimento.

\subsection{2.}

Síntese do RIO3
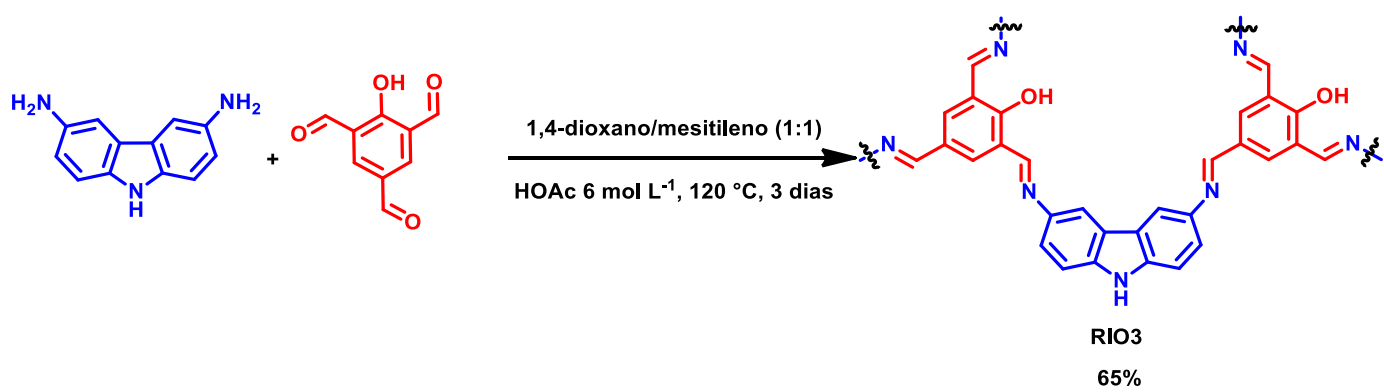

Em síntese similar ao RIO2, 0,0909 g (0,51 mmol) de triformilfenol e 0,1498 $\mathrm{g}(0,76 \mathrm{mmol})$ de 3,6-diamino-9H-carbazol reagiram na presença de HOAc $6 \mathrm{~mol}$ $\mathrm{L}^{-1}$, mesitileno e 1,4-dioxana para gerar $0,1386 \mathrm{~g}$ de um sólido preto em $65 \%$ de rendimento. 


\subsection{3.}

Síntese do RIO6

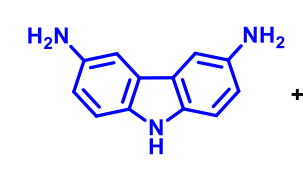

3

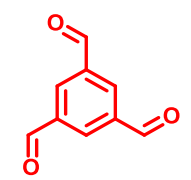

15

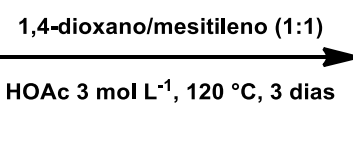

HOAc 3 molt $1,120^{\circ} \mathrm{C}, 3$ dias

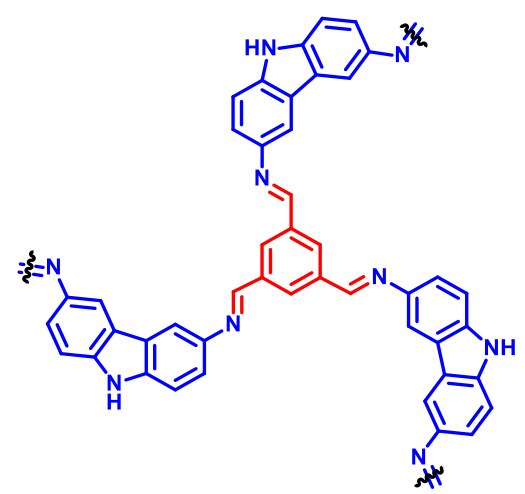

RIO6

$80 \%$

Em síntese similar ao RIO-2, 0,0332 g (2,04 mmol) de 1,3,5-triformilbenzeno e 0,0588 g (2,98 mmol) de 3 reagiram na presença de HOAc $3 \mathrm{~mol} \mathrm{~L}^{-1}$, mesitileno

e 1,4-dioxana para gerar $0,0651 \mathrm{~g}$ de um sólido verde escuro em $80 \%$ de rendimento.

\subsection{4.}

\section{Síntese do RIO5}
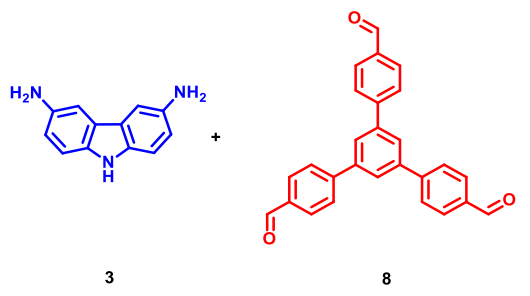

$\underset{\text { HOAc } 3 \mathrm{~mol} \mathrm{~L}^{-1}, 120^{\circ} \mathrm{C}, 3 \text { dias }}{\stackrel{\text { 1,4-dioxano/mesitileno (1:1) }}{\longrightarrow}}$

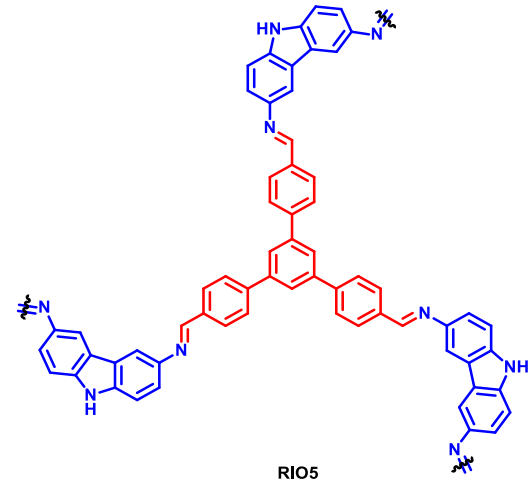

$77 \%$

Em síntese similar ao RIO2, 0,0205 g (0,104 mmol) de 3 e 0,0271 g (0,069 mmol) de 1,3,5-triformilbenzeno reagiram na presença de $\mathrm{HOAc} 3 \mathrm{~mol} \mathrm{~L}^{-1}$, mesitileno e 1,4-dioxana para gerar 0,0365 g de um sólido amarelo escuro em $77 \%$ de rendimento. 


\section{7 Referências bibliográficas}

AERTS, A. et al. Modelling of synchrotron SAXS patterns of silicalite-1 zeolite during crystallization. Physical Chemistry Chemical Physics, v. 13, n. 10, p. 4318-4325, 2011. ISSN 1463-9076. Disponível em: < http://dx.doi.org/10.1039/C0CP01592J >.

ANTUNES, M. M. et al. Integrated reduction and acid-catalysed conversion of furfural in alcohol medium using $\mathrm{Zr}$,Al-containing ordered micro/mesoporous silicates. Applied Catalysis B-Environmental, v. 182, p. 485-503, Mar 2016. ISSN 0926-3373. Disponível em: <<Go to ISI>://WOS:000365050700052 >.

ARAB, P. et al. Synthesis and evaluation of porous azo-linked polymers for carbon dioxide capture and separation. Journal of Materials Chemistry A, v. 3, n. 41, p. 20586-20594, 2015. ISSN 2050-7488. Disponível em: < http://dx.doi.org/10.1039/C5TA04308E >.

ATES, A.; AKGUL, G. Modification of natural zeolite with $\mathrm{NaOH}$ for removal of manganese in drinking water. Powder Technology, v. 287, p. 285-291, Jan 2016. ISSN 0032-5910. Disponível em: <<Go to ISI>://WOS:000365363900029 >.

BAREA, E.; MONTORO, C.; NAVARRO, J. A. R. Toxic gas removal - metal-organic frameworks for the capture and degradation of toxic gases and vapours. Chemical Society Reviews, v. 43, n. 16, p. 5419-5430, 2014. ISSN 0306-0012. Disponível em: < http://dx.doi.org/10.1039/C3CS60475F > .

BARNES, P.; CSOKA, T.; JACQUES, S. Bragg's Law. Londres, 1999. Acesso em: 05 de janeiro.

BARTELMESS, J.; GIORDANI, S. Carbon nano-onions (multi-layer fullerenes): chemistry and applications. Beilstein Journal of Nanotechnology, v. 5, p. 19801998, 2014. ISSN 2190-4286.

BERLANGA, I.; MAS-BALLESTE, R.; ZAMORA, F. Tuning delamination of layered covalent organic frameworks through structural design. Chemical Communications, v. 48, n. 64, p. 7976-7978, 2012. ISSN 1359-7345. Disponível em: < http://dx.doi.org/10.1039/C2CC32187D >

BERLANGA, I. et al. Delamination of Layered Covalent Organic Frameworks. Small, v. 7, n. 9, p. 1207-1211, May 2011. ISSN 1613-6810. Disponível em: <<Go to ISI>://WOS:000289998400011 >.

BERTRAND, G. H. V. et al. Thiophene-based covalent organic frameworks. Proceedings of the National Academy of Sciences of the United States of America, v. 110, n. 13, p. 4923-4928, Mar 26 2013. ISSN 0027-8424. Disponível em: <<Go to ISI ://WOS:000318031900025 >. 
BHIMANAPATI, G. R. et al. Recent Advances in Two-Dimensional Materials beyond Graphene. ACS Nano, v. 9, n. 12, p. 11509-11539, 2015/12/22 2015. ISSN 1936-0851. Disponível em: < http://dx.doi.org/10.1021/acsnano.5b05556 >.

BRUNAUER, S.; EMMETT, P. H.; TELLER, E. Adsorption of Gases in Multimolecular Layers. Journal of the American Chemical Society, v. 60, n. 2, p. 309-319, 1938/02/01 1938. ISSN 0002-7863. Disponível em: < http://dx.doi.org/10.1021/ja01269a023 >.

BRUNNER, K. et al. Carbazole Compounds as Host Materials for Triplet Emitters in Organic Light-Emitting Diodes: Tuning the HOMO Level without Influencing the Triplet Energy in Small Molecules. Journal of the American Chemical Society, v. 126 , n. 19, p. 6035-6042, 2004/05/01 2004. ISSN 0002-7863. Disponível em: < http://dx.doi.org/10.1021/ja049883a >.

BUNCK, D. N.; DICHTEL, W. R. Bulk Synthesis of Exfoliated Two-Dimensional Polymers Using Hydrazone-Linked Covalent Organic Frameworks. Journal of the American Chemical Society, v. 135, n. 40, p. 14952-14955, Oct 2013. ISSN 0002-7863. Disponível em: <<Go to ISI>://WOS:000326356400015 >.

CALIK, M. et al. From Highly Crystalline to Outer Surface-Functionalized Covalent Organic Frameworks-A Modulation Approach. Journal of the American Chemical Society, 2015/12/22 2015. ISSN 0002-7863. Disponível em: < http://dx.doi.org/10.1021/jacs.5b10708 >.

CAMEREL, F.; DONNIO, B.; ZIESSEL, R. Liquid-crystalline functional carbazole and naphthalene platforms. Soft Matter, v. 7, n. 2, p. 412-428, 2011. ISSN 1744683X. Disponível em: < http://dx.doi.org/10.1039/C0SM00547A >.

CHANDRA, S. et al. Interplaying Intrinsic and Extrinsic Proton Conductivities in Covalent Organic Frameworks. Chemistry of Materials, 2016/02/16 2016. ISSN 0897-4756. Disponível em: < http://dx.doi.org/10.1021/acs.chemmater.5b04947 >.

CHEN, J. P.; NATANSOHN, A. Synthesis and Characterization of Novel Carbazole-Containing Soluble Polyimides. Macromolecules, v. 32, n. 10, p. 7, 1999.

CHEN, Q. et al. Microporous Polycarbazole with High Specific Surface Area for Gas Storage and Separation. Journal of the American Chemical Society, v. 134, n. 14, p. 6084-6087, 2012/04/11 2012. ISSN 0002-7863. Disponível em: < http://dx.doi.org/10.1021/ja300438w >.

CHEN, W.-J. et al. Disubstituted 1,8-dipyrazolcarbazole derivatives as a new type of c-myc G-quadruplex binding ligands. Bioorganic \& Medicinal Chemistry, v. 20, n. 9, p. 2829-2836, 5/1/ 2012. ISSN 0968-0896. Disponível em: < http://www.sciencedirect.com/science/article/pii/S0968089612002210 >.

CHEN, X. et al. Locking Covalent Organic Frameworks with Hydrogen Bonds: General and Remarkable Effects on Crystalline Structure, Physical Properties, and Photochemical Activity. Journal of the American Chemical Society, v. 137, n. 9, p. 3241-3247, Mar 2015. ISSN 0002-7863. Disponível em: < <Go to ISI>://WOS:000351187200023 >.

CHEN, Y.-H. et al. Carbazole/fluorene copolymers with dimesitylboron pendants for blue light-emitting diodes. Polymer, v. 52, n. 4, p. 976-986, 2/17/ 2011. ISSN 
0032-3861.

Disponível

em:

$<$

http://www.sciencedirect.com/science/article/pii/S0032386111000127 >.

CHONG, J. H. et al. Highly Stable Keto-Enamine Salicylideneanilines. Org. Lett., v. 5 , n. 21 , p. $4,2003$.

CIESIELSKI, A. et al. Dynamic covalent chemistry of bisimines at the solid/liquid interface monitored by scanning tunnelling microscopy. Nat Chem, v. 6, n. 11, p. 1017-1023, 11//print 2014. ISSN 1755-4330. Disponível em: < http://dx.doi.org/10.1038/nchem.2057 >.

COLSON, J. W. et al. Patterned Growth of Oriented 2D Covalent Organic Framework Thin Films on Single-Layer Graphene. Journal of Polymer Science Part a-Polymer Chemistry, v. 53, n. 2, p. 378-384, Jan 2015.

COLSON, J. W. et al. Oriented 2D Covalent Organic Framework Thin Films on Single-Layer Graphene. Science, v. 332, n. 6026, p. 228-231, Apr 8 2011. ISSN 0036-8075. Disponível em: <<Go to ISI>:/MOS:000289251100049 >.

COTE, A. P. et al. Porous, crystalline, covalent organic frameworks. Science, v. 310, n. 5751, p. 1166-1170, Nov 18 2005. ISSN 0036-8075. Disponível em: <<Go to ISI >://WOS:000233437300040 >.

COTE, A. P. et al. Reticular synthesis of microporous and mesoporous 2D covalent organic frameworks. Journal of the American Chemical Society, v. 129, n. 43, p. 12914-+, Oct 31 2007. ISSN 0002-7863. Disponível em: < <Go to ISI>://WOS:000250818900007 >.

CULLITY, B. D.; STOCK, S. R. Elements of X-Ray Diffraction. 3. Prentice Hall, 2001. 664.

DA RÓZ, A. L. et al. Técnicas de caracterização: princípios e aplicações. Rio de Janeiro: Elsevier, 2015. 217.

DANG, Q.-Q. et al. An azo-linked porous triptycene network as an absorbent for CO2 and iodine uptake. Polymer Chemistry, v. 7, n. 3, p. 643-647, 2016. ISSN 1759-9954. Disponível em: < http://dx.doi.org/10.1039/C5PY01671A >.

DANG, Q.-Q. et al. Heptazine-Based Porous Framework for Selective CO2 Sorption and Organocatalytic Performances. ACS Applied Materials \& Interfaces, v. 7, n. 51, p. 28452-28458, 2015/12/30 2015. ISSN 1944-8244. Disponível em: < http://dx.doi.org/10.1021/acsami.5b09441 >.

DAS, G. et al. Chemical sensing in two dimensional porous covalent organic nanosheets. Chemical Science, v. 6, n. 7, p. 3931-3939, 2015. ISSN 2041-6520. Disponível em: < http://dx.doi.org/10.1039/C5SC00512D > .

DEBLASE, C. R. et al. Rapid and Efficient Redox Processes within 2D Covalent Organic Framework Thin Films. Acs Nano, v. 9, n. 3, p. 3178-3183, Mar 2015.

DEVIC, T.; SERRE, C. High valence $3 p$ and transition metal based MOFs. Chemical Society Reviews, v. 43, n. 16, p. 6097-6115, 2014. ISSN 0306-0012. Disponível em: < http://dx.doi.org/10.1039/C4CS00081A >. 
DING, S.-Y.; WANG, W. Covalent organic frameworks (COFs): from design to applications. Chem. Soc. Rev., v. 42, p. 21, 2013.

DING, S. Y.; WANG, W. Covalent organic frameworks (COFs): from design to applications. Chemical Society Reviews, v. 42, n. 2, p. 548-568, 2013.

DU, X.; WU, E. Porosity of microporous zeolites A, X and ZSM-5 studied by small angle $X$-ray scattering and nitrogen adsorption. Journal of Physics and Chemistry of Solids, v. 68, n. 9, p. 1692-1699, 9// 2007. ISSN 0022-3697. Disponível em: http://www.sciencedirect.com/science/article/pii/S0022369707002016 >.

DUBININ, M. M. Micropore structures of charcoal adsorbents. 1. A general characterization of micro- and supermicropores in the fissure model. Bulletin of the Academy of Sciences of the USSR, Division of chemical science, v. 28, n. 8, p. 1560-1564, 1979/08/01 1979. ISSN 0568-5230. Disponível em: < http://dx.doi.org/10.1007/BF00950967 >.

DUNCAN, N. C. et al. Thermodynamic, kinetic, and structural factors in the synthesis of imine-linked dynamic covalent frameworks. Tetrahedron, v. 68 , n. 1, p. 53-64, 1/7/ 2012. ISSN 0040-4020. Disponível em: < http://www.sciencedirect.com/science/article/pii/S0040402011016085 >.

FANG, Q. et al. Designed synthesis of large-pore crystalline polyimide covalent organic frameworks. Nat Commun, v. 5, 07/23/online 2014. Disponível em: < http://dx.doi.org/10.1038/ncomms5503 >.

FENG, X.; DING, X.; JIANG, D. Covalent organic frameworks. Chemical Society Reviews, v. 41, n. 18, p. 6010-6022, 2012. ISSN 0306-0012. Disponível em: < http://dx.doi.org/10.1039/C2CS35157A >.

FRINDY, S. et al. Copper Nanoparticles Stabilized in a Porous Chitosan Aerogel as a Heterogeneous Catalyst for C-S Cross-coupling. Chemcatchem, v. 7, n. 20, p. 3307-3315, Oct 2015. ISSN 1867-3880. Disponível em: < <Go to ISI>://WOS:000362909200016 >.

GALLEGO, A. et al. Solvent-Induced Delamination of a Multifunctional Two Dimensional Coordination Polymer. Advanced Materials, v. 25, n. 15, p. 21412146, Apr 2013. ISSN 0935-9648. Disponível em: $<<$ Go to ISI>://WOS:000317664700004 >.

GETMAN, R. B. et al. Review and Analysis of Molecular Simulations of Methane, Hydrogen, and Acetylene Storage in Metal-Organic Frameworks. Chemical Reviews, v. 112, n. 2, p. 703-723, 2012/02/08 2012. ISSN 0009-2665. Disponível em: < http://dx.doi.org/10.1021/cr200217c > .

GOESTEN, M. G. et al. Small-angle X-ray scattering documents the growth of metal-organic frameworks. Catalysis Today, v. 205, p. 120-127, 4/30/ 2013. ISSN 0920-5861.

Disponível em: http://www.sciencedirect.com/science/article/pii/S0920586112006347 >.

GREAVES, G. N.; MENEAU, F.; SANKAR, G. SAXS/WAXS and XAFS studies of zeolite stability. Nuclear Instruments and Methods in Physics Research Section B: Beam Interactions with Materials and Atoms, v. 199, p. 98-105, 1// 
2003. ISSN 0168-583X. Disponível em: < http://www.sciencedirect.com/science/article/pii/S0168583X02015999 >.

GRIGALEVICIUS, S. 3,6(2,7),9-Substituted carbazoles as electroactive amorphous materials for optoelectronics. Synthetic Metals, v. 156, n. 1, p. 1-12, 1/5/ 2006. ISSN 0379-6779. Disponível em: < http://www.sciencedirect.com/science/article/pii/S0379677905008404 >.

GUINIER, A.; FOURNET, G. Small-angle scattering of X-rays. New York: John \& Wiley Sons, 1955. 268.

HALSEY, G. Physical Adsorption on Non-Uniform Surfaces. The Journal of Chemical Physics, v. 16, n. 10, p. 931-937, 1948. Disponível em: < http://scitation.aip.org/content/aip/journal/jcp/16/10/10.1063/1.1746689 >.

HAN, F.-D.; YAO, B.; BAI, Y.-J. Preparation of Carbon Nano-Onions and Their Application as Anode Materials for Rechargeable Lithium-Ion Batteries. The Journal of Physical Chemistry C, v. 115, n. 18, p. 8923-8927, 2011/05/12 2011. ISSN 1932-7447. Disponível em: < http://dx.doi.org/10.1021/jp2007599 >.

HE, Y. et al. Methane storage in metal-organic frameworks. Chemical Society Reviews, v. 43, n. 16, p. 5657-5678, 2014. ISSN 0306-0012. Disponível em: < http://dx.doi.org/10.1039/C4CS00032C >.

HSU, S.-L. et al. New carbazole-based conjugated polymers containing pyridylvinyl thiophene units for polymer solar cell applications: Morphological stabilization through hydrogen bonding. Journal of Polymer Science Part A: Polymer Chemistry, v. 49, n. 3, p. 603-611, 2011. ISSN 1099-0518. Disponível em: < http://dx.doi.org/10.1002/pola.24465 >

HUNT, J. R. Synthesis, Characterization, and Gas Adsorption Properties of Covalent Organic Frameworks. 2009. 209 (Doctor of Philosophy in Chemistry). Chemistry, University of California, Los Angeles.

JESSOP, C. A. et al. The Determination of The Pore Size Distribution of Porous Solids Using A Molecular Model to Interpret Nitrogen Adsorption Measurements. In: F. RODRIGUEZ-REINOSO, J. R. K. S. W. S. e UNGER, K. K. (Ed.). Studies in Surface Science and Catalysis: Elsevier, v.Volume 62, 1991. p.123-132. ISBN 0167-2991.

JIANG, J.; YAGHI, O. M. Brønsted Acidity in Metal-Organic Frameworks. Chemical Reviews, v. 115, n. 14, p. 6966-6997, 2015/07/22 2015. ISSN 00092665. Disponível em: < http://dx.doi.org/10.1021/acs.chemrev.5b00221 >.

JIN, Y. et al. Recent advances in dynamic covalent chemistry. Chemical Society Reviews, v. 42, n. 16, p. 6634-6654, 2013. ISSN 0306-0012. Disponível em: < http://dx.doi.org/10.1039/C3CS60044K >.

KANDAMBETH, S. et al. Construction of Crystalline 2D Covalent Organic Frameworks with Remarkable Chemical (Acid/Base) Stability via a Combined Reversible and Irreversible Route. Journal of the American Chemical Society, v. 134, n. 48, p. 19524-19527, Dec 5 2012. ISSN 0002-7863. Disponível em: < $<$ Go to ISI>://WOS:000311869600007 >. 
KATRITZKY, A. R.; TAYLOR, R. Electrophilic Substitution of Heterocycles: Quantitative Aspects. Academic Press, 1990. 467.

KODAIRA, T.; IKEDA, T. Characters of the Tetramethylammonium Ion in ZK-4 Zeolites Depending on Their Si/AI Ratios. The Journal of Physical Chemistry C, v. 114, n. 30, p. 12885-12895, 2010/08/05 2010. ISSN 1932-7447. Disponível em: $<$ http://dx.doi.org/10.1021/jp1022554 >.

KOHLBRECHER, J. SASfit: A program for fitting simple structural models to small angle scattering data. Suíça: Paul Scherrer Institute, 2009. 355.

KOSINOV, N. et al. Recent developments in zeolite membranes for gas separation. Journal of Membrane Science, v. 499, p. 65-79, Feb 2016. ISSN 0376-7388. Disponível em: <<Go to ISI>:/MOS:000365591200008 >.

KUKESH, J. S.; PAULING, L. The problem of the graphite structure. American Mineralogist, v. 35, 1950.

KUPPLER, R. J. et al. Potential applications of metal-organic frameworks. Coordination Chemistry Reviews, v. 253, n. 23-24, p. 3042-3066, 12// 2009. ISSN 0010-8545. Disponível em: < http://www.sciencedirect.com/science/article/pii/S0010854509001271 >.

KUZNETSOV, I. E. et al. Synthesis of statistical carbazole-fluorene-thiophenebenzothiadiazole copolymers and their investigation in organic solar cells. Mendeleev Communications, v. 25, n. 4, p. 277-279, 7// 2015. ISSN 0959-9436. Disponível em: http://www.sciencedirect.com/science/article/pii/S0959943615001339 >. Acesso em: 2015/8//.

LANDERS, J.; GOR, G. Y.; NEIMARK, A. V. Density functional theory methods for characterization of porous materials. Colloids and Surfaces A: Physicochemical and Engineering Aspects, v. 437, p. 3-32, 11/20/ 2013. ISSN 0927-7757. Disponível em: http://www.sciencedirect.com/science/article/pii/S0927775713000277 >.

LANGMI, H. W. et al. Hydrogen Storage in Metal-Organic Frameworks: A Review. Electrochimica Acta, v. 128, p. 368-392, 5/10/ 2014. ISSN 0013-4686. Disponível em: < http://www.sciencedirect.com/science/article/pii/S0013468613021622 >.

LASTOSKIE, C.; GUBBINS, K. E.; QUIRKE, N. Pore size distribution analysis of microporous carbons: a density functional theory approach. The Journal of Physical Chemistry, v. 97, n. 18, p. 4786-4796, 1993/05/01 1993. ISSN $0022-$ 3654. Disponível em: < http://dx.doi.org/10.1021/j100120a035 >.

LEGASPI, C. M. et al. Electronic and optical properties of novel carbazole-based donor-acceptor compounds for applications in blue-emitting organic light-emitting diodes. 2015. p.95491M-95491M-6.

LEMASSON, F. et al. Polymer Library Comprising Fluorene and Carbazole Homoand Copolymers for Selective Single-Walled Carbon Nanotubes Extraction. Macromolecules, v. 45, n. 2, p. 713-722, 2012/01/24 2012. ISSN 0024-9297. Disponível em: < http://dx.doi.org/10.1021/ma201890g >. 
LI, J.-R.; TIMMONS, D. J.; ZHOU, H.-C. Interconversion between Molecular Polyhedra and Metal-Organic Frameworks. Journal of the American Chemical Society, v. 131, n. 18, p. 6368-6369, 2009/05/13 2009. ISSN 0002-7863. Disponível em: < http://dx.doi.org/10.1021/ja901731z >.

LIFSHIN, E. X-ray Characterization of Materials. New York: Wiley, 2008. 277.

LINO, M. A. Nanoestruturas Formadas por Redes Orgânicas Covalentes. 2007. 54 (Mestrado). Departamento de Física, UFMG, Belo horizonte.

LIU, J. et al. Applications of metal-organic frameworks in heterogeneous supramolecular catalysis. Chemical Society Reviews, v. 43, n. 16, p. 6011-6061, 2014. ISSN 0306-0012. Disponível em: < http://dx.doi.org/10.1039/C4CS00094C $>$.

LIU, J. C. et al. Upgrading FCC gasoline through adsorption separation of normal hydrocarbons. Fuel, v. 166, p. 467-472, Feb 2016. ISSN 0016-2361. Disponível em: <<Go to ISI>://WOS:000365627700058 >.

LIU, Y. et al. Control of porosity of novel carbazole-modified polytriazine frameworks for highly selective separation of CO2-N2. Journal of Materials Chemistry A, v. 2, n. 21, p. 7795-7801, 2014. ISSN 2050-7488. Disponível em: < http://dx.doi.org/10.1039/C4TA00298A >.

LOHSE, M. S. et al. Sequential Pore Wall Modification in a Covalent Organic Framework for Application in Lactic Acid Adsorption. Chemistry of Materials, v. 28, n. 2, p. 626-631, 2016/01/26 2016. ISSN 0897-4756. Disponível em: < http://dx.doi.org/10.1021/acs.chemmater.5b04388 >.

LUKOSE, B.; KUC, A.; HEINE, T. The Structure of Layered Covalent-Organic Frameworks. Chemistry - A European Journal, v. 17, n. 8, p. 2388-2392, 2011. ISSN 1521-3765. Disponível em: < http://dx.doi.org/10.1002/chem.201001290 >.

LUO, J.; ZHANG, X.; ZHANG, J. Carbazolic Porous Organic Framework as an Efficient, Metal-Free Visible-Light Photocatalyst for Organic Synthesis. ACS Catalysis, v. 5, n. 4, p. 2250-2254, 2015/04/03 2015. Disponível em: < http://dx.doi.org/10.1021/acscatal.5b00025 >.

MANICKAM, M. et al. The first hexagonal columnar discotic liquid crystalline carbazole derivatives induced by noncovalent [small pi]-[small pi] interactions. Journal of Materials Chemistry, v. 11, n. 11, p. 2790-2800, 2001. ISSN 09599428. Disponível em: < http://dx.doi.org/10.1039/B103052N >.

MASTALERZ, M. Crystal engineering: Covalent crystal growth. Nat Chem, v. 5, n. 10, p. 810-811, 10//print 2013. ISSN 1755-4330. Disponível em: < http://dx.doi.org/10.1038/nchem.1763 >.

MASUDA, M.; MAEDA, C. Synthesis and Characterization of Carbazole-Based Expanded Thiaporphyrins. Chemistry - A European Journal, v. 19, n. 9, p. 29712975, 2013. ISSN 1521-3765. Disponível em: < http://dx.doi.org/10.1002/chem.201202573 >.

MEDINA, D. D. et al. Room Temperature Synthesis of Covalent-Organic Framework Films through Vapor-Assisted Conversion. Journal of the American Chemical Society, v. 137, n. 3, p. 1016-1019, Jan 2015. 
MISHRA, B. K.; SATHYAMURTHY, N. $\pi-\pi$ Interaction in Pyridine. The Journal of Physical Chemistry A, v. 109, n. 1, p. 6-8, 2005/01/01 2005. ISSN 1089-5639. Disponível em: < http://dx.doi.org/10.1021/jp045218c > .

MORPURGO, A. F. Ten years of Nature Physics: The ABC of 2D materials. Nat Phys, v. 11, n. 8, p. 625-626, 08//print 2015. ISSN 1745-2473. Disponível em: < http://dx.doi.org/10.1038/nphys3430 >.

MÜHLMANN, M.; MAGERL, A.; GOEDEL, W. A. Preparation of Composite Membranes with Bicontinuous Structure. Langmuir, v. 28, n. 21, p. 8197-8204, 2012/05/29 2012. ISSN 0743-7463. Disponível em: < http://dx.doi.org/10.1021/la300355h >.

NICOLOSI, V. et al. Liquid Exfoliation of Layered Materials. Science, v. 340, n. 6139, 2013-06-21 00:00:00 2013. Disponível em: < http://science.sciencemag.org/content/sci/340/6139/1226419.full.pdf $>$.

NOVOSELOV, K. S. et al. Electric Field Effect in Atomically Thin Carbon Films. Science, v. 306, n. 5696, p. 666-669, 2004. Disponível em: < http://www.sciencemag.org/content/306/5696/666.abstractN2 - We describe monocrystalline graphitic films, which are a few atoms thick but are nonetheless stable under ambient conditions, metallic, and of remarkably high quality. The films are found to be a two-dimensional semimetal with a tiny overlap between valence and conductance bands, and they exhibit a strong ambipolar electric field effect such that electrons and holes in concentrations up to 1013 per square centimeter and with room-temperature mobilities of $\sim 10,000$ square centimeters per voltsecond can be induced by applying gate voltage. $>$.

NOVOSELOV, K. S. et al. Two-dimensional atomic crystals. Proceedings of the National Academy of Sciences of the United States of America, v. 102, n. 30, p. 10451-10453, July 26, 20052005. Disponível em: < http://www.pnas.org/content/102/30/10451.abstract >.

O'KEEFFE, M.; YAGHI, O. M. Deconstructing the Crystal Structures of MetalOrganic Frameworks and Related Materials into Their Underlying Nets. Chemical Reviews, v. 112, n. 2, p. 675-702, 2012/02/08 2012. ISSN 0009-2665. Disponível em: < http://dx.doi.org/10.1021/cr200205j >.

OLIVIER, J. P.; CONKLIN, W. B.; SZOMBATHELY, M. V. Determination of Pore Size Distribution from Density Functional Theory: A Comparison of Nitrogen and Argon Results. In: J. ROUQUEROL, F. R.-R. K. S. W. S. e UNGER, K. K. (Ed.). Studies in Surface Science and Catalysis: Elsevier, v.Volume 87, 1994. p.8189. ISBN 0167-2991.

ORNES, S. News Feature: Beyond graphene. Proceedings of the National Academy of Sciences, v. 112, n. 43, p. 13128-13130, October 27, 20152015. Disponível em: < http://www.pnas.org/content/112/43/13128.short >

PATEL, H. A. et al. Unprecedented high-temperature CO2 selectivity in N2-phobic nanoporous covalent organic polymers. Nat Commun, v. 4, p. 1357, 01/15/online 2013. Disponível em: < http://dx.doi.org/10.1038/ncomms2359 >.

PATEL, H. A. et al. Directing the Structural Features of N2-Phobic Nanoporous Covalent Organic Polymers for CO2 Capture and Separation. Chemistry - A 
European Journal, v. 20, n. 3, p. 772-780, 2014. ISSN 1521-3765. Disponível em: < http://dx.doi.org/10.1002/chem.201303493 >.

PATTERSON, A. L. The Scherrer Formula for X-Ray Particle Size Determination. Physical Review, v. 56, n. 10, p. 978-982, 11/15/ 1939. Disponível em: < http://link.aps.org/doi/10.1103/PhysRev.56.978 >.

PENA, J. A. et al. Policaprolactone/polyvinylpyrrolidone/siloxane hybrid materials: Synthesis and in vitro delivery of diclofenac and biocompatibility with periodontal ligament fibroblasts. Materials Science \& Engineering C-Materials for Biological Applications, v. 58, p. 60-69, Jan 2016. ISSN 0928-4931. Disponível em: $<<$ Go to ISI $>$ :/WOS:000364247500008 >.

PFEIFER, P.; LIU, K.-Y. Chapter 12. Multilayer adsorption as a tool to investigate the fractal nature of porous adsorbents. In: W. RUDZIŃSKI, W. A. S. e ZGRABLICH, G. (Ed.). Studies in Surface Science and Catalysis: Elsevier, v.Volume 104, 1997. p.625-677. ISBN 0167-2991.

PFEIFER, P. et al. Multilayer adsorption on a fractally rough surface. Physical Review Letters, v. 62, n. 17, p. 1997-2000, 04/24/ 1989. Disponível em: < http://link.aps.org/doi/10.1103/PhysRevLett.62.1997 >.

POROD, G. Die Röntgenkleinwinkelstreuung von dichtgepackten kolloiden Systemen - I. Teil. Kolloid-Zeitschrift, v. 124, n. 2, p. 83-114, 1951. Disponível em: < $\quad$ http://www.scopus.com/inward/record.url?eid=2-s2.034347112128\&partnerID $=40 \& \mathrm{md} 5=a 183 \mathrm{fe} 9 \mathrm{~d} 730463930 \mathrm{~b} 107 \mathrm{f} 2 \mathrm{ee} 2 \mathrm{a} 2591 \mathrm{f}>$.

PROMARAK, V. et al. Thermally and electrochemically stable amorphous holetransporting materials based on carbazole dendrimers for electroluminescent devices. Thin Solid Films, v. 516, n. 10, p. 2881-2888, 3/31/ 2008. ISSN 0040$6090 . \quad$ Disponível em: http://www.sciencedirect.com/science/article/pii/S0040609007008553 >.

QIAO, S.; DU, Z.; YANG, R. Design and synthesis of novel carbazole-spacercarbazole type conjugated microporous networks for gas storage and separation. Journal of Materials Chemistry A, v. 2, n. 6, p. 1877-1885, 2014. ISSN 20507488. Disponível em: < http://dx.doi.org/10.1039/C3TA14017B >.

RABBANI, M. G. et al. A 2D Mesoporous Imine-Linked Covalent Organic Framework for High Pressure Gas Storage Applications. Chemistry - A European Journal, v. 19, n. 10, p. 3324-3328, 2013. ISSN 1521-3765. Disponível em: < http://dx.doi.org/10.1002/chem.201203753 >.

RAVIKOVITCH, P. I. et al. Capillary Hysteresis in Nanopores: Theoretical and Experimental Studies of Nitrogen Adsorption on MCM-41. Langmuir, v. 11, n. 12, p. 4765-4772, 1995/12/01 1995. ISSN 0743-7463. Disponível em: < http://dx.doi.org/10.1021/la00012a030 >.

REICH, M. H. et al. The application of SAXS to determine the fractal properties of porous carbon-based materials. Journal of Colloid and Interface Science, v. 135, n. 2, p. 353-362, 3/15/ 1990. ISSN 0021-9797. Disponível em: < http://www.sciencedirect.com/science/article/pii/0021979790900059 >. 
RIETVELD, $H$. Line profiles of neutron powder-diffraction peaks for structure refinement. Acta Crystallographica, v. 22, n. 1, p. 151-152, 1967. ISSN 0365110X. Disponível em: < http://dx.doi.org/10.1107/S0365110X67000234 >.

A profile refinement method for nuclear and magnetic structures. Journal of Applied Crystallography, v. 2, n. 2, p. 65-71, 1969. ISSN 0021-8898. Disponível em: < http://dx.doi.org/10.1107/S0021889869006558 >.

ROTH, W. J. et al. Layer like porous materials with hierarchical structure. Chemical Society Reviews, 2016. ISSN 0306-0012. Disponível em: < http://dx.doi.org/10.1039/C5CS00508F >.

ROWSELL, J. L. C.; YAGHI, O. M. Metal-organic frameworks: a new class of porous materials. Microporous and Mesoporous Materials, v. 73, n. 1-2, p. 314, 8/6/ 2004. ISSN 1387-1811. Disponível em: < http://www.sciencedirect.com/science/article/pii/S1387181104001295 >.

SALAKHOV, M. S. et al. Oxidative bromination of aniline and its derivatives. Russian Journal of Applied Chemistry v. 81, n. 8, p. 3, 2008.

SCHNABLEGGER, H.; SINGH, Y. The SAXS guide. Austria: Anton Paar, 2011. 98.

SCHNEEMANN, A. et al. Flexible metal-organic frameworks. Chemical Society Reviews, v. 43, n. 16, p. 6062-6096, 2014. ISSN 0306-0012. Disponível em: < http://dx.doi.org/10.1039/C4CS00101J >.

SHI, L. et al. Synthesis, Structure, Properties, and Application of a CarbazoleBased Diaza[7]helicene in a Deep-Blue-Emitting OLED. Chemistry - A European Journal, v. 18, n. 26, p. 8092-8099, 2012. ISSN 1521-3765. Disponível em: < http://dx.doi.org/10.1002/chem.201200068 >.

SING, K. S. W. et al. Reporting physisorption data for gas/solid systems with special reference to the determination of surface area and porosity (Recommendations 1984). Pure Appl. Chem., v. 57, n. 4, p. 17, 1985.

SOUHARCE, B. et al. Amorphous Carbazole-based (Co)polymers for OFET Application. Macromolecular Rapid Communications, v. 30, n. 14, p. 12581262, 2009. ISSN 1521-3927. Disponível em: < http://dx.doi.org/10.1002/marc.200900214 >.

SPITLER, E. L. et al. A mechanistic study of Lewis acid-catalyzed covalent organic framework formation. Chemical Science, v. 2, n. 8, p. 1588-1593, 2011. ISSN 2041-6520. Disponível em: < http://dx.doi.org/10.1039/C1SC00260K >.

STEGBAUER, L.; SCHWINGHAMMER, K.; LOTSCH, B. V. A hydrazone-based covalent organic framework for photocatalytic hydrogen production. Chemical Science, v. 5, n. 7, p. 2789-2793, 2014. ISSN 2041-6520. Disponível em: < http://dx.doi.org/10.1039/C4SC00016A >.

STOECK, U. et al. A highly porous metal-organic framework, constructed from a cuboctahedral super-molecular building block, with exceptionally high methane uptake. Chemical Communications, v. 48, n. 88, p. 10841-10843, 2012. ISSN 1359-7345. Disponível em: < http://dx.doi.org/10.1039/C2CC34840C >. 
STRIBECK, N.; SMARSLY, B. Scattering Methods and the Properties of Polymer Materials. 1. Springer-Verlag Berlin Heidelberg, 2005. 176.

TILLEY, R. J. D. Cristalografia: cristais e estruturas cristalinas. 1. São Paulo: Oficina de Textos, 2014. 271.

TRANCHEMONTAGNE, D. J. et al. Secondary building units, nets and bonding in the chemistry of metal-organic frameworks. Chemical Society Reviews, v. 38, n. 5, p. 1257-1283, 2009. ISSN 0306-0012. Disponível em: < http://dx.doi.org/10.1039/B817735J >.

TSAO, C.-S. et al. Characterization of Pore Structure in Metal-Organic Framework by Small-Angle X-ray Scattering. Journal of the American Chemical Society, v. 129, n. 51, p. 15997-16004, 2007/12/01 2007. ISSN 0002-7863. Disponível em: < http://dx.doi.org/10.1021/ja0752336 >.

URIBE-ROMO, F. J. et al. Crystalline Covalent Organic Frameworks with Hydrazone Linkages. Journal of the American Chemical Society, v. 133, n. 30, p. 11478-11481, Aug 3 2011. ISSN 0002-7863. Disponível em: < <Go to ISI>://WOS:000293872800021 >.

WILL, G. Powder Diffraction: The Rietveld Method and the Two Stage Method to Determine and Refine Crystal Structures from Powder Diffraction Data. 1. Springer-Verlag Berlin Heidelberg, 2006. 224.

WITHERS, F. et al. Light-emitting diodes by band-structure engineering in van der Waals heterostructures. Nat Mater, v. 14, n. 3, p. 301-306, 03//print 2015. ISSN 1476-1122. Disponível em: < http://dx.doi.org/10.1038/nmat4205 >.

XIE, W. et al. Stable Luminescent Metal-Organic Frameworks as Dual-Functional Materials To Encapsulate Ln3+ Ions for White-Light Emission and To Detect Nitroaromatic Explosives. Inorganic Chemistry, v. 54, n. 7, p. 3290-3296, 2015/04/06 2015. ISSN 0020-1669. Disponível em: < http://dx.doi.org/10.1021/ic5029383 >.

$\mathrm{XU}, \mathrm{P}$. et al. Multilayer graphene, Moiré patterns, grain boundaries and defects identified by scanning tunneling microscopy on the m-plane, non-polar surface of SiC. Carbon, v. 80 , p. 75-81, 12// 2014. ISSN 0008-6223. Disponível em: < http://www.sciencedirect.com/science/article/pii/S0008622314007684 >.

YAGHI, O. M.; LI, Q. Reticular Chemistry and Metal-Organic Frameworks for Clean Energy. MRS Bulletin, v. 34, n. 09, p. 682-690, 2009. ISSN 1938-1425. Disponível em: < http://dx.doi.org/10.1557/mrs2009.180 > Acesso em: 2009.

YAGHI, O. M. et al. Reticular synthesis and the design of new materials. Nature, v. 423, n. 6941 , p. 705-714, 06/12/print 2003. ISSN 0028-0836. Disponível em: < http://dx.doi.org/10.1038/nature01650 >.

YANG, W. J. et al. Preparation of Porous Core-Shell Poly L-Lactic Acid/Polyethylene Glycol Superfine Fibres Containing Drug. Journal of Nanoscience and Nanotechnology, v. 15, n. 12, p. 9911-9917, Dec 2015. ISSN 1533-4880. Disponível em: <<Go to ISI>:/MOS:000365555000082 >.

YANG, $X$. et al. Hypercrosslinked microporous polymers based on carbazole for gas storage and separation. Rsc Advances, v. 4, n. 105, p. 61051-61055, 2014 
2014. ISSN 2046-2069. Disponível em: < <Go to ISI>://WOS:000345655600078 $>$.

$\mathrm{YI}, \mathrm{X}$.-C. et al. Synthesis, structure, luminescence and catalytic properties of cadmium(ii) coordination polymers with 9H-carbazole-2,7-dicarboxylic acid. Dalton Transactions, v. 43, n. 9, p. 3691-3697, 2014. ISSN 1477-9226. Disponível em: < http://dx.doi.org/10.1039/C3DT53109K >.

YOON, M.; SRIRAMBALAJI, R.; KIM, K. Homochiral Metal-Organic Frameworks for Asymmetric Heterogeneous Catalysis. Chemical Reviews, v. 112, n. 2, p. 1196-1231, 2012/02/08 2012. ISSN 0009-2665. Disponível em: < http://dx.doi.org/10.1021/cr2003147 >.

ZDRAVKOV, B. et al. Pore classification in the characterization of porous materials: A perspective. Central European Journal of Chemistry, v. 5, n. 2, p. 385-395, 2007/06/01 2007. ISSN 1895-1066. Disponível em: < http://dx.doi.org/10.2478/s11532-007-0017-9 >.

ZHANG, M. et al. Two-Dimensional Metal-Organic Framework with Wide Channels and Responsive Turn-On Fluorescence for the Chemical Sensing of Volatile Organic Compounds. Journal of the American Chemical Society, v. 136, n. 20, p. 7241-7244, 2014/05/21 2014. ISSN 0002-7863. Disponível em: < http://dx.doi.org/10.1021/ja502643p >.

ZHANG, Q. et al. An efficient and clean oxidative bromination reaction of phenol catalyzed by ammonium salt of heteropoly acids supported on silica. Process Safety and Environmental Protection, v. 91, n. 1, p. 86-91, ISSN 0957-5820. Disponível em: < http://dx.doi.org/10.1016/j.psep.2012.03.001 >. Acesso em: 2016/03/13.

ZHANG, T.; LIN, W. Metal-organic frameworks for artificial photosynthesis and photocatalysis. Chemical Society Reviews, v. 43, n. 16, p. 5982-5993, 2014. ISSN 0306-0012. Disponível em: < http://dx.doi.org/10.1039/C4CS00103F >.

ZHANG, X.; LU, J.; ZHANG, J. Porosity Enhancement of Carbazolic Porous Organic Frameworks Using Dendritic Building Blocks for Gas Storage and Separation. Chemistry of Materials, v. 26, n. 13, p. 4023-4029, 2014/07/08 2014. ISSN 0897-4756. Disponível em: < http://dx.doi.org/10.1021/cm501717c >.

ZHANG, Z.-G. et al. Synthesis and photovoltaic properties of copolymers of carbazole and thiophene with conjugated side chain containing acceptor end groups. Polymer Chemistry, v. 2, n. 8, p. 1678-1687, 2011. ISSN 1759-9954. Disponível em: < http://dx.doi.org/10.1039/C1PY00119A >.

ZHOUA, H.-C. J.; KITAGAWA, S. Metal-Organic Frameworks (MOFs). Chem. Soc. Rev., v. 43, p. 5415-5418, 2014.

ZHU, G.; REN, H. Porous Organic Frameworks: Design, Synthesis and Their Advanced Applications. Springer-Verlag Berlin Heidelberg, 2015. 128.

ZHUANG, X. D. et al. Two-Dimensional Soft Nanomaterials: A Fascinating World of Materials. Advanced Materials, v. 27, n. 3, p. 403-427, Jan 2015. 